\title{
Identification of candidate biomarkers and pathways associated with type 1 diabetes mellitus using bioinformatics analysis
}

Basavaraj Vastrad ${ }^{1}$, Chanabasayya Vastrad $*^{2}$

1. Department of Biochemistry, Basaveshwar College of Pharmacy, Gadag, Karnataka 582103, India.

2. Biostatistics and Bioinformatics, Chanabasava Nilaya, Bharthinagar, Dharwad 580001, Karnataka, India.

* Chanabasayya Vastrad

channu.vastrad@gmail.com

Ph: +919480073398

Chanabasava Nilaya, Bharthinagar,

Dharwad 580001 , Karanataka, India 


\begin{abstract}
Type 1 diabetes mellitus (T1DM) is a metabolic disorder for which the underlying molecular mechanisms remain largely unclear. This investigation aimed to elucidate essential candidate genes and pathways in T1DM by integrated bioinformatics analysis. In this study, differentially expressed genes (DEGs) were analyzed using DESeq2 of R package from GSE162689 of the Gene Expression Omnibus (GEO). Gene ontology (GO) enrichment analysis, REACTOME pathway enrichment analysis, and construction and analysis of protein-protein interaction (PPI) network, modules, miRNA-hub gene regulatory network and TF-hub gene regulatory network, and validation of hub genes were then performed. A total of 952 DEGs (477 up regulated and 475 down regulated genes) were identified in T1DM. GO and REACTOME enrichment result results showed that DEGs mainly enriched in multicellular organism development, detection of stimulus, diseases of signal transduction by growth factor receptors and second messengers, and olfactory signaling pathway. The top hub genes such as MYC, EGFR, LNX1, YBX1, HSP90AA1, ESR1, FN1, TK1, ANLN and SMAD9 were screened out as the critical genes among the DEGs from the PPI network, modules, miRNA-hub gene regulatory network and $\mathrm{TF}$-hub gene regulatory network. Receiver operating characteristic curve (ROC) analysis and RT-PCR confirmed that these genes were significantly associated with T1DM. In conclusion, the identified DEGs, particularly the hub genes, strengthen the understanding of the advancement and progression of T1DM, and certain genes might be used as candidate target molecules to diagnose, monitor and treat T1DM.
\end{abstract}

Keywords: differentially expressed genes; Type 1 diabetes mellitus; bioinformatics analysis; biomarkers; protein-protein interaction network 


\section{Introduction}

Type 1 diabetes mellitus (T1DM) is chronic autoimmune diabetes characterized by autoimmune mediated destruction of pancreatic beta cells [1]. T1DM is most generally identified in children and adolescents [2]. Epidemiological studies have shown that the incidence of T1DM has been increasing by $2 \%$ to $5 \%$ globally [3]. T1DM is a complex disease affected by numerous environmental factors, genetic factors and their interactions [4-5]. Several complication of T1DM such as cardiovascular disease [6], hypertension [7], diabetic retinopathy [8], diabetic nephropathy [9], diabetic neuropathy [10], obesity [11] and cognitive impairment [12]. Therefore, exploring the molecular mechanism of T1DM development and its associated biomarkers to improve the early diagnosis and treatment of T1DM.

Although the remarkable improvement is achieved in the treatment of T1DM is insulin therapy [13], the long-term survival rates of T1DM still remain low worldwide. One of the major reasons is that most patients with T1DM were diagnosed at advanced stages. It is crucial to find out new therapeutic targets and novel diagnostic biomarkers for the early diagnosis and timely treatment of T1DM. Therefore, it is still urgent to further explore the exact molecular mechanisms of the development of T1DM. At present, several genes and signaling pathway are identified; for example vitamin D receptor (VDR) [14], HLA-B and HLA-A [15], HLA-DQ [16], HLA $\square$ DQB1, HLA $\square$ DQA1 and HLA $\square$ DRB1 [17], IDDM2 [18], CaMKII/NF- $\kappa$ B/TGF- $\beta 1$ and PPAR- $\gamma$ signaling pathway [19], Keap1/Nrf2 signaling pathway [20], HIF-1/VEGF pathway [21], NLRP3 and NLRP1 inflammasomes signaling pathway [22] and NO/cGMP signaling pathway [23]. Therefore, it is of great practical significance to explore the genes and signaling pathways of T1DM on $\beta$ islet cells.

High-throughput RNA sequencing platform for gene expression analysis have been increasingly recognized as approaches with significant clinical value in areas such as molecular diagnosis, prognostic prediction and identification of novel therapeutic targets [24]. RNA sequencing analysis has been widely used in various gene expression profiling studies examining disease pathogenesis in the last decade, and has revealed many differentially expressed genes (DEGs) associated in various pathways, biological processes, and molecular functions. We 
therefore used an expression profiling by high throughput sequencing dataset to investigate the pathogenesis of T1DM.

We downloaded expression profiling by high throughput sequencing dataset GSE162689 [25], from Gene Expression Omnibus database (GEO) (http://www.ncbi.nlm.nih.gov/geo/) [26], which contain gene expression data from T1DM samples and normal control samples. We then performed deep bioinformatics analysis, including identifying common differential expressed genes (DEGs), gene ontology (GO) enrichment analysis, REACTOME pathway enrichment analysis, and construction and analysis of protein-protein interaction (PPI) network, modules, miRNA-hub gene regulatory network and TF-hub gene regulatory network. The findings were further validated by receiver operating characteristic curve (ROC) analysis and RT-PCR. The aim of this study was to identify DEGs and important pathways, and to explore potential candidate biomarkers for the diagnosis, prognosis and therapeutic targets in T1DM.

\section{Materials and methods}

\section{Data resources}

Expression profiling by high throughput sequencing dataset GSE162689 [25] was obtained from GEO database. The dataset comprised total 59 samples, of which 27 were from T1DM samples and 32 were from normal control samples and was based on the GPL24014 Ion Torrent S5 XL (Homo sapiens).

\section{Identification of DEGs}

Differentially expressed genes (DEGs) between T1DM and normal control samples were identified by using the DESeq2 package on $\mathrm{R}$ language software [27]. DEGs were considered when an adjusted $\mathrm{P}<0.05$, and a $\mid \log 2$ fold change $\mid>$ 0.63 for up regulated genes and $\mid \log 2$ fold change $\mid<-1.3$ for down regulated genes. The adjusted $\mathrm{P}$ values, by employing Benjamini and Hochberg false discovery rate [28], were aimed to correct the occurrence of false positive results. The DEGs were presented in volcano plot and heat map drawn using a plotting tool ggplot2 and gplots based on the $\mathrm{R}$ language.

\section{GO and REACTOME pathway enrichment analysis of DEGs}


One online tool, g:Profiler (http://biit.cs.ut.ee/gprofiler/) [29], was applied to carried out the functional annotation for DEGs. Gene Ontology (GO) (http://geneontology.org/) [30] generally perform enrichment analysis of genomes. And there are mainly biological processes (BP), cellular components (CC) and molecular functions (MF) in the GO enrichment analysis. REACTOME (https://reactome.org/) [31] is a comprehensive database of genomic, chemical, and systemic functional information. Therefore, g:Profiler was used to make enrichment analysis of GO and REACTOME. $\mathrm{P} \square<\square 0.05$ was set as the cutoff criterion.

\section{Construction of the PPI network and module analysis}

PPI network was established using the IntAct Molecular Interaction Database (https://www.ebi.ac.uk/intact/) [32]. To assess possible PPI correlations, previously identified DEGs were mapped to the IntAct database, followed by extraction of PPI pairs with a combined score >0.4. Cytoscape 3.8.2 software (www.cytoscape.org/) [33] was then employed to visualize the PPI network, and the Cytoscape plugin Network Analyzer was used to calculate the node degree [34], betweenness centrality [35], stress centrality [36] and closeness centrality [37] of each protein node. Specifically, nodes with a higher node degree, betweenness centrality, stress centrality and closeness centrality were likely to play a more vital role in maintaining the stability of the entire network. The PEWCC1 (http://apps.cytoscape.org/apps/PEWCC1) [38] plug-in was applied to analyze the modules in the PPI networks, with the default parameters (node score $=0.2, \mathrm{~K}$ core $\geqq 2$, and max depth $=100$ ).

\section{MiRNA-hub gene regulatory network construction}

The miRNAs targeting the T1DM related were predicted using the miRNet database (https://www.mirnet.ca/) [39], and those predicted by at least 14 databases (TarBase, miRTarBase, miRecords, miRanda, miR2Disease, HMDD, PhenomiR, SM2miR, PharmacomiR, EpimiR, starBase, TransmiR, ADmiRE, and TAM 2.0) were selected for constructing the miRNA-hub gene regulatory network by Cytoscape 3.8.2 software.

\section{TF-hub gene regulatory network construction}


The TFs targeting the T1DM related were predicted using the NetworkAnalyst database (https://www.networkanalyst.ca/) [40], and those predicted by RegNetwork database was selected for constructing the TF-hub gene regulatory network by Cytoscape 3.8.2 software.

\section{Validation of hub genes by receiver operating characteristic curve (ROC) analysis}

A ROC curve analysis is an approach for visualizing, organizing and selecting classifiers based on their achievement of hub genes. A diagnostic test was firstly performed in order to estimate the diagnostic value of hub genes in T1DM. ROC curves were obtained by plotting the sensitivity, against the specificity using the $\mathrm{R}$ package "pROC" [41]. Area under the curve (AUC) was used to measure the accuracy of these diagnostic values of the hub genes. An AUC $\square>\square 0.9$ determined that the model had a favorable fitting effect.

\section{Detection of the mRNA expression of the hub genes by RT-PCR}

Pancreatic beta MIN6 cells were maintained in Dulbecco's minimal essential medium (DMEM) supplemented with $15 \%$ fetal calf serum, $50 \mathrm{mg} / \mathrm{l}$ streptomycin and $75 \mathrm{mg} / \mathrm{l}$ penicillin sulphate. MIN6 cells treated with streptozotocin for T2DM and MIN6 cells untreated for normal control. All treated MIN6 cells and untreated MIN6 cells were incubated at $37 \circ \mathrm{C}, 5 \% \mathrm{CO}_{2}$ in humidified incubator. Total RNA was extracted from the treated and untreated cells using TRI reagent (Sigma, USA) according to the manufacturer's protocol. Reverse transcription kit (Thermo Fisher Scientific, Waltham, MA, USA) was used for Converting mRNA to cDNA. Expression levels of mRNAs were determined by RT-PCR using QuantStudio 7 Flex real-time PCR system (Thermo Fisher Scientific, Waltham, MA, USA). The protocol was set as follows: $50 \square{ }^{\circ} \mathrm{C}$ for $2 \square \mathrm{min}, 95 \square{ }^{\circ} \mathrm{C}$ for $10 \square \mathrm{min}, 40 \square$ cycles of $95 \square{ }^{\circ} \mathrm{C}$ for $10 \square \mathrm{s}, 60 \square{ }^{\circ} \mathrm{C}$ for $30 \square \mathrm{s}$. All the samples were normalized to the corresponding expression of internal control $\beta$-actin. The test was performed in triplicate and the relative expression levels were calculated with the $2^{-\Delta \Delta \mathrm{Ct}}$ method [42]. Table 1 is given for primer sequences used in the RT-PCR.

\section{Results}

\section{Identification of DEGs}


On the basis of the cut $\square$ off criteria, DEGs in GEO dataset was identified between T1DN and normal control samples (Table 2). There were 952 DEGs, including 477 up regulated and 475 down regulated genes in GSE162689 with the threshold of adjusted $\mathrm{P}<0.05$, and a $\mid \log 2$ fold change $\mid>0.63$ for up regulated genes and $\mid \log 2$ fold change $\mid<-1.3$ for down regulated genes. The volcano plot of the distribution of DEGs in is shown in Fig. 1. The expression heat map of the DEGs is shown in Fig. 2.

\section{GO and REACTOME pathway enrichment analysis of DEGs}

To characterize the functional roles of the above DEGs, we used GO (Table 3) and REACTOME pathway (Table 4) enrichment analyses. The BP category of the GO analysis results showed that up regulated genes were significantly enriched in multicellular organism development and nitrogen compound metabolic process. For CC, these up regulated were enriched in membrane-enclosed lumen and nuclear lumen. Moreover, up regulated genes were significantly enriched in protein binding and transcription regulator activity in the MF categories. In addition, the most significantly enriched GO terms for down regulated genes were detection of stimulus and multicellular organismal process (BP), cell periphery and plasma membrane $(\mathrm{CC})$, and transmembrane signaling receptor activity and molecular transducer activity (MF). According to REACTOME pathway enrichment analysis, up regulated genes were significantly enriched in diseases of signal transduction by growth factor receptors and second messengers and formation of the cornified envelope. Down regulated genes were enriched in olfactory signaling pathway and sensory perception.

\section{Construction of the PPI network and module analysis}

The PPI network of the DEGs was constructed with 5111 nodes and 9392 edges by using the IntAct database (Fig. 3). A node with a higher node degree, betweenness centrality, stress centrality and closeness centrality consider as a hub genes and are listed in Table 5. The key points of the network include the up regulated hub genes, such as MYC, EGFR, LNX1, YBX1 and HSP90AA1, and the down regulated hub genes, such as ESR1, FN1, TK1, ANLN and SMAD9. To detect significant modules in the PPI network, the PEWCC1 plug $\square$ in was used for analysis, and two modules that had the highest degree stood out. GO and pathway enrichment 
analysis showed that module 1 contained 28 nodes and 63 edges (Fig.4A), which were associated with diseases of signal transduction by growth factor receptors and second messengers, disease, nitrogen compound metabolic process and membraneenclosed lumen, while module 2 had 14 nodes and 30 edges (Fig.4B), which were mainly associated with signal transduction, multicellular organismal process and detection of stimulus.

\section{MiRNA-hub gene regulatory network construction}

The network of miRNAs and predicted targets (hub genes) is presented in Table 6. Based on the miRNAs, a miRNA -hub gene regulatory network was constructed with 2568 nodes (miRNA: 2259; hub gene: 309) and 16618 interaction pairs (Fig.5). Notably, MYC targeted 194 miRNAs, including hsa-mir-4677-3p; HSP90AA1 targeted 188 miRNAs, including hsa-mir-3125; FKBP5 targeted 116 miRNAs, including hsa-mir-4779; RNPS1 targeted 109 miRNAs, including hsamir-548az-3p; SQSTM1 targeted 108 miRNAs, including hsa-mir-106a-5p; ANLN targeted 127 miRNAs, including hsa-mir-664a-3p; CDK1 targeted 109 miRNAs, including hsa-mir-5688;FN1 targeted 105 miRNAs, including hsa-mir-199b3p;ESR1 targeted 98 miRNAs, including hsa-mir-206; TK1 targeted 80 miRNAs, including hsa-mir-6512-3p.

\section{TF-hub gene regulatory network construction}

The network of TFs and predicted targets (hub genes) is presented in Table 6. Based on the TFs, a TF -hub gene regulatory network was constructed with 899 nodes (TF: 604; hub gene: 295) and 3542 interaction pairs (Fig.6). Notably, MAPK3 targeted 48 TFs, including JUND; HSP90AA1 targeted 35 TFs, including HSF2; SQSTM1 targeted 34 TFs, including SMAD4; STUB1 targeted 31 TFs, including ATF6; EGFR targeted 27 TFs, including ELF3; ESR1 targeted 126 TFs, including ELF3; SMAD9 targeted 38 TFs, including ELF3; CDK1 targeted 36 TFs, including ELF3; FN1 targeted 25 TFs, including ELF3; NEK6 targeted 16 TFs, including ELF3.

Validation of hub genes by receiver operating characteristic curve (ROC) analysis 
ROC curve analysis was for evaluating the capacity of MYC, EGFR, LNX1, YBX1, HSP90AA1, ESR1, FN1, TK1, ANLN and SMAD9, so as to distinguish T1DM from normal control (Fig.7). ROC curve analysis showed that MYC, EGFR, LNX1, YBX1, HSP90AA1, ESR1, FN1, TK1, ANLN and SMAD9 expression levels have potential diagnostic value for T1DM patients (AUC $\square>\square 0.9$ ).

\section{Detection of the mRNA expression of the hub genes by RT-PCR}

Next, in order to verify the results of previous bioinformatics analysis, the gene expression levels of MYC, EGFR, LNX1, YBX1, HSP90AA1, ESR1, FN1, TK1, ANLN and SMAD9 were detected by RT-PCR between T1DM and normal control. As shown in Fig 8, compared with normal tissues, MYC, EGFR, LNX1, YBX1 and HSP90AA1 mRNA expression levels were significantly up regulated in the T1DM, and ESR1, FN1, TK1, ANLN and SMAD9 mRNA level were down regulated, which was consistent with the results of bioinformatics analysis.

\section{Discussion}

T1DM is the common forms of chronic autoimmune diabetes that affect an individual's quality of life [43]. However, the potential causes of T1DM remain uncertain. Understanding the underlying molecular pathogenesis of T1DM is of key importance for diagnosis, prognosis, and identifying drug targets. As highthroughput RNA sequencing can provide information regarding the expression levels of thousands of genes in the human genome simultaneously, this methodology has been widely used to predict the potential diagnostic and therapeutic targets for T1DM. In the present investigation, we extracted the data from GSE162689, which includes 27 T1DM samples and 32 normal control samples. We identified 477 up regulated and 475 down regulated genes between T1DM samples and normal control samples using bioinformatics analysis. FGA (fibrinogen alpha chain) [44] and FGB (fibrinogen beta chain) [45] genes have been found to be expressed in cardiovascular disease, but these genes might be novel target for T1DM. IGF2 [46], IAPP (islet amyloid polypeptide) [47], INS (insulin) [48] and MAFA (MAF bZIP transcription factor A) [49] have been reported be associated with the development of T1DM. Previous study have indicated the expression of ADCYAP1 is associated in type 2 diabetes mellitus [50], but this gene might be novel target for T1DM. Gold et al. [51] found the 
CSNK1G1 was a prognostic factor in cognitive impairment, but this gene might be novel target for T1DM.

Furthermore, we investigated the biological functions of these DEGs by using online website, and GO and pathway enrichment analysis. Husemoen et al [52], Zhang et al [53], Hartz et al [54], Słomiński et al [55], Johansson et al [56], Pan et al [57], Lopez-Sanz et al [58], Grant, [59], Słomiński et al [60], Galán et al [61], Jordan et al [62], Winkler et al [63], Yip et al [64], Crookshank et al [65], Lempainen et al [66], Qu and Polychronakos, [67], Morrison et al [68], Zhang et al [69], Gerlinger-Romero et al [70], Belanger et al [71], Dieter et al [72], Wanic et al [73], Ushijima Wanic et al [74], Guo et al [75], Davis et al [76], Elbarbary et al [77], Villasenor et al [78], Zhang et al [79], Lee et al [80], Zhi et al [81], Li Calzi et al [82], Sebastiani et al [83], Cherney et al [84], Doggrell, [85] and Yanagihara et al [86] found that FLG (filaggrin), FGF21, PEMT (phosphatidylethanolamine Nmethyltransferase) KL (klotho), CEL (carboxyl ester lipase), FOSL2, STAT1, TCF7L2, TP53, EGFR (epidermal growth factor receptor), ETS1, KCNJ8, DEAF1, GCG (glucagon), IKZF4, OAS1, IRS1, ABCG2, FBXO32, PTBP1, BACH2, CNDP2, KLF11, MT1E, DPP4, SLC29A3, RGS16, MAS1, GCGR (glucagon receptor), HLA-C, VASP (vasodilator stimulated phosphoprotein), CCR2, PTGS2, GLP1R and JMJD6 are involved in the progression of T1DM. Vassilev et al [87], Qin et al [88], Ma et al [89], West et al [90], Hoffmann et al [91], Deary et al [92], Belangero et al [93], Jung et al [94], Tang et al [95], Goodier et al [96], Petyuk et al [97], Roux et al [98], Castrogiovanni et al [99], Suleiman et al [100], Haack et al [101], Kwiatkowski et al [102], Pinacho et al [103], Luo et al [104], He et al [105], Moudi et al [106], Thevenon et al [107], Li et al [108], Reitz et al [109], Jenkins and Escayg [110], Letronne et al [111], Ma et al [112], Chabbert et al [113], Abramsson et al [114], Aeby et al [115] and Roll et al [116] found that the expression of DCC (DCC netrin 1 receptor), PLP1, SNX19, SH3RF1, TNFRSF1A, NCSTN (nicastrin), DGCR2, NPAS2, CDNF (cerebral dopamine neurotrophic factor), SMCR8, HSPA2, STUB1, CHID1, ATP13A2, SQSTM1, LIG3, SP4, ACSL6, ERN1, ATF6B, LRFN2, NRG3, LRRTM3, GABRA2, ADAM30, GABRR2, TSHZ3, LOXL1, SCN1B and SRPX2 are associated with the prognosis of patients with cognitive impairment, but these genes might be novel target for T1DM. Recent studies found that KCP (kielin cysteine rich BMP regulator) [117], NOG (noggin) [118], COL6A3 [119], BTG2 [120], RPS6 [121], KLF15 [122], 
KLF3 [123], ZFP36 [124], ETV5 [125], TLE3 [126], NNMT (nicotinamide Nmethyltransferase) [127], WDTC1 [128], ZFHX3 [129], SIAH2 [130], MBOAT7 [131], RUNX1T1 [132], MAPK4 [133], KLF9 [134], SELENBP1 [135], HELZ2 [136], ELK1 [137], SERTAD2 [138], CRTC3 [139], ABCB11 [140], TACR1 [141], SLC22A11 [142], PER3 [143], P2RX5 [144], MFAP5 [145], FGL1 [146], OLFM4 [147], NTN1 [148], ESR1 [149], ABCB1 [150], VAV3 [151] and LAMB3 [152] plays an important role in the occurrence and development of obesity, but these genes might be novel target for T1DM. STAR (steroidogenic acute regulatory protein) [153], IL1RN [154], AQP5 [155], EGR1 [156], SFTPD (surfactant protein D) [157], KLF10 [158], PODXL (podocalyxin like) [159], FOXN3 [160], IL6R [161], PBX1 [162], APOD (apolipoprotein D) [163], ACVR2B [164], CD34 [165], INSR (insulin receptor) [166], APOA5 [167], STAR (steroidogenic acute regulatory protein) [168], PDK4 [169], GLS (glutaminase) [170], FKBP5 [171], SLC6A15 [172], MT2A [173], SLC38A4 [174], AQP7 [175], ABHD15 [176], ABCA1 [177], ZNRF1 [178], PPP1R3B [179], MAOA (monoamine oxidase A) [180], UBE2E2 [181], RNASEK (ribonuclease K) [182], PREX1 [183], DGKG (diacylglycerol kinase gamma) [184], POSTN (periostin) [185], COMP (cartilage oligomeric matrix protein) [186], GAP43 [187], P2RY12 [188], SELL (selectin L) [189] and DLG2 [190] have been revealed to be associated with type 2 diabetes mellitus, but these genes might be novel target for T1DM. Expression of ERRFI1 [191], ALOX12 [192], SOCS5 [193], DDIT4 [194], DUSP4 [195], IL6ST [196], DUSP1 [197], SMAD1 [198], NCL (nucleolin) [199], METTL14 [200], FMOD (fibromodulin) [201], CYGB (cytoglobin) [202], UNC5A [203] and TAAR9 [204] are associated with prognosis in patients with diabetic nephropathy, but these genes might be novel target for T1DM. A previous study reported that FAP (fibroblast activation protein alpha) [205], EYA4 [206], BCL9 [207], IRF2BP2 [208], EGR3 [209], GADD45B [210], DMD (dystrophin) [211], LSR (lipolysis stimulated lipoprotein receptor) [212], DLL4 [213], SUN2 [214], SOS1 [215], PIK3CA [216], GAMT (guanidinoacetate N-methyltransferase) [217], RBM47 [218], HSP90AA1 [219], GAB1 [220], S1PR1 [221], EDNRB (endothelin receptor type B) [222], NFKBIA (NFKB inhibitor alpha) [223], GJA1 [224], GADD45G [225], PHLDA1 [226], CMPK2 [227], FIGN (fidgetin, microtubule severing factor) [228], KCNJ2 [229], ABCC9 [230], DIRAS3 [231], EPHX1 [232], RAB4A [233], UBIAD1 [234], CASQ2 [235], TTN (titin) [236], KCNH1 [237], JPH2 [238], OXGR1 [239], UCHL1 [240], SERPINA3 [241], 
MMP28 [242], ADAMTS2 [243], P2RY1 [244], CSF2RA [245], MYO1F [246], SELPLG (selectin P ligand) [247] and SAMHD1 [248] are expressed in cardiovascular disease, but these genes might be novel target for T1DM. MAOB (monoamine oxidase B) [249], VEGFC (vascular endothelial growth factor C) [250], DBP (D-box binding PAR bZIP transcription factor) [251], MYADM (myeloid associated differentiation marker) [252], NES (nestin) [253], SMURF1 [254], EDNRB (endothelin receptor type B) [255], MUC6 [256], TOR2A [257], TNKS (tankyrase) [258], NEDD9 [259], ASIC1 [260], ADAMTS8 [261], DYSF (dysferlin) [262], SLC26A9 [263], SLC45A3 [264] and KCNQ2 [265] contributes to the progression of hypertension, but these genes might be novel target for T1DM. Yang et al [266], Zhang et al [267] and Wang et al [268] demonstrated that SYVN1, BTG1 and CFB (complement factor B) were associated with diabetic retinopathy, but these genes might be novel target for T1DM.

PPI network and modules were used to identify hub genes. The results of the present investigation might provide potential biomarkers for the diagnosis of T1DM. SMAD9 has been shown to be activated in hypertension [269], but this genes might be novel target for T1DM. MYC, LNX1, YBX1, FN1, TK1 and ANLN (anillin actin binding protein) might be the novel biomarkers for T1DM.

In this investigation, the miRNA-hub gene regulatory network and TF-hub gene regulatory network that regulates T1DM was constructed. Recent studies found that CDK1 [270], hsa-mir-199b-3p [271], JUND [272] and FOXF2 [273] plays an important role in the occurrence and development of obesity, but these genes might be novel target for T1DM. The hsa-mir-106a-5p [274], hsa-mir-206 [275], SMAD4 [276] and ATF6 [277] are a major regulator of type 2 diabetes mellitus, but these genes might be novel target for T1DM. Studies have shown that the hsa-mir-106a-5p [278] and HSF2 [279] are essential for regulating cardiovascular disease, but these genes might be novel target for T1DM. MendesSilva et al [280] indicated that hsa-mir-664a-3p facilitated cognitive impairment, but this gene might be novel target for T1DM. ELF3 participated in diabetic nephropathy [281], but this gene might be novel target for T1DM. SRY is crucial for hypertension progression [282], but this gene might be novel target for T1DM. RNPS1, MAPK3, NEK6, hsa-mir-4677-3p, hsa-mir-3125, hsa-mir-4779, hsa-mir548az-3p, hsa-mir-5688, hsa-mir-6512-3p, XAB2, KHDRBS1 and RELA might be the novel biomarkers for T1DM. 
In conclusion, the present investigation shows the global profile of DEGs and relative signaling pathways that might play in the initiation and progression of T1DM. In the pathogenesis of acne, the possible crucial genes are MYC, EGFR, LNX1, YBX1, HSP90AA1, ESR1, FN1, TK1, ANLN and SMAD9, and the possible important GO terms and pathways are multicellular organism development, detection of stimulus, diseases of signal transduction by growth factor receptors and second messengers, and olfactory signaling pathway. Therefore, it provides new research directions for the detection and treatment of T1DM. However, their involvement in the molecular mechanisms of disease needs further clinical studies.

\section{Acknowledgement}

I thank Anders Roger Hedin, Uppsala University, Clinical immunology, Olle Korsgren, Uppsala, Uppland, Sweden, very much, the author who deposited their profiling by high throughput sequencing dataset GSE162689, into the public GEO database.

\section{Conflict of interest}

The authors declare that they have no conflict of interest.

\section{Ethical approval}

This article does not contain any studies with human participants or animals performed by any of the authors.

\section{Informed consent}

No informed consent because this study does not contain human or animals participants.

\section{Availability of data and materials}

The datasets supporting the conclusions of this article are available in the GEO (Gene Expression Omnibus) (https://www.ncbi.nlm.nih.gov/geo/) repository. [(GSE162689) (https://www.ncbi.nlm.nih.gov/geo/query/acc.cgi?acc=GSE162689]

\section{Consent for publication}


Not applicable.

\section{Competing interests}

The authors declare that they have no competing interests.

\section{Author Contributions}

B. V - Writing original draft, and review and editing

C. V - Software and investigation

\section{Authors}

Basavaraj Vastrad

ORCID ID: 0000-0003-2202-7637

Chanabasayya Vastrad

ORCID ID: 0000-0003-3615-4450

\section{References}

1. Bekris LM, Kavanagh TJ, Lernmark A. Targeting type 1 diabetes before and at the clinical onset of disease. Endocr Metab Immune Disord Drug Targets. 2006;6(1):103-124. doi:10.2174/187153006776056576

2. Haller MJ, Atkinson MA, Schatz D. Type 1 diabetes mellitus: etiology, presentation, and management. Pediatr Clin North Am. 2005;52(6):15531578. doi:10.1016/j.pcl.2005.07.006

3. Maahs DM, West NA, Lawrence JM, Mayer-Davis EJ. Epidemiology of type 1 diabetes. Endocrinol Metab Clin North Am. 2010;39(3):481-497. doi:10.1016/j.ecl.2010.05.011

4. Akerblom HK, Vaarala O, Hyöty H, Ilonen J, Knip M. Environmental factors in the etiology of type 1 diabetes. Am J Med Genet. 2002;115(1):1829. doi:10.1002/ajmg.10340

5. Pociot F, Lernmark $\AA$. Genetic risk factors for type 1 diabetes. Lancet. 2016;387(10035):2331-2339. doi:10.1016/S0140-6736(16)30582-7

6. Nathan DM, Cleary PA, Backlund JY, Genuth SM, Lachin JM, Orchard TJ, Raskin P, Zinman B. Intensive diabetes treatment and cardiovascular disease in patients with type 1 diabetes. N Engl J Med. 2005;353(25):2643-2653. doi:10.1056/NEJMoa052187 
7. de Boer IH, Kestenbaum B, Rue TC, Steffes MW, Cleary PA, Molitch ME, Lachin JM, Weiss NS, Brunzell JD. Insulin therapy, hyperglycemia, and hypertension in type 1 diabetes mellitus. Arch Intern Med. 2008;168(17):1867-1873. doi:10.1001/archinternmed.2008.2

8. Hammes HP, Kerner W, Hofer S, Kordonouri O, Raile K, Holl RW. Diabetic retinopathy in type 1 diabetes-a contemporary analysis of 8,784 patients. Diabetologia. 2011;54(8):1977-1984. doi:10.1007/s00125-0112198-1

9. Pätäri A, Forsblom C, Havana M, Taipale H, Groop PH, Holthöfer H. Nephrinuria in diabetic nephropathy of type 1 diabetes. Diabetes. 2003;52(12):2969-2974. doi:10.2337/diabetes.52.12.2969

10.González-Clemente JM, Mauricio D, Richart C, Broch M, Caixàs A, Megia A, Giménez-Palop O, Simón I, Martínez-Riquelme A, Giménez-Pérez G, et al. Diabetic neuropathy is associated with activation of the TNF-alpha system in subjects with type 1 diabetes mellitus. Clin Endocrinol (Oxf). 2005;63(5):525-529. doi:10.1111/j.1365-2265.2005.02376.x

11.Sandhu N, Witmans MB, Lemay JF, Crawford S, Jadavji N, Pacaud D. Prevalence of overweight and obesity in children and adolescents with type 1 diabetes mellitus. J Pediatr Endocrinol Metab. 2008;21(7):631-640. doi:10.1515/JPEM.2008.21.7.631

12. Brismar T, Maurex L, Cooray G, Juntti-Berggren L, Lindström P, Ekberg K, Adner N, Andersson S. Predictors of cognitive impairment in type 1 diabetes. Psychoneuroendocrinology. 2007;32(8-10):1041-1051. doi:10.1016/j.psyneuen.2007.08.002

13. Charbonnel B, Penfornis A, Varroud-Vial M, Kusnik-Joinville O, Detournay B. Insulin therapy for diabetes mellitus: treatment regimens and associated costs. Diabetes Metab. 2012;38(2):156-163. doi:10.1016/j.diabet.2011.10.003

14.Chang TJ, Lei HH, Yeh JI, Chiu KC, Lee KC, Chen MC, Tai TY, Chuang LM. Vitamin D receptor gene polymorphisms influence susceptibility to type 1 diabetes mellitus in the Taiwanese population. Clin Endocrinol (Oxf). 2000;52(5):575-580. doi:10.1046/j.1365-2265.2000.00985.x

15.Nejentsev S, Howson JM, Walker NM, Szeszko J, Field SF, Stevens HE, Reynolds P, Hardy M, King E, Masters J, et al. Localization of type 1 
diabetes susceptibility to the MHC class I genes HLA-B and HLA-A. Nature. 2007;450(7171):887-892. doi:10.1038/nature06406

16.Thorsby E, Rønningen KS. Particular HLA-DQ molecules play a dominant role in determining susceptibility or resistance to type 1 (insulin-dependent) diabetes mellitus. Diabetologia. 1993;36(5):371-377. doi:10.1007/BF00402270

17.Nejentsev S, Sjöroos M, Soukka T, Knip M, Simell O, Lövgren T, Ilonen J.Population-based genetic screening for the estimation of Type 1 diabetes mellitus risk in Finland: selective genotyping of markers in the HLA-DQB1, HLA-DQA1 and HLA-DRB1 loci. Diabet Med. 1999;16(12):985-992. doi:10.1046/j.1464-5491.1999.00186.x

18. Barratt BJ, Payne F, Lowe CE, Hermann R, Healy BC, Harold D, Concannon P, Gharani N, McCarthy MI, Olavesen MG, et al. Remapping the insulin gene/IDDM2 locus in type 1 diabetes. Diabetes. 2004;53(7):1884-1889. doi:10.2337/diabetes.53.7.1884

19.Gbr AA, Abdel Baky NA, Mohamed EA, Zaky HS. Cardioprotective effect of pioglitazone and curcumin against diabetic cardiomyopathy in type 1 diabetes mellitus: impact on CaMKII/NF- $\kappa \mathrm{B} / \mathrm{TGF}-\beta 1$ and PPAR- $\gamma$ signaling pathway. Naunyn Schmiedebergs Arch Pharmacol. 2021;394(2):349-360. doi:10.1007/s00210-020-01979-y

20.Lou Y, Kong M, Li L, et al. Inhibition of the Keap1/Nrf2 Signaling Pathway Significantly Promotes the Progression of Type 1 Diabetes Mellitus. Oxid Med Cell Longev. 2021;2021:7866720. doi:10.1155/2021/7866720

21.Güzel D, Dursun AD, Fiçıcılar H, Tekin D, Tanyeli A, Akat F, Topal Çelikkan F, Sabuncuoğlu B, Baştuğ M. Effect of intermittent hypoxia on the cardiac HIF-1/VEGF pathway in experimental type 1 diabetes mellitus. Anatol J Cardiol. 2016;16(2):76-83. doi:10.5152/akd.2015.5925

22.Liu H, Xu R, Kong Q, Liu J, Yu Z, Zhao C. Downregulated NLRP3 and NLRP1 inflammasomes signaling pathways in the development and progression of type 1 diabetes mellitus. Biomed Pharmacother. 2017;94:619626. doi:10.1016/j.biopha.2017.07.102

23.Farkas K, Jermendy G, Herold M, Ruzicska E, Sasvári M, Somogyi A. Impairment of the NO/cGMP pathway in the fasting and postprandial state in type 1 diabetes mellitus. Exp Clin Endocrinol Diabetes. 2004;112(5):258263. doi:10.1055/s-2004-817973 
24.Potter SS. Single-cell RNA sequencing for the study of development, physiology and disease. Nat Rev Nephrol. 2018;14(8):479-492. doi:10.1038/s41581-018-0021-7

25.Seiron P, Stenwall A, Hedin A, Granlund L, Esguerra JLS, Volkov P, Renström E, Korsgren O, Lundberg M, Skog O. Transcriptional analysis of islets of Langerhans from organ donors of different ages. PLoS One. 2021;16(3):e0247888. doi:10.1371/journal.pone.0247888

26.Clough E, Barrett T. The Gene Expression Omnibus Database. Methods Mol Biol. 2016;1418:93-110. doi:10.1007/978-1-4939-3578-9_5

27. Varet H, Brillet-Guéguen L, Coppée JY, Dillies MA. SARTools: A DESeq2- and EdgeR-Based R Pipeline for Comprehensive Differential Analysis of RNA-Seq Data. PLoS One. 2016;11(6):e0157022. doi:10.1371/journal.pone.0157022

28. Hardcastle TJ. Generalized empirical Bayesian methods for discovery of differential data in high-throughput biology. Bioinformatics. 2016;32(2):195-202. doi:10.1093/bioinformatics/btv569

29.Reimand J, Kull M, Peterson H, Hansen J, Vilo J. g:Profiler--a web-based toolset for functional profiling of gene lists from large-scale experiments. Nucleic Acids Res. 2007;35(Web Server issue):W193-W200. doi:10.1093/nar/gkm226

30.Thomas PD. The Gene Ontology and the Meaning of Biological Function. Methods Mol Biol. 2017;1446:15 $\square 24$. doi:10.1007/978-1-4939-3743-1_2

31.Fabregat A, Jupe S, Matthews L, Sidiropoulos K, Gillespie M, Garapati P, Haw R, Jassal B, Korninger F, May B et al The Reactome Pathway Knowledgebase. Nucleic Acids Res. 2018;46(D1):D649-D655. doi:10.1093/nar/gkx1132

32. Orchard S, Ammari M, Aranda B, Breuza L, Briganti L, Broackes-Carter F, Campbell NH, Chavali G, Chen C, del-Toro N, et al. The MIntAct project-IntAct as a common curation platform for 11 molecular interaction databases. Nucleic Acids Res. 2014;42(Database issue):D358-D363. doi:10.1093/nar/gkt1115

33. Shannon P, Markiel A, Ozier O, Baliga NS, Wang JT, Ramage D, Amin N, Schwikowski B, Ideker T Cytoscape: a software environment for integrated models of biomolecular interaction networks. Genome Res 2003;13(11):2498-2504. doi:10.1101/gr.1239303 
34.Przulj N, Wigle DA, Jurisica I. Functional topology in a network of protein interactions. $\quad$ Bioinformatics. 2004;20(3):340-348. doi:10.1093/bioinformatics/btg415

35.Nguyen TP, Liu WC, Jordán F. Inferring pleiotropy by network analysis: linked diseases in the human PPI network. BMC Syst Biol. 2011;5:179. doi:10.1186/1752-0509-5-179

36. Shi Z, Zhang B. Fast network centrality analysis using GPUs. BMC Bioinformatics. 2011;12:149. doi:10.1186/1471-2105-12-149

37.Fadhal E, Gamieldien J, Mwambene EC. Protein interaction networks as metric spaces: a novel perspective on distribution of hubs. BMC Syst Biol. 2014;8:6. doi:10.1186/1752-0509-8-6

38.Zaki N, Efimov D, Berengueres J. Protein complex detection using interaction reliability assessment and weighted clustering coefficient. BMC Bioinformatics. 2013;14:163. doi:10.1186/1471-2105-14

39.Fan Y, Xia J (2018) miRNet-Functional Analysis and Visual Exploration of miRNA-Target Interactions in a Network Context. Methods Mol Biol 1819:215-233. doi:10.1007/978-1-4939-8618-7_10

40.Zhou G, Soufan O, Ewald J, Hancock REW, Basu N, Xia J (2019) NetworkAnalyst 3.0: a visual analytics platform for comprehensive gene expression profiling and meta-analysis. Nucleic Acids Res 47:W234-W241. doi:10.1093/nar/gkz240

41.Robin X, Turck N, Hainard A, Tiberti N, Lisacek F, Sanchez JC, Müller M. pROC: an open-source package for $\mathrm{R}$ and $\mathrm{S}+$ to analyze and compare ROC curves. BMC Bioinformatics 2011;12:77. doi:10.1186/1471-2105-12-77

42.Livak KJ, Schmittgen TD Analysis of relative gene expression data using real-time quantitative PCR and the 2(-Delta Delta C(T)) Method. Methods 2001;25:402-408. doi:10.1006/meth.2001.1262

43. Gillespie KM. Type 1 diabetes: pathogenesis and prevention. CMAJ. 2006;175(2):165-170. doi:10.1503/cmaj.060244

44.Jacquemin B, Antoniades C, Nyberg F, Plana E, Müller M, Greven S, Salomaa V, Sunyer J, Bellander T, Chalamandaris AG, et al. Common genetic polymorphisms and haplotypes of fibrinogen alpha, beta, and gamma chains affect fibrinogen levels and the response to proinflammatory stimulation in myocardial infarction survivors: the AIRGENE study. $\mathrm{J}$ Am Coll Cardiol. 2008;52(11):941-952. doi:10.1016/j.jacc.2008.06.016 
45.Theodoraki EV, Nikopensius T, Suhorutsenko J, Peppes V, Fili P, Kolovou G, Papamikos V, Richter D, Zakopoulos N, Krjutskov K, et al. Fibrinogen beta variants confer protection against coronary artery disease in a Greek case-control study. BMC Med Genet. 2010;11:28. doi:10.1186/1471-2350$11-28$

46. Vafiadis P, Bennett ST, Todd JA, Grabs R, Polychronakos C. Divergence between genetic determinants of IGF2 transcription levels in leukocytes and of IDDM2-encoded susceptibility to type 1 diabetes. J Clin Endocrinol Metab. 1998;83(8):2933-2939. doi:10.1210/jcem.83.8.5048

47.Paulsson JF, Ludvigsson J, Carlsson A, Casas R, Forsander G, Ivarsson SA, Kockum I, Lernmark Å, Marcus C, Lindblad B, et al. High plasma levels of islet amyloid polypeptide in young with new-onset of type 1 diabetes mellitus. PLoS One. 2014;9(3):e93053. doi:10.1371/journal.pone.0093053

48.Pugliese A, Zeller M, Fernandez A Jr, Zalcberg LJ, Bartlett RJ, Ricordi C, Pietropaolo M, Eisenbarth GS, Bennett ST, Patel DD. The insulin gene is transcribed in the human thymus and transcription levels correlated with allelic variation at the INS VNTR-IDDM2 susceptibility locus for type 1 diabetes. Nat Genet. 1997;15(3):293-297. doi:10.1038/ng0397-293

49.Iacovazzo D, Flanagan SE, Walker E, Quezado R, de Sousa Barros FA, Caswell R, Johnson MB, Wakeling M, Brändle M, Guo M, et al. MAFA missense mutation causes familial insulinomatosis and diabetes mellitus. Proc Natl Acad Sci U S A. 2018;115(5):1027-1032. doi:10.1073/pnas.1712262115

50.Gu HF. Genetic variation screening and association studies of the adenylate cyclase activating polypeptide 1 (ADCYAP1) gene in patients with type 2 diabetes. Hum Mutat. 2002;19(5):572-573. doi:10.1002/humu.9034

51. Gold NB, Li D, Chassevent A, Kaiser FJ, Parenti I, Strom TM, Ramos FJ, Puisac B, Pié J, McWalter K, et al. Heterozygous de novo variants in CSNK1G1 are associated with syndromic developmental delay and autism spectrum disorder. Clin Genet. 2020;98(6):571-576. doi:10.1111/cge.13851

52.Husemoen LL, Skaaby T, Jørgensen T, Thyssen JP, Meldgaard M, Szecsi PB, Stender S, Johansen JD, Linneberg A. No association between loss-offunction mutations in filaggrin and diabetes, cardiovascular disease, and allcause mortality. PLoS One. 2013;8(12):e84293. doi:10.1371/journal.pone.0084293 
53.Zhang J, Weng W, Wang K, Lu X, Cai L, Sun J. The role of FGF21 in type 1 diabetes and its complications. Int J Biol Sci. 2018;14(9):1000-1011. doi:10.7150/ijbs. 25026

54.Hartz CS, Nieman KM, Jacobs RL, Vance DE, Schalinske KL. Hepatic phosphatidylethanolamine N-methyltransferase expression is increased in diabetic rats. J Nutr. 2006;136(12):3005-3009. doi:10.1093/jn/136.12.3005

55.Słomiński B, Ryba-Stanisławowska M, Skrzypkowska M, Gabig-Cimińska M, Myśliwiec M. A new potential mode of cardiorenal protection of KLOTHO gene variability in type 1 diabetic adolescents. J Mol Med (Berl). 2020;98(7):955-962. doi:10.1007/s00109-020-01918-7

56.Johansson BB, Torsvik J, Bjørkhaug L, Vesterhus M, Ragvin A, Tjora E, Fjeld K, Hoem D, Johansson S, Ræder H, et al. Diabetes and pancreatic exocrine dysfunction due to mutations in the carboxyl ester lipase genematurity onset diabetes of the young (CEL-MODY): a protein misfolding disease. J Biol Chem. 2011;286(40):34593-34605. doi:10.1074/jbc.M111.222679

57.Pan S, Li M, Yu H, Xie Z, Li X, Duan X, Huang G, Zhou Z. microRNA143-3p contributes to inflammatory reactions by targeting FOSL2 in PBMCs from patients with autoimmune diabetes mellitus. Acta Diabetol. 2021;58(1):63-72. doi:10.1007/s00592-020-01591-9

58.Lopez-Sanz L, Bernal S, Recio C, Lazaro I, Oguiza A, Melgar A, JimenezCastilla L, Egido J, Gomez-Guerrero C. SOCS1-targeted therapy ameliorates renal and vascular oxidative stress in diabetes via STAT1 and PI3K inhibition. Lab Invest. 2018;98(10):1276-1290. doi:10.1038/s41374-0180043-6

59. Grant SFA. The TCF7L2 Locus: A Genetic Window Into the Pathogenesis of Type 1 and Type 2 Diabetes. Diabetes Care. 2019;42(9):1624-1629. doi:10.2337/dci19-0001

60.Słomiński B, Skrzypkowska M, Ryba-Stanisławowska M, Myśliwiec M, Trzonkowski P. Associations of TP53 codon 72 polymorphism with complications and comorbidities in patients with type 1 diabetes. J Mol Med (Berl). 2021;99(5):675-683. doi:10.1007/s00109-020-02035-1

61.Galán M, Kassan M, Choi SK, Partyka M, Trebak M, Henrion D, Matrougui $\mathrm{K}$. A novel role for epidermal growth factor receptor tyrosine kinase and its downstream endoplasmic reticulum stress in cardiac damage and 
microvascular dysfunction in type 1 diabetes mellitus. Hypertension. 2012;60(1):71-80. doi:10.1161/HYPERTENSIONAHA.112.192500

62.Jordan MA, Poulton LD, Fletcher JM, Baxter AG. Allelic variation of Ets1 does not contribute to NK and NKT cell deficiencies in type 1 diabetes susceptible NOD mice. Rev Diabet Stud. 2009;6(2):104-116. doi:10.1900/RDS.2009.6.104

63.Winkler M, Lutz R, Russ U, Quast U, Bryan J. Analysis of two KCNJ11 neonatal diabetes mutations, V59G and V59A, and the analogous KCNJ8 I60G substitution: differences between the channel subtypes formed with SUR1. J Biol Chem. 2009;284(11):6752-6762. doi:10.1074/jbc.M805435200

64.Yip L, Fuhlbrigge R, Taylor C, Creusot RJ, Nishikawa-Matsumura T, Whiting CC, Schartner JM, Akter R, von Herrath M, Fathman CG. Inflammation and hyperglycemia mediate Deaf1 splicing in the pancreatic lymph nodes via distinct pathways during type 1 diabetes. Diabetes. 2015;64(2):604-617. doi:10.2337/db14-0803

65.Crookshank JA, Serrano D, Wang GS, Patrick C, Morgan BS, Paré MF, Scott FW. Changes in insulin, glucagon and ER stress precede immune activation in type 1 diabetes. J Endocrinol. 2018;239(2):181-195. doi:10.1530/JOE-18-0328

66.Lempainen J, Härkönen T, Laine A, Knip M, Ilonen J; Finnish Pediatric Diabetes Register. Associations of polymorphisms in non-HLA loci with autoantibodies at the diagnosis of type 1 diabetes: INS and IKZF4 associate with insulin autoantibodies. Pediatr Diabetes. 2013;14(7):490-496. doi:10.1111/pedi.12046

67.Qu HQ, Polychronakos C; Type I Diabetes Genetics Consortium.

Reassessment of the type I diabetes association of the OAS1 locus. Genes Immun. 2009;10 Suppl 1(Suppl 1):S69-S73. doi:10.1038/gene.2009.95

68. Morrison VA, Onengut-Gumuscu S, Concannon P. A functional variant of IRS1 is associated with type 1 diabetes in families from the US and UK. Mol Genet Metab. 2004;81(4):291-294. doi:10.1016/j.ymgme.2003.10.018

69.Zhang D, Ding Y, Wang X, Xin W, Du W, Chen W, Zhang X, Li P. Effects of ABCG2 and SLCO1B1 gene variants on inflammation markers in patients with hypercholesterolemia and diabetes mellitus treated with rosuvastatin. 
Eur J Clin Pharmacol. 2020;76(7):939-946. doi:10.1007/s00228-020-028824

70.Gerlinger-Romero F, Yonamine CY, Junior DC, Esteves JV, Machado UF. Dysregulation between TRIM63/FBXO32 expression and soleus muscle wasting in diabetic rats: potential role of miR-1-3p, $-29 \mathrm{a} / \mathrm{b}-3 \mathrm{p}$, and $-133 \mathrm{a} / \mathrm{b}-$ 3p. Mol Cell Biochem. 2017;427(1-2):187-199. doi:10.1007/s11010-016$2910-\mathrm{z}$

71.Belanger K, Nutter CA, Li J, Yu P, Kuyumcu-Martinez MN. A developmentally regulated spliced variant of PTBP1 is upregulated in type 1 diabetic hearts. Biochem Biophys Res Commun. 2019;509(2):384-389. doi:10.1016/j.bbrc.2018.12.150

72.Dieter C, Lemos NE, Dorfman LE, Duarte GCK, Assmann TS, Crispim D. The rs11755527 polymorphism in the $\mathrm{BACH} 2$ gene and type 1 diabetes mellitus: case control study in a Brazilian population. Arch Endocrinol Metab. 2020;64(2):138-143. doi:10.20945/2359-3997000000214

73. Wanic K, Placha G, Dunn J, Smiles A, Warram JH, Krolewski AS. Exclusion of polymorphisms in carnosinase genes (CNDP1 and CNDP2) as a cause of diabetic nephropathy in type 1 diabetes: results of large casecontrol and follow-up studies. Diabetes. 2008;57(9):2547-2551. doi:10.2337/db07-1303

74.Ushijima K, Narumi S, Ogata T, Yokota I, Sugihara S, Kaname T, Horikawa Y, Matsubara Y, Fukami M, Kawamura T;KLF11 variant in a family clinically diagnosed with early childhood-onset type 1B diabetes. Pediatr Diabetes. 2019;20(6):712-719. doi:10.1111/pedi.12868

75. Guo M, Zhang T, Dong X, Xiang JZ, Lei M, Evans T, Graumann J, Chen S. Using hESCs to Probe the Interaction of the Diabetes-Associated Genes CDKAL1 and MT1E. Cell Rep. 2017;19(8):1512-1521. doi:10.1016/j.celrep.2017.04.070

76.Davis H, Jones Briscoe V, Dumbadze S, Davis SN. Using DPP-4 inhibitors to modulate beta cell function in type 1 diabetes and in the treatment of diabetic kidney disease. Expert Opin Investig Drugs. 2019;28(4):377-388. doi:10.1080/13543784.2019.1592156

77.Elbarbary NS, Tjora E, Molnes J, Lie BA, Habib MA, Salem MA, Njølstad PR.An Egyptian family with $\mathrm{H}$ syndrome due to a novel mutation in SLC29A3 illustrating overlapping features with pigmented hypertrichotic 
dermatosis with insulin-dependent diabetes and Faisalabad histiocytosis.

Pediatr Diabetes. 2013;14(6):466-472. doi:10.1111/j.13995448.2012.00925.x

78.Villasenor A, Wang ZV, Rivera LB, Ocal O, Asterholm IW, Scherer PE, Brekken RA, Cleaver O, Wilkie TM. Rgs16 and Rgs8 in embryonic endocrine pancreas and mouse models of diabetes. Dis Model Mech. 2010;3(9-10):567-580. doi:10.1242/dmm.003210

79.Zhang L, Londono P, Yu L, Grimes S, Blackburn P, Gottlieb P, Eisenbarth GS. MAS-1 adjuvant immunotherapy generates robust Th2 type and regulatory immune responses providing long-term protection from diabetes in late-stage pre-diabetic NOD mice. Autoimmunity. 2014;47(5):341-350. doi:10.3109/08916934.2014.910768

80.Lee Y, Wang MY, Du XQ, Charron MJ, Unger RH. Glucagon receptor knockout prevents insulin-deficient type 1 diabetes in mice. Diabetes. 2011;60(2):391-397. doi:10.2337/db10-0426

81.Zhi D, Sun C, Sedimbi SK, Luo F, Shen S, Sanjeevi CB. Killer cell immunoglobulin-like receptor along with HLA-C ligand genes are associated with type 1 diabetes in Chinese Han population. Diabetes Metab Res Rev. 2011;27(8):872-877. doi:10.1002/dmrr.1264

82.Li Calzi S, Purich DL, Chang KH, Afzal A, Nakagawa T, Busik JV, Agarwal A, Segal MS, Grant MB. Carbon monoxide and nitric oxide mediate cytoskeletal reorganization in microvascular cells via vasodilatorstimulated phosphoprotein phosphorylation: evidence for blunted responsiveness in diabetes. Diabetes. 2008;57(9):2488-2494. doi: $10.2337 / \mathrm{db} 08-0381$

83.Sebastiani G, Ventriglia G, Stabilini A, Socci C, Morsiani C, Laurenzi A, Nigi L, Formichi C, Mfarrej B, Petrelli A, et al. Regulatory T-cells from pancreatic lymphnodes of patients with type-1 diabetes express increased levels of microRNA miR-125a-5p that limits CCR2 expression. Sci Rep. 2017;7(1):6897. doi:10.1038/s41598-017-07172-1

84.Cherney DZ, Miller JA, Scholey JW, Nasrallah R, Hébert RL, Dekker MG, Slorach C, Sochett EB, Bradley TJ. Renal hyperfiltration is a determinant of endothelial function responses to cyclooxygenase 2 inhibition in type 1 diabetes. Diabetes Care. 2010;33(6):1344-1346. doi:10.2337/dc09-2340 
85.Doggrell SA. Do glucagon-like peptide-1 receptor (GLP-1R) agonists have potential as adjuncts in the treatment of type 1 diabetes?. Expert Opin Pharmacother. 2018;19(15):1655-1661. doi:10.1080/14656566.2018.1519547

86. Yanagihara T, Tomino T, Uruno T, Fukui Y. Thymic epithelial cell-specific deletion of Jmjd6 reduces Aire protein expression and exacerbates disease development in a mouse model of autoimmune diabetes . Biochem Biophys Res Commun. 2017;489(1):8-13. doi:10.1016/j.bbrc.2017.05.113

87. Vassilev P, Pantoja-Urban AH, Giroux M, Nouel D, Hernandez G, Orsini T, Flores C. Unique effects of social defeat stress in adolescent male mice on the Netrin-1/DCC pathway, prefrontal cortex dopamine and cognition (Social stress in adolescent vs. adult male mice) . eNeuro. 2021;8(2):ENEURO.0045-21.2021. doi:10.1523/ENEURO.0045-21.2021

88. Qin W, Gao J, Xing Q, Yang J, Qian X, Li X, Guo Z, Chen H, Wang L, Huang $X$, et al. A family-based association study of PLP1 and schizophrenia. Neurosci Lett. 2005;375(3):207-210. doi:10.1016/j.neulet.2004.11.013

89.Ma L, Semick SA, Chen Q, Li C, Tao R, Price AJ, Shin JH, Jia Y. Schizophrenia risk variants influence multiple classes of transcripts of sorting nexin 19 (SNX19). Mol Psychiatry. 2020;25(4):831-843. doi:10.1038/s41380-018-0293-0

90.West RJH, Ugbode C, Gao FB, Sweeney ST. The pro-apoptotic JNK scaffold POSH/SH3RF1 mediates CHMP2BIntron5-associated toxicity in animal models of frontotemporal dementia. Hum Mol Genet. 2018;27(8):1382-1395. doi:10.1093/hmg/ddy048

91.Hoffmann LA, Lohse P, König FB, Feneberg W, Hohlfeld R, Kümpfel T. TNFRSF1A R92Q mutation in association with a multiple sclerosis-like demyelinating syndrome. Neurology. 2008;70(13 Pt 2):1155-1156. doi:10.1212/01.wnl.0000296279.98236.8a

92.Deary IJ, Hamilton G, Hayward C, Whalley LJ, Powell J, Starr JM, Lovestone S. Nicastrin gene polymorphisms, cognitive ability level and cognitive ageing. Neurosci Lett. 2005;373(2):110-114. doi:10.1016/j.neulet.2004.09.073

93. Belangero SI, Ota VK, Gadelha A, Berberian AA, Assunção-Leme IB, Noto C, Christofolini DM, Bellucco FT, Santoro ML, Mazzotti DR, et al. DGCR2 
influences cortical thickness through a mechanism independent of schizophrenia pathogenesis. Psychiatry Res. 2019;274:391-394. doi:10.1016/j.psychres.2019.02.068

94.Jung JS, Lee HJ, Cho CH, Kang SG, Yoon HK, Park YM, Moon JH, Yang HJ, Song HM, Kim L. Association between restless legs syndrome and CLOCK and NPAS2 gene polymorphisms in schizophrenia. Chronobiol Int. 2014;31(7):838-844. doi:10.3109/07420528.2014.914034

95.Tang T, Li Y, Jiao Q, Du X, Jiang H. Cerebral Dopamine Neurotrophic Factor: A Potential Therapeutic Agent for Parkinson's Disease. Neurosci Bull. 2017;33(5):568-575. doi:10.1007/s12264-017-0123-4

96. Goodier JL, Soares AO, Pereira GC, DeVine LR, Sanchez L, Cole RN, García-Pérez JL. C9orf72-associated SMCR8 protein binds in the ubiquitin pathway and with proteins linked with neurological disease. Acta Neuropathol Commun. 2020;8(1):110. doi:10.1186/s40478-020-00982-x

97.Petyuk VA, Chang R, Ramirez-Restrepo M, Beckmann ND, Henrion MYR, Piehowski PD, Zhu K, Wang S, Clarke J, Huentelman MJ, et al. The human brainome: network analysis identifies HSPA2 as a novel Alzheimer's disease target. Brain. 2018;141(9):2721-2739. doi:10.1093/brain/awy215

98. Roux T, Barbier M, Papin M, Davoine CS, Sayah S, Coarelli G, Charles P, Marelli C, Parodi L, Tranchant C, et al. Clinical, neuropathological, and genetic characterization of STUB1 variants in cerebellar ataxias: a frequent cause of predominant cognitive impairment. Genet Med. 2020;22(11):18511862. doi:10.1038/s41436-020-0899-x

99.Castrogiovanni P, Sanfilippo C, Imbesi R, Maugeri G, Lo Furno D, Tibullo D, Castorina A, Musumeci G, Di Rosa M. Brain CHID1 Expression Correlates with NRGN and CALB1 in Healthy Subjects and AD Patients. Cells. 2021;10(4):882. doi:10.3390/cells10040882

100. Suleiman J, Hamwi N, El-Hattab AW. ATP13A2 novel mutations causing a rare form of juvenile-onset Parkinson disease. Brain Dev. 2018;40(9):824-826. doi:10.1016/j.braindev.2018.05.017

101. Haack TB, Ignatius $\mathrm{E}$, Calvo-Garrido J, Iuso $\mathrm{A}$, Isohanni $\mathrm{P}$, Maffezzini C, Lönnqvist T, Suomalainen A, Gorza M, Kremer LS, et al. Absence of the Autophagy Adaptor SQSTM1/p62 Causes Childhood-Onset Neurodegeneration with Ataxia, Dystonia, and Gaze Palsy. Am J Hum Genet. 2016;99(3):735-743. doi:10.1016/j.ajhg.2016.06.026 
102. Kwiatkowski D, Czarny P, Toma M, Korycinska A, Sowinska K, Galecki P, Bachurska A, Bielecka-Kowalska A, Szemraj J, Maes M, et al. Association between Single-Nucleotide Polymorphisms of the hOGG1,NEIL1,APEX1, FEN1,LIG1, and LIG3 Genes and Alzheimer's Disease Risk. Neuropsychobiology. 2016;73(2):98-107. doi:10.1159/000444643

103. Pinacho R, Valdizán EM, Pilar-Cuellar F, Prades R, Tarragó T, Haro JM, Ferrer I, Ramos B. Increased SP4 and SP1 transcription factor expression in the postmortem hippocampus of chronic schizophrenia. J Psychiatr Res. 2014;58:189-196. doi:10.1016/j.jpsychires.2014.08.006

104. Luo XJ, Diao HB, Wang JK, Zhang H, Zhao ZM, Su B. Association of haplotypes spanning PDZ-GEF2, LOC728637 and ACSL6 with schizophrenia in Han Chinese. J Med Genet. 2008;45(12):818-826. doi:10.1136/jmg.2008.060657

105. He L, Loika Y, Park Y; Bennett DA, Kellis M, Kulminski AM. Exome-wide age-of-onset analysis reveals exonic variants in ERN1 and SPPL2C associated with Alzheimer's disease. Transl Psychiatry. 2021;11(1):146. doi:10.1038/s41398-021-01263-4

106. Moudi M, Sargazi S, Heidari Nia M, Saravani R, Shirvaliloo M, Shakiba M. Polymorphism in the 3'-UTR of LIF but Not in the ATF6B Gene Associates with Schizophrenia Susceptibility: a Case-Control Study and In Silico Analyses. J Mol Neurosci. 2020;70(12):2093-2101. doi:10.1007/s12031-020-01616-6

107. Thevenon J, Souchay C, Seabold GK, Dygai-Cochet I, Callier P, Gay S, Corbin L, Duplomb L, Thauvin-Robinet C, Masurel-Paulet A, et al. Heterozygous deletion of the LRFN2 gene is associated with working memory deficits. Eur J Hum Genet. 2016;24(6):911-918. doi:10.1038/ejhg.2015.221

108. Li Z, Liu L, Lin W, Zhou Y, Zhang G, Du X, Li Y, Tang W, Zhang X. NRG3 contributes to cognitive deficits in chronic patients with schizophrenia. Schizophr $\quad$ Res. 2020;215:134-139. doi:10.1016/j.schres.2019.10.060

109. Reitz C, Conrad C, Roszkowski K, Rogers RS, Mayeux R. Effect of genetic variation in LRRTM3 on risk of Alzheimer disease. Arch Neurol. 2012;69(7):894-900. doi:10.1001/archneurol.2011.2463 
110. Jenkins A, Escayg A. Reply: Novel GABRA2 variants in epileptic encephalopathy and intellectual disability with seizures. Brain. 2019;142(5):e16. doi:10.1093/brain/awz086

111. Letronne F, Laumet G, Ayral AM, Chapuis J, Demiautte F, Laga M, Vandenberghe ME, Malmanche N, Leroux F, Eysert F, et al. ADAM30 Downregulates APP-Linked Defects Through Cathepsin D Activation in Alzheimer's Disease. EBioMedicine. 2016;9:278-292. doi:10.1016/j.ebiom.2016.06.002

112. Ma Z, Niu B, Shi Z, Li J, Wang J, Zhang F, Gao X, Zhang K. Genetic Polymorphism of GABRR2 Modulates Individuals' General Cognitive Ability in Healthy Chinese Han People. Cell Mol Neurobiol. 2017;37(1):93100. doi:10.1007/s10571-016-0347-2

113. Chabbert D, Caubit X, Roubertoux PL, Carlier M, Habermann B, Jacq B, Salin P, Metwaly M, Frahm C, Fatmi A, et al. Postnatal Tshz3 Deletion Drives Altered Corticostriatal Function and Autism Spectrum Disorder-like Behavior. Biol Psychiatry. 2019;86(4):274-285. doi:10.1016/j.biopsych.2019.03.974

114. Abramsson A, Landgren S, Zetterberg M, Seibt Palmer M, Minthon L, Gustafson DR, Skoog I, Blennow K, Zetterberg H. No association of LOXL1 gene polymorphisms with Alzheimer's disease. Neuromolecular Med. 2011;13(2):160-166. doi:10.1007/s12017-011-8144-Z

115. Aeby A, Sculier C, Bouza AA, Askar B, Lederer D, Schoonjans AS, Vander Ghinst M, Ceulemans B, Offord J, Lopez-Santiago LF, et al. SCN1B-linked early infantile developmental and epileptic encephalopathy. Ann Clin Transl Neurol. 2019;6(12):2354-2367. doi:10.1002/acn3.50921

116. Roll P, Rudolf G, Pereira S, Royer B, Scheffer IE, Massacrier A, Valenti MP, Roeckel-Trevisiol N, Jamali S, Beclin C, et al. SRPX2 mutations in disorders of language cortex and cognition. Hum Mol Genet. 2006;15(7):1195-1207. doi:10.1093/hmg/dd1035

117. Soofi A, Wolf KI, Emont MP, Qi N, Martinez-Santibanez G, Grimley E, Ostwani W, Dressler GR. The kielin/chordin-like protein (KCP) attenuates high-fat diet-induced obesity and metabolic syndrome in mice. $\mathrm{J}$ Biol Chem. 2017;292(22):9051-9062. doi:10.1074/jbc.M116.771428

118. Blázquez-Medela AM, Jumabay M, Rajbhandari P, Sallam T, Guo Y, Yao J, Vergnes L, Reue K, Zhang L, Yao Y, et al. Noggin depletion in 
adipocytes promotes obesity in mice. Mol Metab. 2019;25:50-63. doi:10.1016/j.molmet.2019.04.004

119. McCulloch LJ, Rawling TJ, Sjöholm K, Franck N, Dankel SN, Price EJ, Knight B, Liversedge NH, Mellgren G, Nystrom F, et al. COL6A3 is regulated by leptin in human adipose tissue and reduced in obesity. Endocrinology. 2015;156(1):134-146. doi:10.1210/en.2014-1042

120. Gan M, Shen L, Wang S, Guo Z, Zheng T, Tan Y, Fan Y, Liu L, Chen L, Jiang A, et al. Genistein inhibits high fat diet-induced obesity through miR-222 by targeting BTG2 and adipor1. Food Funct. 2020;11(3):2418-2426. doi:10.1039/c9fo00861f

121. Han X, Guo J, You Y, Zhan J, Huang W. p-Coumaric acid prevents obesity via activating thermogenesis in brown adipose tissue mediated by mTORC1-RPS6. FASEB J. 2020;34(6):7810-7824. doi:10.1096/fj.202000333R

122. Wang G, Wu B, Cui Y, Zhang B, Jiang C, Wang H. Teneligliptin Promotes Bile Acid Synthesis and Attenuates Lipid Accumulation in Obese Mice by Targeting the KLF15-Fgf15 Pathway. Chem Res Toxicol. 2020;33(8):2164-2171. doi:10.1021/acs.chemrestox.0c00192

123. Zhou X, Shi X, Wang J, Zhang X, Xu Y, Liu Y, Li X, Yang G. et al. miR-324-5p promotes adipocyte differentiation and lipid droplet accumulation by targeting Krueppel-like factor 3 (KLF3). J Cell Physiol. 2020;235(10):7484-7495. doi:10.1002/jcp.29652

124. Caracciolo V, Young J, Gonzales D, Ni Y, Flowers SJ, Summer R, Waldman SA, Kim JK, Jung DY, Noh HL, et al. Myeloid-specific deletion of Zfp36 protects against insulin resistance and fatty liver in diet-induced obese mice. Am J Physiol Endocrinol Metab. 2018;315(4):E676-E693. doi:10.1152/ajpendo.00224.2017

125. Lv D, Zhou D, Zhang Y, Zhang S, Zhu YM. Two obesity susceptibility loci in LYPLAL1 and ETV5 independently associated with childhood hypertension in Chinese population. Gene. 2017;627:284-289. doi:10.1016/j.gene.2017.06.030

126. Pearson S, Loft A, Rajbhandari P, Simcox J, Lee S, Tontonoz P, Mandrup S, Villanueva CJ. Loss of TLE3 promotes the mitochondrial program in beige adipocytes and improves glucose metabolism. Genes Dev. 2019;33(13-14):747-762. doi:10.1101/gad.321059.118 
127. Brachs S, Polack J, Brachs M, Jahn-Hofmann K, Elvert R, Pfenninger A, Bärenz F, Margerie D, Mai K, Spranger J, et al. Genetic Nicotinamide NMethyltransferase (Nnmt) Deficiency in Male Mice Improves Insulin Sensitivity in Diet-Induced Obesity but Does Not Affect Glucose Tolerance. Diabetes. 2019;68(3):527-542. doi:10.2337/db18-0780

128. Lai CQ, Parnell LD, Arnett DK, García-Bailo B, Tsai MY, Kabagambe EK, Straka RJ, Province MA, An P, Borecki IB, et al. WDTC1, the ortholog of Drosophila adipose gene, associates with human obesity, modulated by MUFA intake. Obesity (Silver Spring). 2009;17(3):593-600. doi:10.1038/oby.2008.561

129. Yang SA. Association study between ZFHX3 gene polymorphisms and obesity in Korean population. J Exerc Rehabil. 2017;13(4):491-494. doi:10.12965/jer. 1735080.540

130. Kilroy G, Carter LE, Newman S, Burk DH, Manuel J, Möller A, Bowtell DD, Mynatt RL, Ghosh S, Floyd ZE. The ubiquitin ligase Siah2 regulates obesity-induced adipose tissue inflammation. Obesity (Silver Spring). 2015;23(11):2223-2232. doi:10.1002/oby.21220

131. Zusi C, Morandi A, Maguolo A, Corradi M, Costantini S, Mosca A, Crudele A, Mantovani A, Alisi A, Miraglia Del Giudice E, et al. Association between MBOAT7 rs641738 polymorphism and non-alcoholic fatty liver in overweight or obese children. Nutr Metab Cardiovasc Dis. 2021;31(5):15481555. doi:10.1016/j.numecd.2021.01.020

132. Zhou Y, Hambly BD, Simmons D, McLachlan CS. RUNX1T1 rs34269950 is associated with obesity and metabolic syndrome. QJM. 2020; hcaa208. doi:10.1093/qjmed/hcaa208

133. Gao Y, Wang Y, Chen X, Peng Y, Chen F, He Y, Pang W, Yang G, Yu T. MiR-127 attenuates adipogenesis by targeting MAPK4 and HOXC6 in porcine adipocytes. J Cell Physiol. 2019;234(12):21838-21850. doi:10.1002/jcp. 28660

134. Wei Z, Qin X, Kang X, Zhou H, Wang S, Wei D. MiR-142-3p inhibits adipogenic differentiation and autophagy in obesity through targeting KLF9. Mol Cell Endocrinol. 2020;518:111028. doi:10.1016/j.mce.2020.111028 
135. Randi EB, Casili G, Jacquemai S, Szabo C. Selenium-Binding Protein 1 (SELENBP1) Supports Hydrogen Sulfide Biosynthesis and Adipogenesis. Antioxidants (Basel). 2021;10(3):361. doi:10.3390/antiox10030361

136. Yoshino S, Satoh T, Yamada M, Hashimoto K, Tomaru T, KatanoToki A, Kakizaki S, Okada S, Shimizu H, Ozawa A, et al. Protection against high-fat diet-induced obesity in Helz2-deficient male mice due to enhanced expression of hepatic leptin receptor. Endocrinology. 2014;155(9):34593472. doi:10.1210/en.2013-2160

137. Pang L, You L, Ji C, Shi C, Chen L, Yang L, Huang F, Zhou Y, Zhang J, Chen X, et al. miR-1275 inhibits adipogenesis via ELK1 and its expression decreases in obese subjects. J Mol Endocrinol. 2016;57(1):33-43. doi:10.1530/JME-16-0007

138. Chen C, Deng Y, Hu X, Ren H, Zhu J, Fu S, Xie J, Peng Y. miR-128$3 p$ regulates 3T3-L1 adipogenesis and lipolysis by targeting Pparg and Sertad2. J Physiol Biochem. 2018;74(3):381-393. doi:10.1007/s13105-0180625-1

139. Prats-Puig A, Soriano-Rodríguez P, Oliveras G, Carreras-Badosa G, Espuña S, Díaz-Roldán F, de Zegher F, Ibáñez L, Bassols J, Puig T, et al. Soluble CRTC3: A Newly Identified Protein Released by Adipose Tissue That Is Associated with Childhood Obesity. Clin Chem. 2016;62(3):476484. doi:10.1373/clinchem.2015.249136

140. Henkel AS, Kavesh MH, Kriss MS, Dewey AM, Rinella ME, Green RM. Hepatic overexpression of abcb11 promotes hypercholesterolemia and obesity in mice. Gastroenterology. 2011;141(4):1404-1411.e14112. doi:10.1053/j.gastro.2011.06.062

141. Klöting N, Wilke B, Klöting I. Alleles on rat chromosome 4 (D4Got41-Fabp1/Tacr1) regulate subphenotypes of obesity. Obes Res. 2005;13(3):589-595. doi:10.1038/oby.2005.63

142. Giri AK, Prasad G, Bandesh K, Parekatt V, Mahajan A, Banerjee P, Kauser Y, Chakraborty S, Rajashekar D;Multifaceted genome-wide study identifies novel regulatory loci in SLC22A11 and ZNF45 for body mass index in Indians. Mol Genet Genomics. 2020;295(4):1013-1026. doi:10.1007/s00438-020-01678-6

143. Samblas M, Milagro FI, Mansego ML, Marti A, Martinez JA; GENOI members. PTPRS and PER3 methylation levels are associated with 
childhood obesity: results from a genome-wide methylation analysis. Pediatr Obes. 2018;13(3):149-158. doi:10.1111/ijpo.12224

144. Ussar S, Lee KY, Dankel SN, Boucher J, Haering MF, Kleinridders A, Thomou T, Xue R, Macotela Y, Cypess AM, et al. ASC-1, PAT2, and P2RX5 are cell surface markers for white, beige, and brown adipocytes. Sci Transl Med. 2014;6(247):247ra103. doi:10.1126/scitranslmed.3008490

145. Vaittinen M, Kolehmainen M, Rydén M, Eskelinen M, Wabitsch M, Pihlajamäki J, Uusitupa M, Pulkkinen L. MFAP5 is related to obesityassociated adipose tissue and extracellular matrix remodeling and inflammation. Obesity (Silver Spring). 2015;23(7):1371-1378. doi:10.1002/oby. 21103

146. Wu HT, Chen SC, Fan KC, Kuo CH, Lin SY, Wang SH, Chang CJ, Li HY. Targeting fibrinogen-like protein 1 is a novel therapeutic strategy to combat obesity. FASEB J. 2020;34(2):2958-2967. doi:10.1096/fj.201901925R

147. Albuquerque $\mathrm{D}$, Nóbrega $\mathrm{C}$, Rodríguez-López $\mathrm{R}$, Manco L. Association study of common polymorphisms in MSRA, TFAP2B, MC4R, NRXN3, PPARGC1A, TMEM18, SEC16B, HOXB5 and OLFM4 genes with obesity-related traits among Portuguese children. J Hum Genet. 2014;59(6):307-313. doi:10.1038/jhg.2014.23

148. Sharma M, Schlegel M, Brown EJ, Sansbury BE, Weinstock A, Afonso MS, Corr EM, van Solingen C, Shanley LC, Peled D, et al Netrin-1 Alters Adipose Tissue Macrophage Fate and Function in Obesity. Immunometabolism. 2019;1(2):e190010. doi:10.20900/immunometab20190010

149. Guclu-Geyik F, Coban N, Can G, Erginel-Unaltuna N. The rs 2175898 Polymorphism in the ESR1 Gene has a Significant Sex-Specific Effect on Obesity. Biochem Genet. 2020;58(6):935-952. doi:10.1007/s10528-02009987-6

150. Ichihara S, Yamada Y, Kato K, Hibino T, Yokoi K, Matsuo H, Kojima T, Watanabe S, Metoki N, Yoshida H, et al. Association of a polymorphism of ABCB1 with obesity in Japanese individuals. Genomics. 2008;91(6):512-516. doi:10.1016/j.ygeno.2008.03.004

151. Menacho-Márquez M, Nogueiras R, Fabbiano S, Sauzeau V, AlMassadi O, Diéguez C, Bustelo XR. Chronic sympathoexcitation through 
loss of Vav3, a Rac1 activator, results in divergent effects on metabolic syndrome and obesity depending on diet. Cell Metab. 2013;18(2):199-211. doi:10.1016/j.cmet.2013.07.001

152. Jiao H, Kulyté A, Näslund E, Thorell A, Gerdhem P, Kere J, Arner P,

Dahlman I. Whole-Exome Sequencing Suggests LAMB3 as a Susceptibility Gene for Morbid Obesity. Diabetes. 2016;65(10):2980-2989. doi:10.2337/db16-052

153. Qiu Y, Sui X, Zhan Y, Xu C, Li X, Ning Y, Zhi X, Yin L.

Steroidogenic acute regulatory protein (StAR) overexpression attenuates HFD-induced hepatic steatosis and insulin resistance. Biochim Biophys Acta Mol Basis Dis. 2017;1863(4):978-990. doi:10.1016/j.bbadis.2017.01.026

154. Margaryan S, Kriegova E, Fillerova R, Smotkova Kraiczova V, Manukyan G. Hypomethylation of IL1RN and NFKB1 genes is linked to the dysbalance in IL1 $\beta / \mathrm{IL}-1 \mathrm{Ra}$ axis in female patients with type 2 diabetes mellitus. PLoS One. 2020;15(5):e0233737. doi:10.1371/journal.pone.0233737

155. Gao C, Zhang W. Urinary AQP5 is independently associated with eGFR decline in patients with type 2 diabetes and nephropathy. Diabetes Res Clin Pract. 2019;155:107805. doi:10.1016/j.diabres.2019.107805

156. Wu J, Tao W, Bu D, Zhao Y, Zhang T, Chong D, Xue B, Xing Z, Li C. Egr-1 transcriptionally activates protein phosphatase PTP1B to facilitate hyperinsulinemia-induced insulin resistance in the liver in type 2 diabetes. FEBS Lett. 2019;593(21):3054-3063. doi:10.1002/1873-3468.13537

157. Pueyo N, Ortega FJ, Mercader JM, Moreno-Navarrete JM, Sabater M, Bonàs S, Botas P, Delgado E, Ricart W, Martinez-Larrad MT, et al. Common genetic variants of surfactant protein-D (SP-D) are associated with type 2 diabetes. PLoS One. 2013;8(4):e60468. doi:10.1371/journal.pone.0060468

158. Gutierrez-Aguilar R, Benmezroua Y, Balkau B, Marre M, Helbecque N, Charpentier G, Polychronakos C, Sladek R, Froguel P, Neve B. Minor contribution of SMAD7 and KLF10 variants to genetic susceptibility of type 2 diabetes. Diabetes Metab. 2007;33(5):372-378. doi:10.1016/j.diabet.2007.06.002

159. El-Ashmawy HM, Selim FO, Hosny TAM, Almassry HN. Association of serum podocalyxin levels with peripheral arterial disease in 
patients with type 2 diabetes. J Diabetes Complications. 2019;33(7):495499. doi:10.1016/j.jdiacomp.2019.04.003

160. Erickson ML, Karanth S, Ravussin E, Schlegel A. FOXN3 hyperglycemic risk allele and insulin sensitivity in humans. BMJ Open Diabetes Res Care. 2019;7(1):e000688. doi:10.1136/bmjdrc-2019-000688

161. Wu X, Yu T, Ji N, Huang Y, Gao L, Shi W, Yan Y, Li H, Ma L, Wu $\mathrm{K}$, et al. IL6R inhibits viability and apoptosis of pancreatic beta-cells in type 2 diabetes mellitus via regulation by miR-22 of the JAK/STAT signaling pathway. Diabetes Metab Syndr Obes. 2019;12:1645-1657. doi:10.2147/DMSO.S211700

162. Duesing K, Charpentier G, Marre M, Tichet J, Hercberg S, Balkau B, Froguel P, Gibson F. Evaluating the association of common PBX1 variants with type 2 diabetes. BMC Med Genet. 2008;9:14. doi:10.1186/1471-23509-14

163. Do Carmo S, Fournier D, Mounier C, Rassart E. Human apolipoprotein $\mathrm{D}$ overexpression in transgenic mice induces insulin resistance and alters lipid metabolism. Am J Physiol Endocrinol Metab. 2009;296(4):E802-E811. doi:10.1152/ajpendo.90725.2008

164. Dupont S, Hani EH, Cras-Méneur C, De Matos F, Lobbens S, Lecoeur C, Vaxillaire M, Scharfmann R, Froguel P. No evidence for linkage or for diabetes-associated mutations in the activin type 2B receptor gene (ACVR2B) in French patients with mature-onset diabetes of the young or type 2 diabetes. Diabetes. 2001;50(5):1219-1221. doi:10.2337/diabetes.50.5.1219

165. Tripaldi R, Lanuti P, Simeone PG, Liani R, Bologna G, Ciotti S, Simeone P, Di Castelnuovo A, Marchisio M, Cipollone F, et al. Endogenous PCSK9 may influence circulating CD45neg/CD34bright and CD45neg/CD34bright/CD146neg cells in patients with type 2 diabetes mellitus. Sci Rep. 2021;11(1):9659. doi:10.1038/s41598-021-88941-x

166. Parvin M, Jahan F, Sarkar PK, Howlader ZH, Nabi AHMN, Hosen MI. Functional Polymorphism Located in the microRNA Binding Site of the Insulin Receptor (INSR) Gene Confers Risk for Type 2 Diabetes Mellitus in the Bangladeshi Population. Biochem Genet. 2019;57(1):20-33. doi:10.1007/s10528-018-9872-7 
167. Weber KS, Knebel B, Strassburger K, Kotzka J, Stehle P, Szendroedi J, Müssig K, Buyken AE, Roden M. Associations between explorative dietary patterns and serum lipid levels and their interactions with ApoA5 and ApoE haplotype in patients with recently diagnosed type 2 diabetes. Cardiovasc Diabetol. 2016;15(1):138. doi:10.1186/s12933-016-0455-9

168. Qiu Y, Sui X, Cao S, Li X, Ning Y, Wang S, Yin L, Zhi X.

Steroidogenic Acute Regulatory Protein (StAR) Overexpression Reduces Inflammation and Insulin Resistance in Obese Mice. J Cell Biochem. 2017;118(11):3932-3942. doi:10.1002/jcb.26046

169. Mori J, Alrob OA, Wagg CS, Harris RA, Lopaschuk GD, Oudit GY. ANG II causes insulin resistance and induces cardiac metabolic switch and inefficiency: a critical role of PDK4. Am J Physiol Heart Circ Physiol. 2013;304(8):H1103-H1113. doi:10.1152/ajpheart.00636.2012

170. Griffin JWD, Liu Y, Bradshaw PC, Wang K. In Silico Preliminary Association of Ammonia Metabolism Genes GLS, CPS1, and GLUL with Risk of Alzheimer's Disease, Major Depressive Disorder, and Type 2 Diabetes. J Mol Neurosci. 2018;64(3):385-396. doi:10.1007/s12031-0181035-0

171. Sidibeh CO, Pereira MJ, Abalo XM, J Boersma G, Skrtic S, Lundkvist P, Katsogiannos P, Hausch F, Castillejo-López C, Eriksson JW. FKBP5 expression in human adipose tissue: potential role in glucose and lipid metabolism, adipogenesis and type 2 diabetes. Endocrine. 2018;62(1):116128. doi:10.1007/s12020-018-1674-5

172. Haydar S, Grigorescu F, Vintilă M, Cogne Y, Lautier C, Tutuncu Y, Brun JF, Robine JM, Pugeat M, Normand C, et al. Fine-scale haplotype mapping of MUT, AACS, SLC6A15 and PRKCA genes indicates association with insulin resistance of metabolic syndrome and relationship with branched chain amino acid metabolism or regulation. PLoS One. 2019;14(3):e0214122. doi:10.1371/journal.pone.0214122

173. Yang L, Li $\mathrm{H}, \mathrm{Yu} \mathrm{T}$, Zhao $\mathrm{H}$, Cherian MG, Cai L, Liu Y. Polymorphisms in metallothionein-1 and -2 genes associated with the risk of type 2 diabetes mellitus and its complications. Am J Physiol Endocrinol Metab. 2008;294(5):E987-E992. doi:10.1152/ajpendo.90234.2008

174. González-Renteria SM, Loera-Castañeda V, Chairez-Hernández I, Sosa-Macias M, Paniagua-Castro N, Lares-Aseff I, Rodríguez-Moran M, 
Guerrero-Romero F, Galaviz-Hernández C. Association of the polymorphisms $292 \square \mathrm{C}>\mathrm{T}$ and $1304 \square \mathrm{G}>\mathrm{A}$ in the SLC38A4 gene with hyperglycaemia. Diabetes Metab Res Rev. 2013;29(1):39-43. doi:10.1002/dmrr.2344

175. Lebeck J, Søndergaard E, Nielsen S. Increased AQP7 abundance in skeletal muscle from obese men with type 2 diabetes. Am J Physiol Endocrinol Metab. 2018;315(3):E367-E373. doi:10.1152/ajpendo.00468.2017

176. Xia W, Pessentheiner AR, Hofer DC, Amor M, Schreiber R, Schoiswohl G, Eichmann TO, Walenta E, Itariu B, Prager G, et al. Loss of ABHD15 Impairs the Anti-lipolytic Action of Insulin by Altering PDE3B Stability and Contributes to Insulin Resistance. Cell Rep. 2018;23(7):19481961. doi:10.1016/j.celrep.2018.04.055

177. Ben Aissa M, Lewandowski CT, Ratia KM, Lee SH, Layden BT, $\mathrm{LaDu}$ MJ, Thatcher GRJ. Discovery of Nonlipogenic ABCA1 Inducing Compounds with Potential in Alzheimer's Disease and Type 2 Diabetes. ACS Pharmacol Transl Sci. 2021;4(1):143-154. doi:10.1021/acsptsci.0c00149

178. Peng D, Wang J, Zhang R, Jiang F, Tang S, Chen M, Yan J, Sun X, Wang S, Wang T, et al. Common variants in or near ZNRF1, COLEC12, SCYL1BP1 and API5 are associated with diabetic retinopathy in Chinese patients with type 2 diabetes. Diabetologia. 2015;58(6):1231-1238. doi:10.1007/s00125-015-3569-9

179. Manning AK, Goustin AS, Kleinbrink EL, Thepsuwan P, Cai J, Ju D, Leong A, Udler MS, Brown JB, Goodarzi MO, et al. A Long Non-coding RNA, LOC157273, Is an Effector Transcript at the Chromosome 8p23.1PPP1R3B Metabolic Traits and Type 2 Diabetes Risk Locus. Front Genet. 2020;11:615. doi:10.3389/fgene.2020.00615

180. Ganic E, Johansson JK, Bennet H, Fex M, Artner I. Islet-specific monoamine oxidase $\mathrm{A}$ and $\mathrm{B}$ expression depends on MafA transcriptional activity and is compromised in type 2 diabetes. Biochem Biophys Res Commun. 2015;468(4):629-635. doi:10.1016/j.bbrc.2015.11.002

181. Plengvidhya N, Chanprasert C, Chongjaroen N, Yenchitsomanus PT, Homsanit $\mathrm{M}$, Tangjittipokin $\mathrm{W}$. Impact of KCNQ1, CDKN2A/2B, CDKAL1, HHEX, MTNR1B, SLC30A8, TCF7L2, and UBE2E2 on risk of 
developing type 2 diabetes in Thai population. BMC Med Genet. 2018;19(1):93. doi:10.1186/s12881-018-0614-9

182. Traurig M, Hanson RL, Marinelarena A, Kobes S, Piaggi P, Cole S, Curran JE, Blangero J, Göring H, Kumar S, et al. Analysis of SLC16A11 Variants in 12,811 American Indians: Genotype-Obesity Interaction for Type 2 Diabetes and an Association With RNASEK Expression. Diabetes. 2016;65(2):510-519. doi:10.2337/db15-0571

183. Lewis JP, Palmer ND, Ellington JB, Divers J, Ng MC, Lu L, Langefeld CD, Freedman BI, Bowden DW. Analysis of candidate genes on chromosome 20q12-13.1 reveals evidence for BMI mediated association of PREX1 with type 2 diabetes in European Americans. Genomics. 2010;96(4):211-219. doi:10.1016/j.ygeno.2010.07.006

184. Mannerås-Holm L, Kirchner H, Björnholm M, Chibalin AV, Zierath JR. mRNA expression of diacylglycerol kinase isoforms in insulin-sensitive tissues: effects of obesity and insulin resistance. Physiol Rep. 2015;3(4):e12372. doi:10.14814/phy2.12372

185. Luo Y, Qu H, Wang H, Wei H, Wu J, Duan Y, Liu D, Deng H.

Plasma Periostin Levels Are Increased in Chinese Subjects with Obesity and Type 2 Diabetes and Are Positively Correlated with Glucose and Lipid Parameters. Mediators Inflamm. 2016;2016:6423637. doi:10.1155/2016/6423637

186. Arellano Perez Vertti RD, Aguilar Muñiz LS, Morán Martínez J, González Galarza FF, Arguello Astorga R. Cartilage Oligomeric Matrix Protein Levels in Type 2 Diabetes Associated with Primary Knee Osteoarthritis Patients. Genet Test Mol Biomarkers. 2019;23(1):16-22. doi:10.1089/gtmb.2018.0184

187. Bursova S, Dubovy P, Vlckova-Moravcova E, Nemec M, Klusakova I, Belobradkova J, Bednarik J. Expression of growth-associated protein 43 in the skin nerve fibers of patients with type 2 diabetes mellitus. J Neurol Sci. 2012;315(1-2):60-63. doi:10.1016/j.jns.2011.11.038

188. Fejes Z, Póliska S, Czimmerer Z, Káplár M, Penyige A, Gál Szabó G, Beke Debreceni I, Kunapuli SP, Kappelmayer J, Nagy B Jr. Hyperglycaemia suppresses microRNA expression in platelets to increase P2RY12 and SELP levels in type 2 diabetes mellitus. Thromb Haemost. 2017;117(3):529-542. doi:10.1160/TH16-04-0322 
189. Stavarachi M, Panduru NM, Serafinceanu C, Moța E, Moța M, Cimponeriu D, Ion DA. Investigation of P213S SELL gene polymorphism in type 2 diabetes mellitus and related end stage renal disease. A case-control study. Rom J Morphol Embryol. 2011;52(3 Suppl):995-998.

190. Yang CH, Mangiafico SP, Waibel M, Loudovaris T, Loh K, Thomas HE, Morahan G, Andrikopoulos S. E2f8 and Dlg2 genes have independent effects on impaired insulin secretion associated with hyperglycaemia. Diabetologia. 2020;63(7):1333-1348. doi:10.1007/s00125-020-05137-0

191. Lee IS, Lee JH, Kim HJ, Lee JM, Lee SK, Kim HS, Lee JM, Park KS, $\mathrm{Ku}$ BJ. Novel ERBB receptor feedback inhibitor 1 (ERRFI1) + $808 \mathrm{~T} / \mathrm{G}$ polymorphism confers protective effect on diabetic nephropathy in a Korean population. Dis Markers. 2013;34(2):113-124. doi:10.3233/DMA-120949

192. Roumeliotis AK, Roumeliotis SK, Panagoutsos SA, Tsetsos F, Georgitsi M, Manolopoulos V, Paschou P, Passadakis PS. Association of ALOX12 gene polymorphism with all-cause and cardiovascular mortality in diabetic nephropathy. Int Urol Nephrol. 2018;50(2):321-329. doi:10.1007/s11255-017-1755-Z

193. Tsai YC, Kuo PL, Hung WW, Wu LY, Wu PH, Chang WA, Kuo MC, Hsu YL. Angpt2 Induces Mesangial Cell Apoptosis through the MicroRNA33-5p-SOCS5 Loop in Diabetic Nephropathy. Mol Ther Nucleic Acids. 2018;13:543-555. doi:10.1016/j.omtn.2018.10.003

194. Wang H, Wang J, Qu H, Wei H, Ji B, Yang Z, Wu J, He Q, Luo Y, Liu D, et al. In vitro and in vivo inhibition of mTOR by 1,25dihydroxyvitamin D3 to improve early diabetic nephropathy via the DDIT4/TSC2/mTOR pathway. Endocrine. 2016;54(2):348-359. doi:10.1007/s12020-016-0999-1

195. Denhez B, Rousseau M, Dancosst DA, Lizotte F, Guay A, AugerMessier M, Côté AM, Geraldes P. Diabetes-Induced DUSP4 Reduction Promotes Podocyte Dysfunction and Progression of Diabetic Nephropathy. Diabetes. 2019;68(5):1026-1039. doi:10.2337/db18-0837

196. Huang H, Zhang G, Ge Z. IncRNA MALAT1 Promotes Renal Fibrosis in Diabetic Nephropathy by Targeting the miR-2355-3p/IL6ST Axis. Front Pharmacol. 2021;12:647650. doi:10.3389/fphar.2021.647650 
197. Sheng J, Li H, Dai Q, Lu C, Xu M, Zhang J, Feng J. DUSP1 recuses diabetic nephropathy via repressing JNK-Mff-mitochondrial fission pathways. J Cell Physiol. 2019;234(3):3043-3057. doi:10.1002/jcp.27124

198. Doi T, Moriya T, Fujita Y, Minagawa N, Usami M, Sasaki T, Abe H, Kishi S, Murakami T, Ouchi M, et al. Urinary IgG4 and Smad1 Are Specific Biomarkers for Renal Structural and Functional Changes in Early Stages of Diabetic Nephropathy. Diabetes. 2018;67(5):986-993. doi:10.2337/db171043

199. Wang S, Chen X, Wang M, Yao D, Chen T, Yan Q, Lu W. Long NonCoding RNA CYP4B1-PS1-001 Inhibits Proliferation and Fibrosis in Diabetic Nephropathy by Interacting with Nucleolin. Cell Physiol Biochem. 2018;49(6):2174-2187. doi:10.1159/000493821

200. Xu Z, Jia K, Wang H, Gao F, Zhao S, Li F, Hao J. METTL14regulated PI3K/Akt signaling pathway via PTEN affects HDAC5-mediated epithelial-mesenchymal transition of renal tubular cells in diabetic kidney disease. Cell Death Dis. 2021;12(1):32. doi:10.1038/s41419-020-03312-0

201. Feng S, Gao Y, Yin D, Lv L, Wen Y, Li Z, Wang B, Wu M, Liu B. Identification of Lumican and Fibromodulin as Hub Genes Associated with Accumulation of Extracellular Matrix in Diabetic Nephropathy. Kidney Blood Press Res. 2021;1-11. doi:10.1159/000514013

202. Xu ZJ, Shu S, Li ZJ, Liu YM, Zhang RY, Zhang Y. Liuwei Dihuang pill treats diabetic nephropathy in rats by inhibiting of TGF- $\beta / S M A D S$, MAPK, and NF-kB and upregulating expression of cytoglobin in renal tissues. Medicine (Baltimore). 2017;96(3):e5879. doi:10.1097/MD.0000000000005879

203. Jiao X, Zhang D, Hong Q, Yan L, Han Q, Shao F, Cai G, Chen X, Zhu H. Netrin-1 works with UNC5B to regulate angiogenesis in diabetic kidney disease. Front Med. 2020;14(3):293-304. doi:10.1007/s11684-0190715-7

204. Ruiz-Hernández A, Cabrera-Becerra S, Vera-Juárez G, Hong E, Fengyang H, Arauz J, Villafaña S. Diabetic nephropathy produces alterations in the tissue expression profile of the orphan receptors GPR149, GPR153, GPR176, TAAR3, TAAR5 and TAAR9 in Wistar rats. Nucleosides Nucleotides Nucleic Acids. 2020;39(8):1150-1161. doi:10.1080/15257770.2020.1780437 
205. Heckmann MB, Reinhardt F, Finke D, Katus HA, Haberkorn U, Leuschner F, Lehmann LH. Relationship Between Cardiac Fibroblast Activation Protein Activity by Positron Emission Tomography and Cardiovascular Disease. Circ Cardiovasc Imaging. 2020;13(9):e010628. doi:10.1161/CIRCIMAGING.120.010628

206. Williams T, Hundertmark M, Nordbeck P, Voll S, Arias-Loza PA, Oppelt D, Mühlfelder M, Schraut S, Elsner I, Czolbe M, et al. Eya4 Induces Hypertrophy via Regulation of p27kip1. Circ Cardiovasc Genet. 2015;8(6):752-764. doi:10.1161/CIRCGENETICS.115.001134

207. Cantù C, Felker A, Zimmerli D, Prummel KD, Cabello EM, Chiavacci E, Méndez-Acevedo KM, Kirchgeorg L, Burger S, Ripoll J, et al. Mutations in Bc19 and Pygo genes cause congenital heart defects by tissuespecific perturbation of Wnt/ $\beta$-catenin signaling. Genes Dev. 2018;32(2122):1443-1458. doi:10.1101/gad.315531.118

208. Chen HH, Keyhanian K, Zhou X, Vilmundarson RO, Almontashiri NA, Cruz SA, Pandey NR, Lerma Yap N, Ho T, Stewart CA, et al. IRF2BP2 Reduces Macrophage Inflammation and Susceptibility to Atherosclerosis. Circ Res. 2015;117(8):671-683. doi:10.1161/CIRCRESAHA.114.305777

209. Li X, Ma YT, Xie X, Yang YN, Ma X, Zheng YY, Pan S, Liu F, Chen BD. Association of Egr3 genetic polymorphisms and coronary artery disease in the Uygur and Han of China. Lipids Health Dis. 2014;13:84. doi:10.1186/1476-511X-13-84

210. Wang J, Wang H, Chen J, Wang X, Sun K, Wang Y, Wang J, Yang $\mathrm{X}$, Song $\mathrm{X}$, Xin $\mathrm{Y}$, et al. GADD45B inhibits MKK7-induced cardiac hypertrophy and the polymorphisms of GADD45B is associated with interventricular septum hypertrophy. Biochem Biophys Res Commun. 2008;372(4):623-628. doi:10.1016/j.bbrc.2008.05.122

211. Rodriguez-Gonzalez M, Lubian-Gutierrez M, Cascales-Poyatos HM, Perez-Reviriego AA, Castellano-Martinez A. Role of the ReninAngiotensin-Aldosterone System in Dystrophin-Deficient Cardiomyopathy. Int J Mol Sci. 2020;22(1):356. doi:10.3390/ijms22010356

212. Yen FT, Roitel O, Bonnard L, Notet V, Pratte D, Stenger C, Magueur E, Bihain BE. Lipolysis stimulated lipoprotein receptor: a novel molecular link between hyperlipidemia, weight gain, and atherosclerosis in mice. J Biol Chem. 2008;283(37):25650-25659. doi:10.1074/jbc.M801027200 
213. Nakano T, Katsuki S, Chen M, Decano JL, Halu A, Lee LH, Pestana DVS, Kum AST, Kuromoto RK, Golden WS, et al. Uremic Toxin Indoxyl Sulfate Promotes Proinflammatory Macrophage Activation Via the Interplay of OATP2B1 and Dll4-Notch Signaling. Circulation. 2019;139(1):78-96. doi:10.1161/CIRCULATIONAHA.118.034588

214. Stewart RM, Rodriguez EC, King MC. Ablation of SUN2-containing LINC complexes drives cardiac hypertrophy without interstitial fibrosis. Mol Biol Cell. 2019;30(14):1664-1675. doi:10.1091/mbc.E18-07-0438

215. Cowan JR, Salyer L, Wright NT, Kinnamon DD, Amaya P, Jordan E, Bamshad MJ, Nickerson DA, Hershberger RE. SOS1 Gain-of-Function Variants in Dilated Cardiomyopathy. Circ Genom Precis Med. 2020;13(4):e002892. doi:10.1161/CIRCGEN.119.002892

216. Yang X, Li X, Lin Q, Xu Q. Up-regulation of microRNA-203 inhibits myocardial fibrosis and oxidative stress in mice with diabetic cardiomyopathy through the inhibition of PI3K/Akt signaling pathway via PIK3CA. Gene. 2019;715:143995. doi:10.1016/j.gene.2019.143995

217. Schmidt A, Marescau B, Boehm EA, Renema WK, Peco R, Das A, Steinfeld R, Chan S, Wallis J, Davidoff M, et al. Severely altered guanidino compound levels, disturbed body weight homeostasis and impaired fertility in a mouse model of guanidinoacetate N-methyltransferase (GAMT) deficiency. Hum Mol Genet. 2004;13(9):905-921. doi:10.1093/hmg/ddh112

218. Liu C, Zhang H, Chen Y, Wang S, Chen Z, Liu Z, Wang J. Identifying RBM47, HCK, CD53, TYROBP, and HAVCR2 as Hub Genes in Advanced Atherosclerotic Plaques by Network-Based Analysis and Validation. Front Genet. 2021;11:602908. doi:10.3389/fgene.2020.602908

219. Zhu WS, Guo W, Zhu JN, Tang CM, Fu YH, Lin QX, Tan N, Shan ZX. Hsp90aa1: a novel target gene of miR-1 in cardiac ischemia/reperfusion injury. Sci Rep. 2016;6:24498. doi:10.1038/srep24498

220. Qian X, Wang H, Wang Y, Chen J, Guo X, Deng H. Enhanced Autophagy in GAB1-Deficient Vascular Endothelial Cells Is Responsible for Atherosclerosis Progression. Front Physiol. 2021;11:559396. doi:10.3389/fphys.2020.559396

221. Cannavo A, Rengo G, Liccardo D, Pagano G, Zincarelli C, De Angelis MC, Puglia R, Di Pietro E, Rabinowitz JE, Barone MV, et al. $\beta 1$ adrenergic receptor and sphingosine-1-phosphate receptor 1 (S1PR1) 
reciprocal downregulation influences cardiac hypertrophic response and progression to heart failure: protective role of S1PR1 cardiac gene therapy. Circulation. 2013;128(15):1612-1622.

doi:10.1161/CIRCULATIONAHA.113.002659

222. Stobdan T, Zhou D, Williams AT, Cabrales P, Haddad GG. Cardiacspecific knockout and pharmacological inhibition of Endothelin receptor type B lead to cardiac resistance to extreme hypoxia. J Mol Med (Berl). 2018;96(9):975-982. doi:10.1007/s00109-018-1673-2

223. Song KY, Zhang XZ, Li F, Ji QR. Silencing of ATP2B1-AS1 contributes to protection against myocardial infarction in mouse via blocking NFKBIA-mediated NF- $\kappa$ B signalling pathway. J Cell Mol Med. 2020;24(8):4466-4479. doi:10.1111/jcmm.15105

224. Yang B, Lin H, Xiao J, Lu Y, Luo X, Li B, Zhang Y, Xu C, Bai Y, Wang $\mathrm{H}$, et al. The muscle-specific microRNA miR-1 regulates cardiac arrhythmogenic potential by targeting GJA1 and KCNJ2 [published correction appears in Nat Med. 2011 Dec;17(12):1693]. Nat Med. 2007;13(4):486-491. doi:10.1038/nm1569

225. Wan X, Yao B, Ma Y, Liu Y, Tang Y, Hu J, Li M, Fu S, Zheng X, Yin D. MicroRNA-128-1-5p attenuates myocardial ischemia/reperfusion injury by suppressing Gadd45g-mediated apoptotic signaling. Biochem Biophys Res Commun. 2020;530(1):314-321. doi:10.1016/j.bbrc.2020.07.009

226. Guo Y, Jia P, Chen Y, Yu H, Xin X, Bao Y, Yang H, Wu N, Sun Y, Jia D. PHLDA1 is a new therapeutic target of oxidative stress and ischemia reperfusion-induced myocardial injury. Life Sci. 2020;245:117347. doi:10.1016/j.lfs.2020.117347

227. Lai JH, Hung LF, Huang CY, Wu DW, Wu CH, Ho LJ. Mitochondrial protein CMPK2 regulates IFN alpha-enhanced foam cell formation, potentially contributing to premature atherosclerosis in SLE. Arthritis Res Ther. 2021;23(1):120. doi:10.1186/s13075-021-02470-6

228. Wang D, Chu M, Wang F, Zhou A, Ruan M, Chen Y. A Genetic Variant in FIGN Gene Reduces the Risk of Congenital Heart Disease in Han Chinese Populations. Pediatr Cardiol. 2017;38(6):1169-1174. doi:10.1007/s00246-017-1636-3 
229. Vega AL, Tester DJ, Ackerman MJ, Makielski JC. Protein kinase Adependent biophysical phenotype for V227F-KCNJ2 mutation in catecholaminergic polymorphic ventricular tachycardia. Circ Arrhythm Electrophysiol. 2009;2(5):540-547. doi:10.1161/CIRCEP.109.872309

230. Minoretti P, Falcone C, Aldeghi A, Olivieri V, Mori F, Emanuele E, Calcagnino M, Geroldi D. A novel Val734Ile variant in the ABCC9 gene associated with myocardial infarction. Clin Chim Acta. 2006;370(1-2):124128. doi:10.1016/j.cca.2006.02.007

231. Zhuo C, Jiang R, Lin X, Shao M. LncRNA H19 inhibits autophagy by epigenetically silencing of DIRAS3 in diabetic cardiomyopathy. Oncotarget. 2017;8(1):1429-1437. doi:10.18632/oncotarget.13637

232. Edin ML, Hamedani BG, Gruzdev A, Graves JP, Lih FB, Arbes SJ 3rd, Singh R, Orjuela Leon AC, Bradbury JA, DeGraff LM, et al. Epoxide hydrolase 1 (EPHX1) hydrolyzes epoxyeicosanoids and impairs cardiac recovery after ischemia. J Biol Chem. 2018;293(9):3281-3292. doi:10.1074/jbc.RA117.000298

233. Sack MN. Rab4a signaling unmasks a pivotal link between myocardial homeostasis and metabolic remodeling in the diabetic heart. J Mol Cell Cardiol. 2010;49(6):908-910. doi:10.1016/j.yjmcc.2010.09.002

234. Yan B, Wang J. UBIAD1 expression is associated with cardiac hypertrophy in spontaneously hypertensive rats. Mol Med Rep. 2019;19(1):651-659. doi:10.3892/mmr.2018.9693

235. $\mathrm{Ng} \mathrm{K}$, Titus EW, Lieve KV, Roston TM, Mazzanti A, Deiter FH, Denjoy I, Ingles J, Till J, Robyns $\mathrm{T}$, et al. An International Multicenter Evaluation of Inheritance Patterns, Arrhythmic Risks, and Underlying Mechanisms of CASQ2-Catecholaminergic Polymorphic Ventricular Tachycardia. Circulation. 2020;142(10):932-947. doi:10.1161/CIRCULATIONAHA.120.045723

236. Linschoten M, Teske AJ, Baas AF, Vink A, Dooijes D, Baars HF, Asselbergs FW. Truncating Titin (TTN) Variants in Chemotherapy-Induced Cardiomyopathy. J Card Fail. 2017;23(6):476-479. doi:10.1016/j.cardfail.2017.03.003

237. Noori MR, Zhang B, Pan L. Is KCNH1 mutation related to coronary artery ectasia. BMC Cardiovasc Disord. 2019;19(1):296. doi:10.1186/s12872-019-01276-4 
238. Hu J, Gao C, Wei C, Xue Y, Shao C, Hao Y, Gou LT, Zhou Y, Zhang $\mathrm{J}$, Ren S, et al. RBFox2-miR-34a-Jph2 axis contributes to cardiac decompensation during heart failure. Proc Natl Acad Sci U S A. 2019;116(13):6172-6180. doi:10.1073/pnas.1822176116

239. Omede A, Zi M, Prehar S, Maqsood A, Stafford N, Mamas M, Cartwright E, Oceandy D. The oxoglutarate receptor 1 (OXGR1) modulates pressure overload-induced cardiac hypertrophy in mice. Biochem Biophys Res Commun. 2016;479(4):708-714. doi:10.1016/j.bbrc.2016.09.147

240. Bi HL, Zhang YL, Yang J, Shu Q, Yang XL, Yan X, Chen C, Li Z, Li HH. Inhibition of UCHL1 by LDN-57444 attenuates Ang II-Induced atrial fibrillation in mice. Hypertens Res. 2020;43(3):168-177. doi:10.1038/s41440-019-0354- z

241. Zhao L, Zheng M, Guo Z, Li K, Liu Y, Chen M, Yang X. Circulating Serpina3 levels predict the major adverse cardiac events in patients with myocardial infarction. Int J Cardiol. 2020;300:34-38. doi:10.1016/j.ijcard.2019.08.034

242. Zhou K, Li Y, Xu Y, Guo R. Circulating Matrix Metalloproteinase-28 Levels Are Related to GRACE Scores and Short-Term Outcomes in Patients with Acute Myocardial Infarction. Biomed Res Int. 2020;2020:9206703. doi:10.1155/2020/9206703

243. Wang X, Chen W, Zhang J, Khan A, Li L, Huang F, Qiu Z, Wang L, Chen X. Critical Role of ADAMTS2 (A Disintegrin and Metalloproteinase With Thrombospondin Motifs 2) in Cardiac Hypertrophy Induced by Pressure Overload. Hypertension. 2017;69(6):1060-1069. doi:10.1161/HYPERTENSIONAHA.116.08581

244. Timur AA, Murugesan G, Zhang L, Aung PP, Barnard J, Wang QK, Gaussem P, Silverstein RL, Bhatt DL, Kottke-Marchant K. P2RY1 and P2RY12 polymorphisms and on-aspirin platelet reactivity in patients with coronary artery disease. Int $\mathbf{J}$ Lab Hematol. 2012;34(5):473-483. doi:10.1111/j.1751-553X.2012.01420.x

245. Huang R, Cao Y, Li H, Hu Z, Zhang H, Zhang L, Su W, Xu Y, Liang L, Melgiri ND, et al. miR-532-3p-CSF2RA Axis as a Key Regulator of Vulnerable Atherosclerotic Plaque Formation. Can J Cardiol. 2020;36(11):1782-1794. doi:10.1016/j.cjca.2019.12.018 
246. Mo XG, Liu W, Yang Y, Imani S, Lu S, Dan G, Nie X, Yan J, Zhan R, Li X, et al. NCF2, MYO1F, S1PR4, and FCN1 as potential noninvasive diagnostic biomarkers in patients with obstructive coronary artery: A weighted gene co-expression network analysis. J Cell Biochem. 2019;120(10):18219-18235. doi:10.1002/jcb.29128

247. Tregouet DA, Barbaux S, Poirier O, Blankenberg S, Bickel C, Escolano S, Rupprecht HJ, Meyer J, Cambien F, Tiret L. SELPLG gene polymorphisms in relation to plasma SELPLG levels and coronary artery disease. Ann Hum Genet. 2003;67(Pt 6):504-511. doi:10.1046/j.15298817.2003.00053.X

248. Li W, Xin B, Yan J, Wu Y, Hu B, Liu L, Wang Y, Ahn J, Skowronski J, Zhang Z, et al. SAMHD1 Gene Mutations Are Associated with Cerebral Large-Artery Atherosclerosis. Biomed Res Int. 2015;2015:739586. doi:10.1155/2015/739586

249. Guicheney P, Soliman H, Launay JM, Dreux C, Meyer P. Circulating monoamine oxidase $\mathrm{B}$ and phenolsulfotransferase activities in essential hypertensive patients. Clin Exp Hypertens A. 1988;10(4):533-544. doi:10.3109/10641968809033907

250. Selvarajah V, Mäki-Petäjä KM, Pedro L, Bruggraber SFA, Burling K, Goodhart AK, Brown MJ, McEniery CM, Wilkinson IB. Novel Mechanism for Buffering Dietary Salt in Humans: Effects of Salt Loading on Skin Sodium, Vascular Endothelial Growth Factor C, and Blood Pressure. Hypertension. 2017;70(5):930-937. doi:10.1161/HYPERTENSIONAHA.117.10003

251. Zhao Q, Sun H, Yin L, Wang L. $\operatorname{miR} \square 126 \mathrm{a} \square 5 \mathrm{p} \square \mathrm{Dbp}$ and $\mathrm{miR} \square 31 \mathrm{a} \square \mathrm{Crot} / \mathrm{Mrpl} 4$ interaction pairs crucial for the development of hypertension and stroke. Mol Med Rep. 2019;20(5):4151-4167. doi:10.3892/mmr.2019.10679

252. Sun L, Lin P, Chen Y, Yu H, Ren S, Wang J, Zhao L, Du G. miR$182-3 \mathrm{p} /$ Myadm contribute to pulmonary artery hypertension vascular remodeling via a KLF4/p21-dependent mechanism. Theranostics. 2020;10(12):5581-5599. doi:10.7150/thno.44687

253. Zhou JJ, Li H, Qian YL, Quan RL, Chen XX, Li L, Li Y, Wang PH, Meng XM, Jing XL, et al. Nestin represents a potential marker of pulmonary vascular remodeling in pulmonary arterial hypertension associated with 
congenital heart disease. J Mol Cell Cardiol. 2020;149:41-53. doi:10.1016/j.yjmcc.2020.09.005

254. Baptista R, Marques C, Catarino S, Enguita FJ, Costa MC, Matafome P, Zuzarte M, Castro G, Reis A, Monteiro P, et al. MicroRNA-424(322) as a new marker of disease progression in pulmonary arterial hypertension and its role in right ventricular hypertrophy by targeting SMURF1. Cardiovasc Res. 2018;114(1):53-64. doi:10.1093/cvr/cvx187

255. Zicha J, Dobešová Z, Zídek V, Silhavý J, Simáková M, Mlejnek P, Vaněčková I, Kuneš J, Pravenec M. Pharmacogenetic analysis of captopril effects on blood pressure: possible role of the Ednrb (endothelin receptor type B) candidate gene. Physiol Res. 2014;63(2):263-265. doi:10.33549/physiolres.932732

256. Zou L, Li W, Han J, Yang Y, Jin J, Xiao F, Xu X, Zhai Z. Identification of a low frequency missense mutation in MUC6 contributing to pulmonary artery hypertension by whole-exome sequencing. Pulm Circ. 2018;8(3):2045894018794374. doi:10.1177/2045894018794374

257. Sun S, Zhang F, Pan Y, Xu Y, Chen A, Wang J, Tang H, Han Y. A TOR2A Gene Product: Salusin- $\beta$ Contributes to Attenuated Vasodilatation of Spontaneously Hypertensive Rats. Cardiovasc Drugs Ther. 2021;35(1):125-139. doi:10.1007/s10557-020-06983-1

258. Eaaswarkhanth M, Dos Santos ALC, Gokcumen O, Al-Mulla F, Thanaraj TA. Genome-Wide Selection Scan in an Arabian Peninsula Population Identifies a TNKS Haplotype Linked to Metabolic Traits and Hypertension. Genome Biol Evol. 2020;12(3):77-87. doi:10.1093/gbe/evaa033

259. Wang J, Yang K, Yuan JX. NEDD9, a Hypoxia-upregulated Mediator for Pathogenic Platelet-endothelial Cell Interaction in Pulmonary Hypertension. Am J Respir Crit Care Med. 2021;10.1164/rccm.2021010007ED. doi:10.1164/rccm.202101-0007ED

260. Nitta CH, Osmond DA, Herbert LM, Beasley BF, Resta TC, Walker BR, Jernigan NL. Role of ASIC1 in the development of chronic hypoxiainduced pulmonary hypertension. Am J Physiol Heart Circ Physiol. 2014;306(1):H41-H52. doi:10.1152/ajpheart.00269.2013

261. Omura J, Satoh K, Kikuchi N, Satoh T, Kurosawa R, Nogi M, Ohtsuki T, Al-Mamun ME, Siddique MAH, Yaoita N, et al. ADAMTS8 Promotes 
the Development of Pulmonary Arterial Hypertension and Right Ventricular Failure: A Possible Novel Therapeutic Target. Circ Res. 2019;125(10):884906. doi:10.1161/CIRCRESAHA.119.315398

262. White Z, Milad N, Tehrani AY, Chen WW, Donen G, Sellers SL, Bernatchez P. Angiotensin II receptor blocker losartan exacerbates muscle damage and exhibits weak blood pressure-lowering activity in a dysferlinnull model of Limb-Girdle muscular dystrophy type 2B. PLoS One. 2019;14(8):e0220903. doi:10.1371/journal.pone.0220903

263. Amlal H, Xu J, Barone S, Zahedi K, Soleimani M. The chloride channel/transporter Slc26a9 regulates the systemic arterial pressure and renal chloride excretion. J Mol Med (Berl). 2013;91(5):561-572. doi:10.1007/s00109-012-0973-1

264. Le Ribeuz H, Courboulin A, Ghigna MR, Lambert M, Hautefort A, Humbert M, Montani D, Cohen-Kaminsky S, Perros F, Antigny F. In vivo miR-138-5p inhibition alleviates monocrotaline-induced pulmonary hypertension and normalizes pulmonary KCNK3 and SLC45A3 expression. Respir Res. 2020;21(1):186. doi:10.1186/s12931-020-01444-7

265. Berg T. M-currents (Kv7.2-7.3/KCNQ2-KCNQ3) Are Responsible for Dysfunctional Autonomic Control in Hypertensive Rats. Front Physiol. 2016;7:584. doi:10.3389/fphys.2016.00584

266. Yang S, He H, Ma QS, Zhang Y, Zhu Y, Wan X, Wang FW, Wang SS, Liu L, Li B. Experimental study of the protective effects of SYVN1 against diabetic retinopathy. Sci Rep. 2015;5:14036. doi:10.1038/srep14036 267. Zhang ZZ, Qin XH, Zhang J. MicroRNA-183 inhibition exerts suppressive effects on diabetic retinopathy by inactivating BTG1-mediated PI3K/Akt/VEGF signaling pathway. Am J Physiol Endocrinol Metab. 2019;316(6):E1050-E1060. doi:10.1152/ajpendo.00444.2018

268. Wang J, Yang MM, Li YB, Liu GD, Teng Y, Liu XM. Association of $\mathrm{CFH}$ and CFB gene polymorphisms with retinopathy in type 2 diabetic patients. Mediators Inflamm. 2013;2013:748435. doi:10.1155/2013/748435

269. Chen Y, Ye C, Chen J, Lin D, Wang H, Wang S. Association of the gene polymorphisms of BMPR2, ACVRL1, SMAD9 and their interactions with the risk of essential hypertension in the Chinese Han population. Biosci Rep. 2019;39(1):BSR20181217. doi:10.1042/BSR20181217 
270. Gregg T, Sdao SM, Dhillon RS, Rensvold JW, Lewandowski SL, Pagliarini DJ, Denu JM, Merrins MJ. Obesity-dependent CDK1 signaling stimulates mitochondrial respiration at complex I in pancreatic $\beta$-cells. J Biol Chem. 2019;294(12):4656-4666. doi:10.1074/jbc.RA118.006085

271. Karere GM, Cox LA, Bishop AC, South AM, Shaltout HA, MercadoDeane MG, Cuda S. Sex Differences in MicroRNA Expression and Cardiometabolic Risk Factors in Hispanic Adolescents with Obesity. J Pediatr. 2021;S0022-3476(21)00319-X. doi:10.1016/j.jpeds.2021.03.070

272. Costantino S, Akhmedov A, Melina G, Mohammed SA, Othman A, Ambrosini S, Wijnen WJ, Sada L, Ciavarella GM, Liberale L, et al. Obesityinduced activation of JunD promotes myocardial lipid accumulation and metabolic cardiomyopathy. Eur Heart J. 2019;40(12):997-1008. doi:10.1093/eurheartj/ehy903

273. Westergren R, Nilsson D, Heglind M, Arani Z, Grände M, Cederberg A, Ahrén B, Enerbäck S. Overexpression of Foxf2 in adipose tissue is associated with lower levels of IRS1 and decreased glucose uptake in vivo. Am J Physiol Endocrinol Metab. 2010;298(3):E548-E554. doi:10.1152/ajpendo.00395.2009

274. Catanzaro G, Besharat ZM, Chiacchiarini M, Abballe L, Sabato C, Vacca A, Borgiani P, Dotta F, Tesauro M, Po A, et al. Circulating MicroRNAs in Elderly Type 2 Diabetic Patients. Int J Endocrinol. 2018;2018:6872635. doi:10.1155/2018/6872635

275. Demirsoy İH, Ertural DY, Balci Ş, Çınkır Ü, Sezer K, Tamer L, Aras N. Profiles of Circulating MiRNAs Following Metformin Treatment in Patients with Type 2 Diabetes. J Med Biochem. 2018;37(4):499-506. doi:10.2478/jomb-2018-0009

276. Li L, Bai Y, Du R, Tang L, Li L. The role of Smad4 in the regulation of insulin resistance, inflammation and cell proliferation in HTR8-Svneo cells. Cell Biochem Funct. 2021;39(1):126-138. doi:10.1002/cbf.3594

277. Wang N, Zhang D, Mao X, Zou F, Jin H, Ouyang J. Astragalus polysaccharides decreased the expression of PTP1B through relieving ER stress induced activation of ATF6 in a rat model of type 2 diabetes. Mol Cell Endocrinol. 2009;307(1-2):89-98. doi:10.1016/j.mce.2009.03.001

278. Onrat ST, Onrat E, Ercan Onay E, Yalım Z, Avşar A. The Genetic Determination of the Differentiation Between Ischemic Dilated 
Cardiomyopathy and Idiopathic Dilated Cardiomyopathy. Genet Test Mol Biomarkers. 2018;22(11):644-651. doi:10.1089/gtmb.2018.0188

279. Huang CY, Kuo CH, Pai PY, Ho TJ, Lin YM, Chen RJ, Tsai FJ, Vijaya Padma V, Kuo WW, Huang CY. Inhibition of HSF2 SUMOylation via MEL18 upregulates IGF-IIR and leads to hypertension-induced cardiac hypertrophy. Int J Cardiol. 2018;257:283-290. doi:10.1016/j.ijcard.2017.10.102

280. Mendes-Silva AP, Pereira KS, Tolentino-Araujo GT, Nicolau Ede S, Silva-Ferreira CM, Teixeira AL, Diniz BS. Shared Biologic Pathways Between Alzheimer Disease and Major Depression: A Systematic Review of MicroRNA Expression Studies. Am J Geriatr Psychiatry. 2016;24(10):903912. doi:10.1016/j.jagp.2016.07.017

281. Sakurai A, Ono H, Ochi A, Matsuura M, Yoshimoto S, Kishi S, Murakami T, Tominaga T, Nagai K, Abe H, et al. Involvement of Elf3 on Smad3 activation-dependent injuries in podocytes and excretion of urinary exosome in diabetic nephropathy. PLoS One. 2019;14(5):e0216788. doi:10.1371/journal.pone.0216788

282. Yan L, Cogan JD, Hedges LK, Nunley B, Hamid R, Austin ED. The Y Chromosome Regulates BMPR2 Expression via SRY: A Possible Reason "Why" Fewer Males Develop Pulmonary Arterial Hypertension. Am J Respir Crit Care Med. 2018;198(12):1581-1583. doi:10.1164/rccm.2018020308LE

\section{Tables}

Table 1 The sequences of primers for quantitative RT-PCR

\begin{tabular}{ccc}
\hline Genes & Forward Primers & Reverse Primers \\
\hline MYC & CTGTACCTCGTCCGATTCC & GCTCTTCTTCAGAGTCGCT \\
EGFR & TGGAGCTATGGTGTCACTG & TGAGATGTCACTTGCTGGG \\
LNX1 & CTGTACTCGGAACTGGCTC & TGGCCATTAGTGTCCAGTC \\
YBX1 & AAGAAGGTCATCGCAACGA & CAAATACGTCTTCCTTGGTGTC \\
HSP90AA1 & CAATTCATCGGACGCTCTG & AGATTGATGTGCAGCTCCT \\
ESR1 & CCTCTGGCTACCATTATGGG & AGTCATTGTGTCCTTGAATGC \\
FN1 & TACCAAGGCTGGATGATGG & TGCATCTGTTTCTGGAGGT \\
TK1 & AGATTCAGGTGATTCTCGGG & ACTTGTACTGGGCGATCTG \\
ANLN & TCCGACCACAAAGAGAAGAC & AGAGCCAGTTCTTGGTGAC \\
SMAD9 & CACATTGGAAAGGGTGTGC & GACAAAGATGCTGCTGTCG \\
\hline
\end{tabular}


Table 2 The statistical metrics for key differentially expressed genes (DEGs)

\begin{tabular}{|c|c|c|c|c|c|c|}
\hline Gene Symbol & $\operatorname{logFC}$ & pValue & adj.P.Val & tvalue & Regulation & Gene Name \\
\hline CRNN & 5.712946 & 1.99E-09 & $6.00 \mathrm{E}-07$ & 5.998709 & Up & cornulin \\
\hline PGA5 & 4.614794 & $6.37 \mathrm{E}-06$ & 0.000351 & 4.513665 & Up & pepsinogen A5 \\
\hline PGA4 & 4.56097 & $6.52 \mathrm{E}-06$ & 0.000356 & 4.508769 & $\mathrm{Up}$ & pepsinogen A4 \\
\hline PGA3 & 4.488203 & $2.38 \mathrm{E}-06$ & 0.00017 & 4.718 & Up & pepsinogen $\mathrm{A} 3$ \\
\hline CGA & 4.197712 & $1.53 \mathrm{E}-05$ & 0.000659 & 4.324569 & $\mathrm{Up}$ & glycoprotein hormones, alpha polypeptide \\
\hline FGA & 4.148471 & 0.000107 & 0.002674 & 3.873135 & $\mathrm{Up}$ & fibrinogen alpha chain \\
\hline IGF2 & 3.675622 & $1.58 \mathrm{E}-06$ & 0.000129 & 4.800531 & Up & insulin like growth factor 2 \\
\hline KRT6A & 3.542048 & $3.39 \mathrm{E}-06$ & 0.000219 & 4.645643 & $\mathrm{Up}$ & keratin $6 \mathrm{~A}$ \\
\hline FGB & 3.450811 & 0.00024 & 0.004787 & 3.6727 & $\mathrm{Up}$ & fibrinogen beta chain \\
\hline LCE3D & 3.269781 & 4.62E-09 & $1.14 \mathrm{E}-06$ & 5.860339 & Up & late cornified envelope 3D \\
\hline PRR9 & 3.141513 & $2.53 \mathrm{E}-08$ & 4.72E-06 & 5.571309 & Up & proline rich 9 \\
\hline SLC6A15 & 3.082853 & 0.004861 & 0.038891 & 2.816137 & $\mathrm{Up}$ & solute carrier family 6 member 15 \\
\hline APOA5 & 3.070951 & $6.13 \mathrm{E}-06$ & 0.000342 & 4.521718 & $\mathrm{Up}$ & apolipoprotein A5 \\
\hline SPRR3 & 2.937684 & $1.25 \mathrm{E}-05$ & 0.000573 & 4.368603 & Up & small proline rich protein 3 \\
\hline FLG & 2.932836 & 0.000863 & 0.01179 & 3.331797 & $\mathrm{Up}$ & filaggrin \\
\hline SPRR2D & 2.867184 & 0.000152 & 0.003454 & 3.787481 & $\mathrm{Up}$ & small proline rich protein $2 \mathrm{D}$ \\
\hline SPRR1B & 2.866557 & 2.47E-05 & 0.000915 & 4.217563 & Up & small proline rich protein $1 \mathrm{~B}$ \\
\hline SLITRK6 & 2.858672 & $3.81 \mathrm{E}-05$ & 0.001252 & 4.118929 & Up & SLIT and NTRK like family member 6 \\
\hline СТ62 & 2.82068 & 0.000229 & 0.004614 & 3.684932 & $\mathrm{Up}$ & cancer/testis associated 62 \\
\hline FGF21 & 2.789926 & $3.91 \mathrm{E}-06$ & 0.000244 & 4.615907 & Up & fibroblast growth factor 21 \\
\hline FGG & 2.773228 & 0.001178 & 0.01471 & 3.244101 & Up & fibrinogen gamma chain \\
\hline $\mathrm{TBX} 22$ & 2.752029 & $5.13 \mathrm{E}-05$ & 0.001556 & 4.049842 & $\mathrm{Up}$ & T-box transcription factor 22 \\
\hline CALCR & 2.747775 & 0.000411 & 0.006924 & 3.533141 & $\mathrm{Up}$ & calcitonin receptor \\
\hline PGC & 2.688901 & $2.74 \mathrm{E}-05$ & 0.000994 & 4.194452 & Up & progastricsin \\
\hline SPRR1A & 2.664413 & 0.000477 & 0.007678 & 3.493077 & $\mathrm{Up}$ & small proline rich protein $1 \mathrm{~A}$ \\
\hline ABCB11 & 2.650492 & 0.004481 & 0.036813 & 2.842169 & Up & ATP binding cassette subfamily B member 11 \\
\hline $\mathrm{USH} 2 \mathrm{~A}$ & 2.631238 & 0.002995 & 0.027872 & 2.968252 & Up & usherin \\
\hline OTX2 & 2.568693 & $6.44 \mathrm{E}-06$ & 0.000354 & 4.511363 & Up & orthodenticlehomeobox 2 \\
\hline HBM & 2.562338 & 0.002326 & 0.023468 & 3.045118 & Up & hemoglobin subunit mu \\
\hline DCC & 2.561422 & 0.000102 & 0.002565 & 3.885894 & Up & DCC netrin 1 receptor \\
\hline POTED & 2.474492 & 0.002454 & 0.024342 & 3.028922 & Up & POTE ankyrin domain family member D \\
\hline MUC21 & 2.456424 & 0.005692 & 0.043083 & 2.765033 & Up & mucin 21 , cell surface associated \\
\hline $\mathrm{KCP}$ & 2.393659 & 0.001362 & 0.016053 & 3.202565 & $\mathrm{Up}$ & kielin cysteine rich BMP regulator \\
\hline RGPD3 & 2.363618 & 0.003817 & 0.032868 & 2.892895 & Up & RANBP2 like and GRIP domain containing 3 \\
\hline NOG & 2.354832 & 0.000792 & 0.01105 & 3.355497 & Up & noggin \\
\hline STAR & 2.354313 & 0.000103 & 0.002597 & 3.882572 & $\mathrm{Up}$ & steroidogenic acute regulatory protein \\
\hline KRT16 & 2.299283 & 0.004488 & 0.036852 & 2.841684 & Up & keratin 16 \\
\hline HSFX2 & 2.284692 & 0.000834 & 0.01146 & 3.341177 & Up & heat shock transcription factor family, $\mathrm{X}$-linked 2 \\
\hline
\end{tabular}




\begin{tabular}{|c|c|c|c|c|c|c|}
\hline IL1RN & 2.270537 & 0.001478 & 0.017037 & 3.179045 & Up & interleukin 1 receptor antagonist \\
\hline ZSCAN10 & 2.266233 & 0.000319 & 0.005811 & 3.599153 & Up & zinc finger and SCAN domain containing 10 \\
\hline MAGEA2 & 2.264446 & 0.000456 & 0.007479 & 3.505373 & Up & MAGE family member A2 \\
\hline SHISA2 & 2.254679 & $2.83 \mathrm{E}-05$ & 0.001022 & 4.186632 & Up & shisa family member 2 \\
\hline TACR1 & 2.231669 & 0.001599 & 0.017899 & 3.156123 & Up & tachykinin receptor 1 \\
\hline AQP5 & 2.195113 & 0.00015 & 0.003428 & 3.791855 & Up & aquaporin 5 \\
\hline PRRG3 & 2.180564 & 0.005567 & 0.042512 & 2.77226 & Up & proline rich and Gla domain 3 \\
\hline SYNDIG1 & 2.170655 & 0.002504 & 0.024649 & 3.022825 & Up & synapse differentiation inducing 1 \\
\hline TFAP2C & 2.160589 & 0.000396 & 0.006739 & 3.542676 & Up & transcription factor AP-2 gamma \\
\hline ERRFI1 & 2.155407 & $3.75 \mathrm{E}-08$ & $6.56 \mathrm{E}-06$ & 5.5022 & Up & ERBB receptor feedback inhibitor 1 \\
\hline TMEM174 & 2.090104 & $7.82 \mathrm{E}-05$ & 0.002098 & 3.949874 & Up & transmembrane protein 174 \\
\hline CNTNAP4 & 2.08132 & 0.001501 & 0.017188 & 3.174485 & Up & contactin associated protein family member 4 \\
\hline PLP1 & 2.069097 & 0.001613 & 0.017994 & 3.153457 & Up & proteolipid protein 1 \\
\hline RUNX1T1 & 2.059542 & $8.51 \mathrm{E}-05$ & 0.002242 & 3.929478 & Up & RUNX1 partner transcriptional co-repressor 1 \\
\hline ALOX12 & 2.044757 & 0.007045 & 0.049709 & 2.694705 & Up & arachidonate 12 -lipoxygenase, $12 \mathrm{~S}$ type \\
\hline KRT13 & 2.038413 & 0.002945 & 0.027488 & 2.973453 & Up & keratin 13 \\
\hline SLC7A14 & 1.98194 & 0.006299 & 0.0461 & 2.731787 & Up & solute carrier family 7 member 14 \\
\hline SPRR2E & 1.941341 & 0.006326 & 0.046256 & 2.730406 & Up & small proline rich protein $2 \mathrm{E}$ \\
\hline PDK4 & 1.930909 & $2.91 \mathrm{E}-10$ & $1.25 \mathrm{E}-07$ & 6.303686 & Up & pyruvate dehydrogenase kinase 4 \\
\hline TENM1 & 1.914484 & 0.006644 & 0.047813 & 2.714165 & Up & teneurintransmembrane protein 1 \\
\hline PRLHR & 1.912351 & 0.006684 & 0.047973 & 2.712197 & Up & prolactin releasing hormone receptor \\
\hline HAO1 & 1.901548 & 0.004154 & 0.03502 & 2.866261 & Up & hydroxyacid oxidase 1 \\
\hline SLC22A11 & 1.873469 & 0.006672 & 0.047915 & 2.7128 & Up & solute carrier family 22 member 11 \\
\hline LOC729080 & 1.856377 & 0.007083 & 0.049857 & 2.692934 & Up & glycine cleavage system protein $\mathrm{H}$ (aminomethyl carrier) pseudogene \\
\hline PEMT & 1.849123 & 7.27E-06 & 0.000386 & 4.485648 & Up & phosphatidylethanolamine N-methyltransferase \\
\hline LY6H & 1.840253 & 0.0016 & 0.017903 & 3.155867 & Up & lymphocyte antigen 6 family member $\mathrm{H}$ \\
\hline FAM205A & 1.836628 & 0.004029 & 0.034239 & 2.875852 & Up & family with sequence similarity 205 member A \\
\hline TMEM236 & 1.814489 & 0.000914 & 0.012245 & 3.315815 & Up & transmembrane protein 236 \\
\hline $\mathrm{KCNJ} 13$ & 1.809864 & 0.004278 & 0.035664 & 2.856913 & Up & potassium inwardly rectifying channel subfamily $\mathrm{J}$ member 13 \\
\hline FAP & 1.803439 & 0.000962 & 0.01274 & 3.301429 & Up & fibroblast activation protein alpha \\
\hline EYA4 & 1.800375 & 0.003266 & 0.029605 & 2.941492 & Up & EYA transcriptional coactivator and phosphatase 4 \\
\hline BTBD11 & 1.791996 & 0.002099 & 0.021686 & 3.075855 & Up & BTB domain containing 11 \\
\hline OR5J2 & 1.786096 & 0.000858 & 0.011727 & 3.333497 & Up & olfactory receptor family 5 subfamily $\mathrm{J}$ member 2 \\
\hline FBP2 & 1.783474 & 0.001941 & 0.020527 & 3.099056 & Up & fructose-bisphosphatase 2 \\
\hline LCE3E & 1.78332 & 0.000904 & 0.012149 & 3.318662 & Up & late cornified envelope $3 \mathrm{E}$ \\
\hline ZNF554 & 1.777372 & 0.000256 & 0.005002 & 3.656153 & Up & zinc finger protein 554 \\
\hline OR10H1 & 1.769139 & 0.001545 & 0.017516 & 3.166037 & Up & olfactory receptor family 10 subfamily $\mathrm{H}$ member 1 \\
\hline AQP7P1 & 1.76578 & 0.000244 & 0.004837 & 3.668581 & Up & aquaporin 7 pseudogene 1 \\
\hline EGR1 & 1.751068 & $8.94 \mathrm{E}-07$ & 7.97E-05 & 4.913629 & Up & early growth response 1 \\
\hline CSGALNACT1 & 1.736673 & 0.000245 & 0.004842 & 3.666956 & Up & chondroitin sulfate $\mathrm{N}$-acetylgalactosaminyltransferase 1 \\
\hline MT2A & 1.736195 & 7.33E-07 & $6.80 \mathrm{E}-05$ & 4.952342 & Up & metallothionein $2 \mathrm{~A}$ \\
\hline MAL & 1.723595 & $5.94 \mathrm{E}-06$ & 0.000338 & 4.528542 & Up & mal, $\mathrm{T}$ cell differentiation protein \\
\hline SLC38A4 & 1.716457 & 0.00026 & 0.00507 & 3.652138 & Up & solute carrier family 38 member 4 \\
\hline
\end{tabular}




\begin{tabular}{|c|c|c|c|c|c|c|}
\hline GCG & 1.704823 & 0.004274 & 0.035664 & 2.857184 & Up & glucagon \\
\hline OR13D1 & 1.699677 & 0.004653 & 0.037774 & 2.830118 & $\mathrm{Up}$ & olfactory receptor family 13 subfamily D member 1 \\
\hline ASIC1 & 1.678655 & 0.00502 & 0.039748 & 2.805723 & Up & acid sensing ion channel subunit 1 \\
\hline MMP16 & 1.671308 & 0.005478 & 0.041991 & 2.777507 & Up & matrix metallopeptidase 16 \\
\hline ADAMTS8 & 1.657804 & 0.005782 & 0.043574 & 2.759899 & Up & ADAM metallopeptidase with thrombospondin type 1 motif 8 \\
\hline PTGER4 & 1.653859 & $3.38 \mathrm{E}-07$ & $3.75 \mathrm{E}-05$ & 5.101075 & Up & prostaglandin E receptor 4 \\
\hline TMEM201 & 1.653235 & $5.59 \mathrm{E}-10$ & $2.16 \mathrm{E}-07$ & 6.201596 & Up & transmembrane protein 201 \\
\hline FLJ40194 & 1.624297 & 0.004189 & 0.035182 & 2.863583 & Up & uncharacterized FLJ40194 \\
\hline SPATA31C2 & 1.606051 & 0.007008 & 0.049527 & 2.696447 & Up & SPATA31 subfamily C member 2 \\
\hline COL6A3 & 1.59849 & $2.57 \mathrm{E}-08$ & 4.74E-06 & 5.56868 & Up & collagen type VI alpha 3 chain \\
\hline MAPK4 & 1.583571 & 0.002391 & 0.023885 & 3.0368 & Up & mitogen-activated protein kinase 4 \\
\hline OAS2 & 1.57667 & 0.002062 & 0.02144 & 3.08113 & Up & 2'-5'-oligoadenylate synthetase 2 \\
\hline AQP7 & 1.564682 & $2.01 \mathrm{E}-05$ & 0.000792 & 4.263552 & Up & aquaporin 7 \\
\hline SLC25A48 & 1.563621 & 0.001616 & 0.017994 & 3.152948 & Up & solute carrier family 25 member 48 \\
\hline ETV4 & 1.562936 & 0.000269 & 0.005148 & 3.643839 & Up & ETS variant transcription factor 4 \\
\hline MAOB & 1.561413 & $1.32 \mathrm{E}-08$ & $2.88 \mathrm{E}-06$ & 5.683282 & Up & monoamine oxidase $\mathrm{B}$ \\
\hline $\mathrm{C} 2 \mathrm{CD} 4 \mathrm{~B}$ & 1.560294 & $1.38 \mathrm{E}-11$ & 9.97E-09 & 6.760282 & Up & $\mathrm{C} 2$ calcium dependent domain containing 4B \\
\hline $\mathrm{CCDC} 178$ & 1.555319 & 0.006459 & 0.046949 & 2.723504 & Up & coiled-coil domain containing 178 \\
\hline GPC6 & 1.545071 & 0.000569 & 0.008694 & 3.445993 & Up & glypican 6 \\
\hline $\mathrm{KCNJ} 2$ & 1.54264 & 0.005658 & 0.042973 & 2.766965 & Up & potassium inwardly rectifying channel subfamily $\mathrm{J}$ member 2 \\
\hline OR5D14 & 1.535933 & 0.004061 & 0.034442 & 2.873396 & Up & olfactory receptor family 5 subfamily D member 14 \\
\hline MT1E & 1.527259 & 4.13E-05 & 0.001326 & 4.100352 & Up & metallothionein $1 \mathrm{E}$ \\
\hline SOCS5 & 1.523522 & 0.002001 & 0.02099 & 3.090019 & Up & suppressor of cytokine signaling 5 \\
\hline GMNC & 1.517516 & 0.001378 & 0.016174 & 3.199272 & Up & geminin coiled-coil domain containing \\
\hline BCL9 & 1.517476 & $6.32 \mathrm{E}-05$ & 0.00178 & 4.00057 & Up & BCL9 transcription coactivator \\
\hline PDK3 & 1.516039 & $5.57 \mathrm{E}-05$ & 0.001659 & 4.030114 & Up & pyruvate dehydrogenase kinase 3 \\
\hline $\mathrm{ABCC} 9$ & 1.508688 & $3.88 \mathrm{E}-05$ & 0.001266 & 4.114451 & Up & ATP binding cassette subfamily $\mathrm{C}$ member 9 \\
\hline POU6F2 & 1.507127 & 0.000877 & 0.011878 & 3.327431 & Up & POU class 6 homeobox 2 \\
\hline BTG2 & 1.506976 & $1.08 \mathrm{E}-05$ & 0.000512 & 4.40043 & Up & BTG anti-proliferation factor 2 \\
\hline A4GNT & 1.487207 & 0.006669 & 0.047915 & 2.712924 & Up & alpha-1,4-N-acetylglucosaminyltransferase \\
\hline CST6 & 1.474865 & 0.005179 & 0.040581 & 2.795655 & Up & cystatin E/M \\
\hline CELP & 1.456416 & 0.000752 & 0.010713 & 3.369855 & Up & carboxyl ester lipase pseudogene \\
\hline PRR15 & 1.44211 & 4.79E-05 & 0.001473 & 4.065781 & Up & proline rich 15 \\
\hline VEGFC & 1.439026 & 0.000138 & 0.00323 & 3.81237 & Up & vascular endothelial growth factor $\mathrm{C}$ \\
\hline FAM20C & 1.417883 & $3.53 \mathrm{E}-07$ & $3.87 \mathrm{E}-05$ & 5.092481 & Up & FAM20C golgi associated secretory pathway kinase \\
\hline MPZ & 1.412425 & 0.001225 & 0.015005 & 3.232986 & Up & myelin protein zero \\
\hline C16orf89 & 1.406088 & 0.002355 & 0.023671 & 3.041349 & Up & chromosome 16 open reading frame 89 \\
\hline USP27X & 1.405375 & $2.98 \mathrm{E}-05$ & 0.001061 & 4.175094 & Up & ubiquitin specific peptidase $27 \mathrm{X}$-linked \\
\hline STK32B & 1.401504 & 0.00137 & 0.016106 & 3.200934 & Up & serine/threonine kinase 32B \\
\hline TMEM176A & 1.395841 & 0.001167 & 0.014603 & 3.24678 & Up & transmembrane protein $176 \mathrm{~A}$ \\
\hline KLK13 & 1.39366 & 0.003137 & 0.028793 & 2.95399 & Up & kallikrein related peptidase 13 \\
\hline RPS6 & 1.393238 & 0.000141 & 0.003288 & 3.806963 & $\mathrm{Up}$ & ribosomal protein S6 \\
\hline ID3 & 1.379774 & 0.001032 & 0.01339 & 3.281721 & Up & inhibitor of DNA binding 3, HLH protein \\
\hline
\end{tabular}




\begin{tabular}{|c|c|c|c|c|c|c|}
\hline PGAP2 & 1.372801 & 0.003315 & 0.029859 & 2.936936 & Up & post-GPI attachment to proteins 2 \\
\hline ALOXE3 & 1.371318 & 0.005208 & 0.040713 & 2.793904 & $\mathrm{Up}$ & arachidonatelipoxygenase 3 \\
\hline LSM11 & 1.370033 & 0.000167 & 0.003679 & 3.763746 & Up & LSM11, U7 small nuclear RNA associated \\
\hline BCAP31 & 1.366767 & 0.000323 & 0.005863 & 3.596276 & Up & B cell receptor associated protein 31 \\
\hline DDIT4 & 1.357877 & $2.95 \mathrm{E}-05$ & 0.001054 & 4.177066 & Up & DNA damage inducible transcript 4 \\
\hline DPP4 & 1.354505 & 0.000874 & 0.01186 & 3.328261 & Up & dipeptidyl peptidase 4 \\
\hline TYSND1 & 1.351009 & $1.59 \mathrm{E}-09$ & $5.04 \mathrm{E}-07$ & 6.035046 & Up & trypsin like peroxisomal matrix peptidase 1 \\
\hline IRF2BP2 & 1.34637 & $5.95 \mathrm{E}-18$ & $2.15 \mathrm{E}-14$ & 8.633426 & Up & interferon regulatory factor 2 binding protein 2 \\
\hline KLF15 & 1.343721 & $1.94 \mathrm{E}-06$ & 0.000145 & 4.760024 & Up & Kruppel like factor 15 \\
\hline PCDHB7 & 1.334027 & 0.002902 & 0.027259 & 2.97794 & Up & protocadherin beta 7 \\
\hline EGR3 & 1.31896 & 0.00597 & 0.044535 & 2.749441 & Up & early growth response 3 \\
\hline RNF165 & 1.312414 & 0.004877 & 0.038959 & 2.815046 & Up & ring finger protein 165 \\
\hline GRPR & 1.2879 & 0.000461 & 0.007519 & 3.502487 & Up & gastrin releasing peptide receptor \\
\hline SLC10A5 & 1.281611 & 0.000367 & 0.006373 & 3.562596 & Up & solute carrier family 10 member 5 \\
\hline AQP8 & 1.275576 & 0.000165 & 0.003653 & 3.767345 & Up & aquaporin 8 \\
\hline SLC22A17 & 1.275441 & 0.005167 & 0.040504 & 2.796408 & Up & solute carrier family 22 member 17 \\
\hline PHLDA1 & 1.265 & $7.26 \mathrm{E}-07$ & $6.77 \mathrm{E}-05$ & 4.954344 & Up & pleckstrin homology like domain family A member 1 \\
\hline FAM86B2 & 1.261397 & 0.00011 & 0.002723 & 3.868009 & Up & family with sequence similarity 86 member B2 \\
\hline TNXA & 1.26094 & 0.000548 & 0.008447 & 3.456266 & Up & tenascin XA (pseudogene) \\
\hline LTBP4 & 1.249779 & $1.25 \mathrm{E}-10$ & $6.48 \mathrm{E}-08$ & 6.432767 & Up & latent transforming growth factor beta binding protein 4 \\
\hline IKZF4 & 1.247809 & 0.005701 & 0.043119 & 2.764503 & Up & IKAROS family zinc finger 4 \\
\hline CREB3L1 & 1.240081 & 0.001747 & 0.019045 & 3.13026 & Up & cAMP responsive element binding protein 3 like 1 \\
\hline $\mathrm{A} 1 \mathrm{CF}$ & 1.237404 & 0.000302 & 0.00558 & 3.613598 & Up & APOBEC 1 complementation factor \\
\hline EMX1 & 1.231921 & 0.007097 & 0.049918 & 2.692267 & Up & empty spiracles homeobox 1 \\
\hline NAT10 & 1.230925 & 0.000288 & 0.005418 & 3.625785 & Up & $\mathrm{N}$-acetyltransferase 10 \\
\hline NETO2 & 1.226436 & $2.78 \mathrm{E}-05$ & 0.001004 & 4.191134 & Up & neuropilin and tolloid like 2 \\
\hline ACSL6 & 1.22516 & 0.000699 & 0.010166 & 3.390161 & Up & acyl-CoA synthetase long chain family member 6 \\
\hline KLF3 & 1.222656 & 2.23E-09 & $6.52 \mathrm{E}-07$ & 5.979866 & Up & Kruppel like factor 3 \\
\hline ZFP36 & 1.222469 & $2.71 \mathrm{E}-07$ & $3.23 \mathrm{E}-05$ & 5.142302 & Up & ZFP36 ring finger protein \\
\hline QDPR & 1.212418 & 0.000429 & 0.007144 & 3.521702 & Up & quinoiddihydropteridinereductase \\
\hline OAS1 & 1.211224 & 0.004602 & 0.03752 & 2.833639 & Up & 2'-5'-oligoadenylate synthetase 1 \\
\hline ETV5 & 1.20819 & $3.13 \mathrm{E}-06$ & 0.00021 & 4.662414 & Up & ETS variant transcription factor 5 \\
\hline GRIK5 & 1.206035 & 0.002239 & 0.022781 & 3.056565 & Up & glutamate ionotropic receptor kainate type subunit 5 \\
\hline KL & 1.201704 & 0.006204 & 0.045712 & 2.736802 & Up & klotho \\
\hline ZNF385C & 1.200196 & 0.00318 & 0.029058 & 2.94975 & Up & zinc finger protein $385 \mathrm{C}$ \\
\hline TMEM168 & 1.200047 & 0.001202 & 0.014842 & 3.238427 & Up & transmembrane protein 168 \\
\hline GADD45B & 1.195691 & $6.00 \mathrm{E}-06$ & 0.000339 & 4.526504 & Up & growth arrest and DNA damage inducible beta \\
\hline SLC29A3 & 1.193652 & $1.40 \mathrm{E}-05$ & 0.000618 & 4.344205 & Up & solute carrier family 29 member 3 \\
\hline GPR63 & 1.189122 & $5.77 \mathrm{E}-05$ & 0.001693 & 4.022037 & Up & G protein-coupled receptor 63 \\
\hline MAN1A1 & 1.187174 & $5.53 \mathrm{E}-06$ & 0.000322 & 4.54348 & Up & mannosidase alpha class $1 \mathrm{~A}$ member 1 \\
\hline NXN & 1.184622 & $3.38 \mathrm{E}-05$ & 0.001161 & 4.146023 & Up & nucleoredoxin \\
\hline CGREF1 & 1.181501 & 0.004649 & 0.037769 & 2.830375 & Up & cell growth regulator with EF-hand domain 1 \\
\hline TLE3 & 1.181041 & $1.46 \mathrm{E}-09$ & 4.91E-07 & 6.048256 & Up & TLE family member 3 , transcriptional corepressor \\
\hline
\end{tabular}




\begin{tabular}{|c|c|c|c|c|c|c|}
\hline RPL8 & 1.175798 & 8.84E-06 & 0.000445 & 4.443715 & Up & ribosomal protein L8 \\
\hline HEYL & 1.175375 & $7.83 \mathrm{E}-05$ & 0.002098 & 3.94967 & Up & hes related family bHLH transcription factor with YRPW motif like \\
\hline PER3 & 1.174824 & $2.57 \mathrm{E}-06$ & 0.00018 & 4.702617 & Up & period circadian regulator 3 \\
\hline $\mathrm{CXXC} 4$ & 1.172558 & 0.000526 & 0.008232 & 3.46716 & Up & CXXC finger protein 4 \\
\hline HRAS & 1.17075 & $4.69 \mathrm{E}-05$ & 0.001454 & 4.070447 & Up & HRas proto-oncogene, GTPase \\
\hline GLI3 & 1.168455 & 0.00011 & 0.002728 & 3.866542 & Up & GLI family zinc finger 3 \\
\hline SYCN & 1.16423 & 0.001588 & 0.017817 & 3.158183 & Up & syncollin \\
\hline WDR89 & 1.15871 & 0.003082 & 0.028428 & 2.959443 & Up & WD repeat domain 89 \\
\hline KIAA0408 & 1.156987 & 0.00359 & 0.031565 & 2.912147 & Up & KIAA0408 \\
\hline SFTPD & 1.156467 & 0.000869 & 0.011855 & 3.329763 & Up & surfactant protein $\mathrm{D}$ \\
\hline MYC & 1.155459 & 0.000232 & 0.004664 & 3.68131 & Up & MYC proto-oncogene, bHLH transcription factor \\
\hline TTI1 & 1.153438 & 7.67E-06 & 0.000403 & 4.474283 & Up & TELO2 interacting protein 1 \\
\hline IFIT3 & 1.153223 & 0.001484 & 0.017069 & 3.177774 & Up & interferon induced protein with tetratricopeptide repeats 3 \\
\hline IGSF8 & 1.147182 & $3.42 \mathrm{E}-05$ & 0.00117 & 4.143533 & Up & immunoglobulin superfamily member 8 \\
\hline RPRD2 & 1.136951 & 4.05E-09 & $1.04 \mathrm{E}-06$ & 5.882334 & Up & regulation of nuclear pre-mRNA domain containing 2 \\
\hline MT1JP & 1.135989 & 0.002674 & 0.025796 & 3.002974 & Up & metallothionein $1 \mathrm{~J}$, pseudogene \\
\hline SNORA81 & 1.134404 & 7.05E-05 & 0.001942 & 3.974527 & Up & small nucleolar RNA, H/ACA box 81 \\
\hline DMD & 1.134394 & 0.0025 & 0.024649 & 3.02331 & Up & dystrophin \\
\hline ZNF416 & 1.12885 & 3.44E-06 & 0.00022 & 4.642339 & Up & zinc finger protein 416 \\
\hline AQP12B & 1.122447 & 0.003687 & 0.032134 & 2.903728 & Up & aquaporin $12 \mathrm{~B}$ \\
\hline FKBP8 & 1.12091 & 0.000337 & 0.006069 & 3.585204 & Up & FKBP prolylisomerase 8 \\
\hline IRS1 & 1.109776 & $2.50 \mathrm{E}-09$ & 7.07E-07 & 5.961342 & Up & insulin receptor substrate 1 \\
\hline KIAA1958 & 1.104138 & $2.20 \mathrm{E}-07$ & $2.72 \mathrm{E}-05$ & 5.181865 & Up & KIAA1958 \\
\hline RPS28 & 1.099636 & $2.86 \mathrm{E}-10$ & $1.25 \mathrm{E}-07$ & 6.306441 & Up & ribosomal protein S28 \\
\hline TMEM140 & 1.093078 & 0.00016 & 0.003573 & 3.774447 & Up & transmembrane protein 140 \\
\hline DBP & 1.092264 & $1.15 \mathrm{E}-06$ & $9.80 \mathrm{E}-05$ & 4.86439 & Up & D-box binding PAR bZIP transcription factor \\
\hline MUC6 & 1.08831 & 0.005474 & 0.041981 & 2.777718 & Up & mucin 6, oligomeric mucus/gel-forming \\
\hline MTCH1 & 1.088002 & 0.004192 & 0.035182 & 2.86336 & Up & mitochondrial carrier 1 \\
\hline CHST10 & 1.086677 & 0.005118 & 0.040291 & 2.799519 & Up & carbohydrate sulfotransferase 10 \\
\hline ABHD15 & 1.086125 & 0.000312 & 0.005712 & 3.605158 & Up & abhydrolase domain containing 15 \\
\hline KLF9 & 1.080005 & $8.43 \mathrm{E}-13$ & $9.53 \mathrm{E}-10$ & 7.15394 & Up & Kruppel like factor 9 \\
\hline EIF4B & 1.06405 & 0.000817 & 0.011276 & 3.347136 & Up & eukaryotic translation initiation factor 4B \\
\hline KLF10 & 1.055746 & 0.000299 & 0.005546 & 3.616276 & Up & Kruppel like factor 10 \\
\hline PODXL & 1.05305 & $1.75 \mathrm{E}-06$ & 0.000137 & 4.780037 & Up & podocalyxin like \\
\hline BVES & 1.050529 & 0.000813 & 0.011258 & 3.348218 & Up & blood vessel epicardial substance \\
\hline GLTP & 1.050372 & $5.80 \mathrm{E}-06$ & 0.000333 & 4.533591 & Up & glycolipid transfer protein \\
\hline MNT & 1.045232 & $2.72 \mathrm{E}-05$ & 0.000992 & 4.195389 & Up & MAX network transcriptional repressor \\
\hline LSR & 1.044877 & $1.76 \mathrm{E}-05$ & 0.000726 & 4.292801 & Up & lipolysis stimulated lipoprotein receptor \\
\hline CEL & 1.038816 & 0.002503 & 0.024649 & 3.023013 & Up & carboxyl ester lipase \\
\hline NUP205 & 1.036199 & 0.002925 & 0.027371 & 2.975558 & Up & nucleoporin 205 \\
\hline MT1L & 1.036012 & 0.001676 & 0.018469 & 3.142292 & Up & metallothionein $1 \mathrm{~L}$, pseudogene \\
\hline FOSL2 & 1.035358 & $3.00 \mathrm{E}-05$ & 0.001065 & 4.173687 & Up & FOS like 2, AP-1 transcription factor subunit \\
\hline ACVR2B-AS1 & 1.03269 & 0.002713 & 0.026028 & 2.998466 & Up & ACVR2B antisense RNA 1 \\
\hline
\end{tabular}




\begin{tabular}{|c|c|c|c|c|c|c|}
\hline SLC1A5 & 1.032611 & 0.000353 & 0.006238 & 3.572762 & Up & solute carrier family 1 member 5 \\
\hline ZNF362 & 1.03072 & $5.17 \mathrm{E}-06$ & 0.000306 & 4.557695 & Up & zinc finger protein 362 \\
\hline WASF1 & 1.029075 & $9.96 \mathrm{E}-05$ & 0.002531 & 3.891542 & Up & WASP family member 1 \\
\hline PAPSS2 & 1.024653 & 0.003229 & 0.029385 & 2.945045 & Up & 3'-phosphoadenosine 5'-phosphosulfate synthase 2 \\
\hline TMCO4 & 1.023584 & 0.000267 & 0.005139 & 3.645801 & Up & transmembrane and coiled-coil domains 4 \\
\hline KIAA1549 & 1.022711 & 0.000159 & 0.003558 & 3.777019 & Up & KIAA1549 \\
\hline NR1D1 & 1.022533 & 0.002444 & 0.024264 & 3.030221 & Up & nuclear receptor subfamily 1 group D member 1 \\
\hline DUSP4 & 1.013696 & $5.02 \mathrm{E}-05$ & 0.001535 & 4.054499 & Up & dual specificity phosphatase 4 \\
\hline SNX19 & 1.013619 & $3.95 \mathrm{E}-05$ & 0.001287 & 4.110135 & Up & sorting nexin 19 \\
\hline SMCR8 & 1.013255 & $1.35 \mathrm{E}-05$ & 0.000604 & 4.351545 & Up & SMCR8-C9orf72 complex subunit \\
\hline $\mathrm{FECH}$ & 1.008972 & $1.98 \mathrm{E}-05$ & 0.000786 & 4.267423 & Up & ferrochelatase \\
\hline FOXN3 & 1.007664 & $3.12 \mathrm{E}-10$ & $1.31 \mathrm{E}-07$ & 6.292462 & Up & forkhead box N3 \\
\hline IL6ST & 1.006029 & 0.002468 & 0.024433 & 3.027296 & Up & interleukin 6 signal transducer \\
\hline IL6R & 0.999744 & 0.006884 & 0.048917 & 2.702392 & Up & interleukin 6 receptor \\
\hline PCDHB6 & 0.994986 & 0.005158 & 0.040486 & 2.796974 & Up & protocadherin beta 6 \\
\hline ZNF581 & 0.993708 & 0.000106 & 0.00265 & 3.876665 & Up & zinc finger protein 581 \\
\hline KLF6 & 0.991792 & $6.78 \mathrm{E}-07$ & $6.43 \mathrm{E}-05$ & 4.967609 & Up & Kruppel like factor 6 \\
\hline CPA1 & 0.99028 & 0.003622 & 0.031696 & 2.909338 & Up & carboxypeptidase A1 \\
\hline ABCA1 & 0.989596 & 0.000135 & 0.003174 & 3.817307 & Up & ATP binding cassette subfamily A member 1 \\
\hline ZFP36L1 & 0.983112 & 0.000597 & 0.009015 & 3.432766 & Up & ZFP36 ring finger protein like 1 \\
\hline PBX1 & 0.979927 & $4.02 \mathrm{E}-13$ & $5.59 \mathrm{E}-10$ & 7.254949 & Up & PBX homeobox 1 \\
\hline DYSF & 0.977559 & 0.006334 & 0.046301 & 2.729951 & Up & dysferlin \\
\hline SH3RF1 & 0.977474 & 0.000206 & 0.004295 & 3.711432 & Up & SH3 domain containing ring finger 1 \\
\hline PLEKHG6 & 0.975335 & 0.000311 & 0.0057 & 3.605994 & Up & pleckstrin homology and RhoGEF domain containing G6 \\
\hline URM1 & 0.974945 & $1.43 \mathrm{E}-08$ & $3.05 \mathrm{E}-06$ & 5.670336 & Up & ubiquitin related modifier 1 \\
\hline ERN1 & 0.974217 & 0.000112 & 0.002749 & 3.86398 & Up & endoplasmic reticulum to nucleus signaling 1 \\
\hline RPL18 & 0.972875 & $1.59 \mathrm{E}-06$ & 0.000129 & 4.799987 & Up & ribosomal protein L18 \\
\hline CNTN3 & 0.966787 & 0.001627 & 0.018064 & 3.151099 & Up & contactin 3 \\
\hline CYGB & 0.960228 & 4.03E-05 & 0.001303 & 4.105482 & Up & cytoglobin \\
\hline RNF24 & 0.952932 & 0.000767 & 0.010872 & 3.364507 & Up & ring finger protein 24 \\
\hline ABCG2 & 0.942728 & 0.002598 & 0.025251 & 3.011741 & Up & ATP binding cassette subfamily G member 2 (Junior blood group) \\
\hline PRRC1 & 0.940958 & $1.44 \mathrm{E}-05$ & 0.000633 & 4.337711 & Up & proline rich coiled-coil 1 \\
\hline NHEJ1 & 0.940305 & 0.005191 & 0.040636 & 2.794938 & Up & non-homologous end joining factor 1 \\
\hline PDK2 & 0.936816 & $1.05 \mathrm{E}-05$ & 0.000505 & 4.406224 & Up & pyruvate dehydrogenase kinase 2 \\
\hline $\mathrm{BOC}$ & 0.933366 & $6.19 \mathrm{E}-06$ & 0.000345 & 4.519766 & Up & BOC cell adhesion associated, oncogene regulated \\
\hline PNPLA4 & 0.92827 & $1.98 \mathrm{E}-09$ & $6.00 \mathrm{E}-07$ & 5.999168 & Up & patatin like phospholipase domain containing 4 \\
\hline SELENBP1 & 0.925116 & $5.37 \mathrm{E}-07$ & $5.49 \mathrm{E}-05$ & 5.012682 & Up & selenium binding protein 1 \\
\hline STAT1 & 0.92016 & $2.19 \mathrm{E}-08$ & $4.26 \mathrm{E}-06$ & 5.596302 & Up & signal transducer and activator of transcription 1 \\
\hline TMC4 & 0.918004 & $7.50 \mathrm{E}-06$ & 0.000396 & 4.479012 & Up & transmembrane channel like 4 \\
\hline HSPA2 & 0.917681 & 0.000234 & 0.004701 & 3.678748 & Up & heat shock protein family A (Hsp70) member 2 \\
\hline DUSP1 & 0.916798 & $6.01 \mathrm{E}-06$ & 0.000339 & 4.526156 & Up & dual specificity phosphatase 1 \\
\hline CLSTN2 & 0.915169 & 0.000756 & 0.010747 & 3.368549 & Up & calsyntenin 2 \\
\hline DIP2B & 0.914675 & $3.23 \mathrm{E}-05$ & 0.001126 & 4.156545 & Up & disco interacting protein 2 homolog $\mathrm{B}$ \\
\hline
\end{tabular}




\begin{tabular}{|c|c|c|c|c|c|c|}
\hline FMOD & 0.902186 & 0.001186 & 0.01473 & 3.242196 & Up & fibromodulin \\
\hline SNORA46 & 0.900951 & 0.006185 & 0.045618 & 2.737784 & Up & small nucleolar RNA, H/ACA box 46 \\
\hline MYADM & 0.899156 & $9.01 \mathrm{E}-06$ & 0.000447 & 4.439634 & Up & myeloid associated differentiation marker \\
\hline ARPC1A & 0.896149 & 8.17E-09 & $1.92 \mathrm{E}-06$ & 5.764985 & Up & actin related protein $2 / 3$ complex subunit $1 \mathrm{~A}$ \\
\hline PCDHB11 & 0.894232 & 0.006266 & 0.045933 & 2.733512 & Up & protocadherin beta 11 \\
\hline KCTD12 & 0.89297 & 0.000774 & 0.010938 & 3.361758 & Up & potassium channel tetramerization domain containing 12 \\
\hline APOD & 0.89142 & 0.00345 & 0.030622 & 2.924542 & Up & apolipoprotein D \\
\hline GLS & 0.884954 & 0.00026 & 0.00507 & 3.652426 & Up & glutaminase \\
\hline FBXO32 & 0.881866 & $3.15 \mathrm{E}-06$ & 0.000211 & 4.660468 & Up & F-box protein 32 \\
\hline ST6GALNAC6 & 0.879554 & $2.07 \mathrm{E}-05$ & 0.000809 & 4.257572 & Up & ST6 N-acetylgalactosaminide alpha-2,6-sialyltransferase 6 \\
\hline SRM & 0.878308 & 0.000309 & 0.005677 & 3.607559 & Up & spermidine synthase \\
\hline DIRAS3 & 0.876306 & 0.003122 & 0.028685 & 2.955463 & Up & DIRAS family GTPase 3 \\
\hline NR0B2 & 0.874431 & 7.41E-05 & 0.002024 & 3.962782 & Up & nuclear receptor subfamily 0 group B member 2 \\
\hline NHS & 0.87443 & 0.005302 & 0.041077 & 2.788104 & Up & NHS actin remodeling regulator \\
\hline SYVN1 & 0.872096 & 0.000139 & 0.003248 & 3.810686 & Up & synoviolin 1 \\
\hline ARL6IP1 & 0.872037 & 0.001505 & 0.017219 & 3.173755 & Up & ADP ribosylation factor like GTPase 6 interacting protein 1 \\
\hline TCF7L2 & 0.871267 & $8.46 \mathrm{E}-06$ & 0.000435 & 4.45327 & Up & transcription factor 7 like 2 \\
\hline TMUB 1 & 0.869907 & $2.94 \mathrm{E}-05$ & 0.00105 & 4.178279 & Up & transmembrane and ubiquitin like domain containing 1 \\
\hline SNHG9 & 0.868128 & 0.000191 & 0.004072 & 3.730146 & Up & small nucleolar RNA host gene 9 \\
\hline DHRS11 & 0.86627 & $5.84 \mathrm{E}-08$ & $9.11 \mathrm{E}-06$ & 5.423684 & Up & dehydrogenase/reductase 11 \\
\hline MRPL37 & 0.864054 & $1.60 \mathrm{E}-06$ & 0.000129 & 4.79874 & Up & mitochondrial ribosomal protein $\mathrm{L} 37$ \\
\hline DLL4 & 0.858948 & 0.003304 & 0.029823 & 2.937894 & Up & delta like canonical Notch ligand 4 \\
\hline HELZ2 & 0.856157 & $8.62 \mathrm{E}-05$ & 0.002263 & 3.926561 & Up & helicase with zinc finger 2 \\
\hline NNMT & 0.851608 & 0.001206 & 0.014883 & 3.237453 & Up & nicotinamide $\mathrm{N}$-methyltransferase \\
\hline SMAD1 & 0.850932 & $1.92 \mathrm{E}-07$ & $2.46 \mathrm{E}-05$ & 5.206868 & Up & SMAD family member 1 \\
\hline TP53 & 0.850773 & 0.000201 & 0.004226 & 3.717618 & Up & tumor protein $\mathrm{p} 53$ \\
\hline PCDH18 & 0.850737 & 0.000247 & 0.004858 & 3.665575 & Up & protocadherin 18 \\
\hline FAM160B2 & 0.848165 & 0.00339 & 0.030322 & 2.929974 & Up & family with sequence similarity 160 member B2 \\
\hline ELK1 & 0.84679 & $7.59 \mathrm{E}-05$ & 0.002058 & 3.957072 & Up & ETS transcription factor ELK1 \\
\hline SUN2 & 0.846146 & 4.47E-08 & 7.36E-06 & 5.471101 & Up & Sad1 and UNC84 domain containing 2 \\
\hline TMEM150A & 0.84345 & 7.57E-07 & $6.88 \mathrm{E}-05$ & 4.946241 & Up & transmembrane protein $150 \mathrm{~A}$ \\
\hline PTBP1 & 0.84235 & $1.45 \mathrm{E}-05$ & 0.000636 & 4.335712 & Up & polypyrimidine tract binding protein 1 \\
\hline SOS1 & 0.842032 & $1.25 \mathrm{E}-05$ & 0.000573 & 4.369507 & Up & SOS Ras/Rac guanine nucleotide exchange factor 1 \\
\hline PRKACA & 0.841424 & 0.000208 & 0.004333 & 3.708612 & Up & protein kinase cAMP-activated catalytic subunit alpha \\
\hline $\mathrm{BACH} 2$ & 0.840276 & 0.004124 & 0.034884 & 2.868539 & Up & BTB domain and CNC homolog 2 \\
\hline TOR2A & 0.838785 & 0.000805 & 0.011164 & 3.351168 & Up & torsin family 2 member $\mathrm{A}$ \\
\hline CTSF & 0.836129 & $6.47 \mathrm{E}-06$ & 0.000355 & 4.51037 & Up & cathepsin F \\
\hline EGFR & 0.835307 & 0.002303 & 0.023314 & 3.048103 & Up & epidermal growth factor receptor \\
\hline ETS1 & 0.834376 & 0.002812 & 0.0267 & 2.987581 & Up & ETS proto-oncogene 1, transcription factor \\
\hline PIK3CA & 0.834263 & $9.81 \mathrm{E}-06$ & 0.000476 & 4.421306 & Up & phosphatidylinositol-4,5-bisphosphate 3-kinase catalytic subunit alpha \\
\hline ZNRF1 & 0.834005 & 0.000348 & 0.006201 & 3.57648 & Up & zinc and ring finger 1 \\
\hline CMPK2 & 0.833442 & 0.000382 & 0.006568 & 3.552511 & Up & cytidine/uridine monophosphate kinase 2 \\
\hline C17orf49 & 0.831035 & $6.49 \mathrm{E}-08$ & $9.94 \mathrm{E}-06$ & 5.404842 & Up & chromosome 17 open reading frame 49 \\
\hline
\end{tabular}




\begin{tabular}{|c|c|c|c|c|c|c|}
\hline GUK1 & 0.830906 & 0.005863 & 0.043941 & 2.755329 & Up & guanylate kinase 1 \\
\hline TSHZ1 & 0.830001 & 0.001412 & 0.016467 & 3.192239 & Up & teashirt zinc finger homeobox 1 \\
\hline ZNF326 & 0.829871 & $2.09 \mathrm{E}-05$ & 0.000816 & 4.255297 & Up & zinc finger protein 326 \\
\hline MED13L & 0.825296 & $1.99 \mathrm{E}-05$ & 0.000788 & 4.266458 & Up & mediator complex subunit $13 \mathrm{~L}$ \\
\hline GCNT2 & 0.824275 & 0.006687 & 0.047973 & 2.712061 & Up & glucosaminyl ( $\mathrm{N}$-acetyl) transferase 2 (I blood group) \\
\hline SAE1 & 0.821934 & $1.76 \mathrm{E}-05$ & 0.000726 & 4.292772 & Up & SUMO1 activating enzyme subunit 1 \\
\hline GTPBP8 & 0.820509 & $1.28 \mathrm{E}-06$ & 0.000107 & 4.842977 & Up & GTP binding protein 8 (putative) \\
\hline PKN1 & 0.820314 & $9.18 \mathrm{E}-05$ & 0.002377 & 3.911368 & Up & protein kinase $\mathrm{N} 1$ \\
\hline TNFRSF1A & 0.819517 & $8.65 \mathrm{E}-06$ & 0.000442 & 4.448543 & Up & TNF receptor superfamily member $1 \mathrm{~A}$ \\
\hline ELOVL1 & 0.818479 & $2.24 \mathrm{E}-06$ & 0.000163 & 4.730554 & Up & ELOVL fatty acid elongase 1 \\
\hline TUT1 & 0.81736 & 0.000101 & 0.002556 & 3.887148 & Up & terminal uridylyltransferase $1, \mathrm{U} 6 \mathrm{snRNA}$-specific \\
\hline NCSTN & 0.814539 & $5.60 \mathrm{E}-10$ & $2.16 \mathrm{E}-07$ & 6.201177 & Up & nicastrin \\
\hline MFAP2 & 0.814276 & 0.004538 & 0.037128 & 2.838125 & Up & microfibril associated protein 2 \\
\hline YBX1 & 0.812937 & $9.16 \mathrm{E}-05$ & 0.002377 & 3.911852 & Up & Y-box binding protein 1 \\
\hline PPP1R3B & 0.810696 & 0.000614 & 0.009215 & 3.425208 & Up & protein phosphatase 1 regulatory subunit $3 \mathrm{~B}$ \\
\hline PLCE1 & 0.80763 & 0.005261 & 0.040902 & 2.790596 & Up & phospholipase $\mathrm{C}$ epsilon 1 \\
\hline NDST1 & 0.801304 & $1.38 \mathrm{E}-10$ & $6.95 \mathrm{E}-08$ & 6.417856 & Up & $\mathrm{N}$-deacetylase and $\mathrm{N}$-sulfotransferase 1 \\
\hline KCNJ8 & 0.800647 & 0.000248 & 0.004871 & 3.664642 & Up & potassium inwardly rectifying channel subfamily $\mathrm{J}$ member 8 \\
\hline ATF6B & 0.795539 & $5.53 \mathrm{E}-06$ & 0.000322 & 4.543457 & Up & activating transcription factor 6 beta \\
\hline GAMT & 0.794851 & 0.000283 & 0.00535 & 3.630634 & Up & guanidinoacetate $\mathrm{N}$-methyltransferase \\
\hline DGCR2 & 0.792202 & 0.000263 & 0.005112 & 3.649418 & Up & DiGeorge syndrome critical region gene 2 \\
\hline ME2 & 0.792173 & 0.002342 & 0.02356 & 3.043104 & Up & malic enzyme 2 \\
\hline SNORA70F & 0.791991 & 0.001262 & 0.015252 & 3.22447 & Up & small nucleolar RNA, H/ACA box 70F \\
\hline TPI1 & 0.791213 & 0.000701 & 0.010178 & 3.389207 & Up & triosephosphateisomerase 1 \\
\hline JMJD8 & 0.790139 & $3.01 \mathrm{E}-05$ & 0.001068 & 4.172555 & Up & jumonji domain containing 8 \\
\hline NES & 0.788137 & $1.56 \mathrm{E}-05$ & 0.000667 & 4.320476 & Up & nestin \\
\hline CDC42EP3 & 0.787657 & 0.006527 & 0.047324 & 2.72008 & Up & CDC42 effector protein 3 \\
\hline SECISBP2L & 0.785942 & 0.002747 & 0.026216 & 2.994768 & Up & SECIS binding protein 2 like \\
\hline PRPF8 & 0.785467 & 4.09E-05 & 0.001317 & 4.102281 & Up & pre-mRNA processing factor 8 \\
\hline DNAJC4 & 0.784209 & $1.19 \mathrm{E}-06$ & 0.000101 & 4.856749 & Up & DnaJ heat shock protein family (Hsp40) member C4 \\
\hline EIF3B & 0.783198 & $4.65 \mathrm{E}-05$ & 0.001445 & 4.072672 & Up & eukaryotic translation initiation factor 3 subunit B \\
\hline EPHX1 & 0.78283 & 0.000166 & 0.003661 & 3.766555 & Up & epoxide hydrolase 1 \\
\hline WDTC1 & 0.782558 & $8.41 \mathrm{E}-06$ & 0.000434 & 4.454475 & Up & WD and tetratricopeptide repeats 1 \\
\hline MAML1 & 0.78192 & $2.54 \mathrm{E}-05$ & 0.000933 & 4.210975 & Up & mastermind like transcriptional coactivator 1 \\
\hline PCDHB4 & 0.779944 & 0.00151 & 0.01726 & 3.172676 & Up & protocadherin beta 4 \\
\hline CRNKL1 & 0.776112 & 0.001354 & 0.015976 & 3.204332 & Up & crooked neck pre-mRNA splicing factor 1 \\
\hline NFIB & 0.775622 & 0.005204 & 0.040705 & 2.794109 & Up & nuclear factor I B \\
\hline MAPK3 & 0.774729 & $6.63 \mathrm{E}-06$ & 0.000361 & 4.505204 & Up & mitogen-activated protein kinase 3 \\
\hline SLC23A2 & 0.771981 & 0.005612 & 0.042695 & 2.769626 & Up & solute carrier family 23 member 2 \\
\hline RPL18A & 0.771037 & 0.000204 & 0.004258 & 3.713912 & Up & ribosomal protein L18a \\
\hline FAM83B & 0.769782 & 0.000435 & 0.007223 & 3.51776 & Up & family with sequence similarity 83 member B \\
\hline CNDP2 & 0.768381 & 0.000586 & 0.008901 & 3.43821 & Up & carnosinedipeptidase 2 \\
\hline SERTAD2 & 0.768202 & $3.98 \mathrm{E}-05$ & 0.001293 & 4.108585 & Up & SERTA domain containing 2 \\
\hline
\end{tabular}




\begin{tabular}{|c|c|c|c|c|c|c|}
\hline RCE1 & 0.76665 & 0.000172 & 0.003741 & 3.757149 & $\mathrm{Up}$ & Ras converting CAAX endopeptidase 1 \\
\hline C2orf69 & 0.766464 & 8.05E-05 & 0.002142 & 3.942914 & Up & chromosome 2 open reading frame 69 \\
\hline FOXK1 & 0.764006 & 0.001585 & 0.0178 & 3.158636 & Up & forkhead box K1 \\
\hline ZNF646 & 0.763811 & 0.000536 & 0.00834 & 3.462129 & $\mathrm{Up}$ & zinc finger protein 646 \\
\hline CAMSAP3 & 0.762877 & $1.95 \mathrm{E}-05$ & 0.000779 & 4.271089 & Up & calmodulin regulated spectrin associated protein family member 3 \\
\hline ACVR2B & 0.761578 & $2.49 \mathrm{E}-05$ & 0.000919 & 4.215416 & Up & activin $\mathrm{A}$ receptor type $2 \mathrm{~B}$ \\
\hline ATXN7L1 & 0.761216 & 0.001983 & 0.020842 & 3.09281 & Up & ataxin 7 like 1 \\
\hline LRRC8B & 0.761015 & 0.000468 & 0.007577 & 3.49819 & Up & leucine rich repeat containing 8 VRAC subunit B \\
\hline PLOD3 & 0.760059 & $3.88 \mathrm{E}-05$ & 0.001266 & 4.114231 & Up & procollagen-lysine,2-oxoglutarate 5-dioxygenase 3 \\
\hline FAM193B & 0.758019 & $1.78 \mathrm{E}-05$ & 0.000726 & 4.291384 & Up & family with sequence similarity 193 member B \\
\hline ZFHX3 & 0.757752 & 0.001036 & 0.013414 & 3.280609 & $\mathrm{Up}$ & zinc finger homeobox 3 \\
\hline SMURF1 & 0.756591 & $1.06 \mathrm{E}-05$ & 0.000508 & 4.404419 & Up & SMAD specific E3 ubiquitin protein ligase 1 \\
\hline AOX1 & 0.756086 & 0.003594 & 0.031565 & 2.911801 & Up & aldehyde oxidase 1 \\
\hline RPS15 & 0.755554 & $6.99 \mathrm{E}-07$ & $6.59 \mathrm{E}-05$ & 4.961597 & Up & ribosomal protein S15 \\
\hline PRMT6 & 0.753247 & 0.001239 & 0.01511 & 3.22983 & Up & protein arginine methyltransferase 6 \\
\hline TRIM24 & 0.752928 & $1.16 \mathrm{E}-05$ & 0.000543 & 4.384086 & Up & tripartite motif containing 24 \\
\hline PRKCSH & 0.750891 & 0.000284 & 0.005365 & 3.629653 & Up & protein kinase $\mathrm{C}$ substrate $80 \mathrm{~K}-\mathrm{H}$ \\
\hline ETV6 & 0.75061 & $9.73 \mathrm{E}-07$ & $8.46 \mathrm{E}-05$ & 4.896989 & Up & ETS variant transcription factor 6 \\
\hline GSK3A & 0.7503 & 0.000194 & 0.004091 & 3.727348 & Up & glycogen synthase kinase 3 alpha \\
\hline WDR74 & 0.749277 & 0.000605 & 0.009092 & 3.429532 & Up & WD repeat domain 74 \\
\hline $\mathrm{KCNC} 4$ & 0.746517 & 0.002407 & 0.023989 & 3.03483 & Up & potassium voltage-gated channel subfamily $\mathrm{C}$ member 4 \\
\hline LARP6 & 0.745789 & 7.94E-05 & 0.002124 & 3.946332 & Up & La ribonucleoprotein 6 , translational regulator \\
\hline BCOR & 0.744144 & 0.00012 & 0.002934 & 3.845436 & Up & BCL6 corepressor \\
\hline PSD4 & 0.741924 & 0.005215 & 0.040726 & 2.793473 & Up & pleckstrin and Sec7 domain containing 4 \\
\hline URB1 & 0.74192 & $6.05 \mathrm{E}-05$ & 0.00174 & 4.01084 & Up & URB1 ribosome biogenesis homolog \\
\hline RAB4A & 0.740681 & 0.000763 & 0.010829 & 3.365815 & Up & RAB4A, member RAS oncogene family \\
\hline ZNF341 & 0.740369 & 0.002638 & 0.025544 & 3.007083 & Up & zinc finger protein 341 \\
\hline SGTA & 0.740279 & 0.000162 & 0.003593 & 3.77241 & $\mathrm{Up}$ & small glutamine rich tetratricopeptide repeat containing alpha \\
\hline STUB1 & 0.739139 & 0.000973 & 0.012833 & 3.298143 & Up & STIP1 homology and U-box containing protein 1 \\
\hline SLC35E1 & 0.736682 & $9.91 \mathrm{E}-09$ & $2.30 \mathrm{E}-06$ & 5.732304 & Up & solute carrier family 35 member E1 \\
\hline RSBN1 & 0.73582 & $4.22 \mathrm{E}-08$ & 7.07E-06 & 5.481284 & Up & round spermatid basic protein 1 \\
\hline NPAS2 & 0.732705 & $3.23 \mathrm{E}-05$ & 0.001126 & 4.156955 & Up & neuronal PAS domain protein 2 \\
\hline MAOA & 0.731781 & $4.31 \mathrm{E}-06$ & 0.000262 & 4.595946 & Up & monoamine oxidase $\mathrm{A}$ \\
\hline USP1 & 0.728983 & 0.003174 & 0.029017 & 2.950339 & Up & ubiquitin specific peptidase 1 \\
\hline RBM47 & 0.728968 & $1.56 \mathrm{E}-08$ & $3.21 \mathrm{E}-06$ & 5.654557 & Up & RNA binding motif protein 47 \\
\hline RNF43 & 0.728384 & 0.000997 & 0.013032 & 3.291369 & Up & ring finger protein 43 \\
\hline KIAA0930 & 0.728341 & $6.95 \mathrm{E}-05$ & 0.001924 & 3.977861 & Up & KIAA0930 \\
\hline SHISA5 & 0.72744 & 0.000573 & 0.008736 & 3.444214 & Up & shisa family member 5 \\
\hline TCOF1 & 0.727002 & 0.00054 & 0.008367 & 3.460175 & Up & treacle ribosome biogenesis factor 1 \\
\hline NCL & 0.725941 & 0.002185 & 0.022354 & 3.063829 & Up & nucleolin \\
\hline FKBP5 & 0.724631 & $7.85 \mathrm{E}-06$ & 0.000411 & 4.469326 & Up & FKBP prolylisomerase 5 \\
\hline RBM22 & 0.723796 & $3.19 \mathrm{E}-06$ & 0.000211 & 4.6585 & Up & RNA binding motif protein 22 \\
\hline SLC48A1 & 0.720957 & $2.30 \mathrm{E}-05$ & 0.000874 & 4.233151 & Up & solute carrier family 48 member 1 \\
\hline
\end{tabular}




\begin{tabular}{|c|c|c|c|c|c|c|}
\hline GNL1 & 0.720727 & 0.000309 & 0.005676 & 3.607864 & $\mathrm{Up}$ & G protein nucleolar 1 (putative) \\
\hline FOXP1 & 0.720205 & $1.58 \mathrm{E}-09$ & $5.04 \mathrm{E}-07$ & 6.036016 & $\mathrm{Up}$ & forkhead box P1 \\
\hline TRAPPC3 & 0.719608 & 0.000551 & 0.008489 & 3.45471 & Up & trafficking protein particle complex 3 \\
\hline METTL14 & 0.718111 & 0.000565 & 0.008669 & 3.447662 & Up & methyltransferase like 14 \\
\hline PIGM & 0.716435 & 0.000194 & 0.004091 & 3.727242 & Up & phosphatidylinositol glycan anchor biosynthesis class $\mathrm{M}$ \\
\hline MZT2B & 0.714175 & 0.001677 & 0.018471 & 3.142085 & Up & mitotic spindle organizing protein $2 \mathrm{~B}$ \\
\hline ATF7IP & 0.712488 & 4.27E-09 & $1.07 \mathrm{E}-06$ & 5.873211 & Up & activating transcription factor 7 interacting protein \\
\hline RWDD2B & 0.711793 & 0.000232 & 0.00466 & 3.681821 & Up & RWD domain containing $2 \mathrm{~B}$ \\
\hline POLR1D & 0.708737 & 0.005643 & 0.042875 & 2.767845 & Up & RNA polymerase I and III subunit D \\
\hline UBIAD1 & 0.706576 & $8.09 \mathrm{E}-06$ & 0.00042 & 4.46291 & Up & UbiAprenyltransferase domain containing 1 \\
\hline SFXN2 & 0.700426 & 0.001682 & 0.018509 & 3.141299 & Up & sideroflexin 2 \\
\hline FIGN & 0.699523 & $3.68 \mathrm{E}-05$ & 0.001226 & 4.126718 & Up & fidgetin, microtubule severing factor \\
\hline UBAP2 & 0.699319 & 3.77E-08 & $6.56 \mathrm{E}-06$ & 5.50114 & Up & ubiquitin associated protein 2 \\
\hline UBE2E2 & 0.699156 & $5.75 \mathrm{E}-05$ & 0.001693 & 4.022695 & Up & ubiquitin conjugating enzyme E2 E2 \\
\hline MX1 & 0.698814 & 0.003319 & 0.029859 & 2.936555 & Up & MX dynamin like GTPase 1 \\
\hline SPPL3 & 0.697852 & 0.000696 & 0.010145 & 3.390959 & Up & signal peptide peptidase like 3 \\
\hline KCTD11 & 0.697791 & $2.01 \mathrm{E}-05$ & 0.000792 & 4.263333 & Up & potassium channel tetramerization domain containing 11 \\
\hline HSP90AA1 & 0.696743 & 0.00019 & 0.00406 & 3.731557 & Up & heat shock protein 90 alpha family class A member 1 \\
\hline BTG1 & 0.694132 & 4.22E-06 & 0.000257 & 4.600208 & Up & BTG anti-proliferation factor 1 \\
\hline GALM & 0.693238 & 0.005154 & 0.040486 & 2.797233 & Up & galactosemutarotase \\
\hline GAB1 & 0.693194 & $1.58 \mathrm{E}-08$ & $3.21 \mathrm{E}-06$ & 5.652613 & Up & GRB2 associated binding protein 1 \\
\hline PXMP2 & 0.692523 & 0.001283 & 0.015424 & 3.21973 & Up & peroxisomal membrane protein 2 \\
\hline SCARNA17 & 0.691261 & $8.34 \mathrm{E}-06$ & 0.000432 & 4.456247 & Up & small Cajal body-specific RNA 17 \\
\hline S1PR1 & 0.691074 & $6.64 \mathrm{E}-05$ & 0.001855 & 3.988707 & Up & sphingosine-1-phosphate receptor 1 \\
\hline THRB & 0.691029 & 0.000885 & 0.011987 & 3.324668 & Up & thyroid hormone receptor beta \\
\hline RPL39 & 0.690209 & 0.005561 & 0.042488 & 2.77258 & Up & ribosomal protein L39 \\
\hline UTP14A & 0.6899 & 0.003424 & 0.030472 & 2.926834 & Up & UTP14A small subunit processome component \\
\hline EDNRB & 0.689734 & 0.000237 & 0.004752 & 3.6754 & Up & endothelin receptor type B \\
\hline CRTC3 & 0.689519 & $8.27 \mathrm{E}-05$ & 0.002191 & 3.936548 & Up & CREB regulated transcription coactivator 3 \\
\hline AK1 & 0.689426 & 0.001162 & 0.014574 & 3.248124 & Up & adenylate kinase 1 \\
\hline PTGER3 & 0.687494 & 0.001956 & 0.020638 & 3.09677 & Up & prostaglandin E receptor 3 \\
\hline SYBU & 0.687308 & 0.000239 & 0.004773 & 3.674039 & Up & syntabulin \\
\hline MED25 & 0.687197 & 0.002406 & 0.023989 & 3.034873 & Up & mediator complex subunit 25 \\
\hline ERP29 & 0.686161 & 0.000267 & 0.005139 & 3.645521 & Up & endoplasmic reticulum protein 29 \\
\hline RBM23 & 0.685812 & 0.000216 & 0.004436 & 3.699217 & Up & RNA binding motif protein 23 \\
\hline GPATCH4 & 0.684195 & 0.001189 & 0.014747 & 3.241437 & Up & G-patch domain containing 4 \\
\hline $\mathrm{CDNF}$ & 0.684189 & 0.001318 & 0.015708 & 3.212028 & Up & cerebral dopamine neurotrophic factor \\
\hline RNASEK & 0.683852 & 0.005382 & 0.041449 & 2.783259 & Up & ribonuclease $\mathrm{K}$ \\
\hline LPCAT3 & 0.683539 & 0.000328 & 0.005946 & 3.591945 & Up & lysophosphatidylcholineacyltransferase 3 \\
\hline CASC3 & 0.683245 & 0.000342 & 0.006117 & 3.581073 & Up & CASC3 exon junction complex subunit \\
\hline MTMR3 & 0.682235 & 0.000873 & 0.01186 & 3.328634 & Up & myotubularin related protein 3 \\
\hline TNKS & 0.681959 & 0.000955 & 0.012674 & 3.303437 & $\mathrm{Up}$ & tankyrase \\
\hline SF3A1 & 0.681792 & 0.000107 & 0.002666 & 3.87484 & $\mathrm{Up}$ & splicing factor 3 a subunit 1 \\
\hline
\end{tabular}




\begin{tabular}{|c|c|c|c|c|c|c|}
\hline CHID1 & 0.681692 & $2.35 \mathrm{E}-05$ & 0.000888 & 4.228751 & Up & chitinase domain containing 1 \\
\hline AGPAT3 & 0.679929 & 4.02E-06 & 0.000249 & 4.610538 & Up & 1-acylglycerol-3-phosphate O-acyltransferase 3 \\
\hline ADPRHL1 & 0.67793 & 0.003299 & 0.029823 & 2.93839 & Up & ADP-ribosylhydrolase like 1 \\
\hline MEX3C & 0.676707 & $1.74 \mathrm{E}-07$ & $2.28 \mathrm{E}-05$ & 5.225485 & Up & mex-3 RNA binding family member $\mathrm{C}$ \\
\hline SIAH2 & 0.676628 & 4.59E-05 & 0.001437 & 4.075423 & $\mathrm{Up}$ & siah E3 ubiquitin protein ligase 2 \\
\hline ACD & 0.674822 & 0.000397 & 0.006739 & 3.541993 & Up & ACD shelterin complex subunit and telomerase recruitment factor \\
\hline NFKBIA & 0.671989 & $2.49 \mathrm{E}-09$ & 7.07E-07 & 5.961923 & Up & NFKB inhibitor alpha \\
\hline CDC42EP4 & 0.670577 & $3.53 \mathrm{E}-05$ & 0.001193 & 4.136046 & Up & CDC42 effector protein 4 \\
\hline ARHGAP17 & 0.670458 & 0.000353 & 0.006238 & 3.572609 & Up & Rho GTPase activating protein 17 \\
\hline GJA1 & 0.669532 & 0.000191 & 0.004071 & 3.730543 & Up & gap junction protein alpha 1 \\
\hline RNPS1 & 0.669286 & 0.000469 & 0.007577 & 3.498063 & Up & RNA binding protein with serine rich domain 1 \\
\hline ATP13A2 & 0.668974 & 0.001969 & 0.020738 & 3.094808 & Up & ATPase cation transporting $13 \mathrm{~A} 2$ \\
\hline ZSWIM3 & 0.666665 & 0.005783 & 0.043574 & 2.759838 & Up & zinc finger SWIM-type containing 3 \\
\hline TXNDC5 & 0.666561 & $6.22 \mathrm{E}-05$ & 0.001775 & 4.004346 & Up & thioredoxin domain containing 5 \\
\hline PPFIBP2 & 0.66328 & 0.00471 & 0.038127 & 2.826221 & Up & PPFIA binding protein 2 \\
\hline MRPL49 & 0.661083 & $4.76 \mathrm{E}-05$ & 0.001473 & 4.066891 & Up & mitochondrial ribosomal protein L49 \\
\hline SLC35C2 & 0.660269 & 0.002623 & 0.025458 & 3.008774 & Up & solute carrier family 35 member $\mathrm{C} 2$ \\
\hline CD34 & 0.656903 & 0.001941 & 0.020527 & 3.099122 & Up & CD34 molecule \\
\hline SQSTM1 & 0.656832 & 0.000903 & 0.012146 & 3.319117 & Up & sequestosome 1 \\
\hline DEAF1 & 0.656044 & 0.000482 & 0.007723 & 3.490807 & Up & DEAF1 transcription factor \\
\hline CPNE8 & 0.655935 & 0.006745 & 0.048175 & 2.709168 & Up & copine 8 \\
\hline INSR & 0.655878 & 0.001522 & 0.017355 & 3.170368 & Up & insulin receptor \\
\hline RPL19 & 0.655743 & 0.0001 & 0.002543 & 3.889412 & Up & ribosomal protein L19 \\
\hline NR1D2 & 0.655727 & 0.001279 & 0.015407 & 3.220621 & Up & nuclear receptor subfamily 1 group D member 2 \\
\hline SLC25A43 & 0.655559 & 0.000873 & 0.01186 & 3.32843 & Up & solute carrier family 25 member 43 \\
\hline AGBL5 & 0.654572 & 0.003824 & 0.032915 & 2.892293 & Up & ATP/GTP binding protein like 5 \\
\hline SLC39A4 & 0.653952 & 0.005292 & 0.041019 & 2.788697 & Up & solute carrier family 39 member 4 \\
\hline SP2 & 0.652169 & 0.002758 & 0.026271 & 2.993532 & Up & $\mathrm{Sp} 2$ transcription factor \\
\hline SLC2A4RG & 0.65117 & 0.00165 & 0.018241 & 3.146991 & Up & SLC2A4 regulator \\
\hline YIPF3 & 0.650173 & $3.26 \mathrm{E}-05$ & 0.001131 & 4.15422 & Up & Yip1 domain family member 3 \\
\hline MRPS18B & 0.649811 & $7.15 \mathrm{E}-06$ & 0.000383 & 4.489106 & Up & mitochondrial ribosomal protein S18B \\
\hline NEDD9 & 0.648825 & 0.000492 & 0.007837 & 3.485031 & Up & neural precursor cell expressed, developmentally down-regulated 9 \\
\hline GADD45G & 0.648736 & 0.006811 & 0.048569 & 2.705943 & Up & growth arrest and DNA damage inducible gamma \\
\hline ZNRF3 & 0.648723 & 0.001296 & 0.015533 & 3.216764 & Up & zinc and ring finger 3 \\
\hline MAST3 & 0.648387 & 0.001533 & 0.017433 & 3.168306 & Up & microtubule associated serine/threonine kinase 3 \\
\hline SNX12 & 0.648357 & 0.001185 & 0.014729 & 3.242554 & Up & sorting nexin 12 \\
\hline TMED5 & 0.647804 & $4.52 \mathrm{E}-05$ & 0.001421 & 4.079333 & Up & transmembrane p24 trafficking protein 5 \\
\hline BAZ2A & 0.647031 & 0.000218 & 0.004449 & 3.69755 & Up & bromodomain adjacent to zinc finger domain $2 \mathrm{~A}$ \\
\hline CCDC86 & 0.646936 & 0.000592 & 0.008966 & 3.435136 & Up & coiled-coil domain containing 86 \\
\hline MBOAT7 & 0.644983 & 0.005086 & 0.040095 & 2.801514 & Up & membrane bound $\mathrm{O}$-acyltransferase domain containing 7 \\
\hline GID8 & 0.644926 & 0.00015 & 0.003436 & 3.790262 & Up & GID complex subunit 8 homolog \\
\hline DCPS & 0.642919 & 0.002036 & 0.021241 & 3.084943 & Up & decapping enzyme, scavenger \\
\hline LIG3 & 0.642442 & $5.43 \mathrm{E}-05$ & 0.001633 & 4.036185 & Up & DNA ligase 3 \\
\hline
\end{tabular}




\begin{tabular}{|c|c|c|c|c|c|c|}
\hline BSG & 0.641779 & 0.001141 & 0.014369 & 3.253151 & Up & basigin (Ok blood group) \\
\hline SP4 & 0.640664 & 0.000992 & 0.012988 & 3.292727 & Up & Sp4 transcription factor \\
\hline KLF11 & 0.63968 & $1.52 \mathrm{E}-05$ & 0.000659 & 4.325257 & $\mathrm{Up}$ & Kruppel like factor 11 \\
\hline CIZ1 & 0.63856 & $1.87 \mathrm{E}-05$ & 0.000756 & 4.279502 & Up & CDKN1A interacting zinc finger protein 1 \\
\hline LNX1 & 0.636517 & $1.47 \mathrm{E}-05$ & 0.000641 & 4.333615 & Up & ligand of numb-protein X 1 \\
\hline RALB & 0.63579 & 3.37E-06 & 0.000219 & 4.646621 & Up & RAS like proto-oncogene B \\
\hline BTF3 & 0.632977 & 0.000199 & 0.004195 & 3.720016 & Up & basic transcription factor 3 \\
\hline ZNF836 & 0.632392 & 0.002077 & 0.021526 & 3.078926 & Up & zinc finger protein 836 \\
\hline NET1 & 0.631653 & 0.005749 & 0.043387 & 2.761785 & Up & neuroepithelial cell transforming 1 \\
\hline IAPP & -10.801 & $2.63 \mathrm{E}-45$ & $2.38 \mathrm{E}-41$ & -14.126 & Down & islet amyloid polypeptide \\
\hline INS & -10.3513 & $7.60 \mathrm{E}-52$ & $1.37 \mathrm{E}-47$ & -15.1498 & Down & insulin \\
\hline HAPLN4 & -6.9522 & $3.78 \mathrm{E}-09$ & $1.00 \mathrm{E}-06$ & -5.89366 & Down & hyaluronan and proteoglycan link protein 4 \\
\hline ADCYAP1 & -6.37952 & $7.01 \mathrm{E}-16$ & $1.81 \mathrm{E}-12$ & -8.07029 & Down & adenylatecyclase activating polypeptide 1 \\
\hline CSNK1G1 & -6.37349 & $5.07 \mathrm{E}-14$ & $8.34 \mathrm{E}-11$ & -7.53001 & Down & casein kinase 1 gamma 1 \\
\hline MAFA & -6.08612 & $2.10 \mathrm{E}-12$ & $1.90 \mathrm{E}-09$ & -7.02742 & Down & MAF bZIP transcription factor A \\
\hline IGLL5 & -5.95682 & 0.00111 & 0.014081 & -3.26108 & Down & immunoglobulin lambda like polypeptide 5 \\
\hline WSCD2 & -5.89111 & $1.55 \mathrm{E}-09$ & $5.04 \mathrm{E}-07$ & -6.03927 & Down & WSC domain containing 2 \\
\hline $\mathrm{PLCH} 2$ & -5.70065 & $1.54 \mathrm{E}-15$ & $3.49 \mathrm{E}-12$ & -7.9734 & Down & phospholipase $\mathrm{C}$ eta 2 \\
\hline SLCO1A2 & -5.65472 & $9.18 \mathrm{E}-05$ & 0.002377 & -3.9112 & Down & solute carrier organic anion transporter family member $1 \mathrm{~A} 2$ \\
\hline HHATL & -5.54001 & $4.92 \mathrm{E}-11$ & $3.23 \mathrm{E}-08$ & -6.57335 & Down & hedgehog acyltransferase like \\
\hline DMBT1 & -5.11154 & 0.000502 & 0.007945 & -3.47993 & Down & deleted in malignant brain tumors 1 \\
\hline RGS16 & -4.81121 & $1.53 \mathrm{E}-18$ & $9.23 \mathrm{E}-15$ & -8.78743 & Down & regulator of $\mathrm{G}$ protein signaling 16 \\
\hline PREX1 & -4.79312 & $5.00 \mathrm{E}-11$ & $3.23 \mathrm{E}-08$ & -6.57103 & Down & phosphatidylinositol-3,4,5-trisphosphate dependent Rac exchange factor 1 \\
\hline SYT16 & -4.64825 & $1.25 \mathrm{E}-08$ & $2.80 \mathrm{E}-06$ & -5.69211 & Down & synaptotagmin 16 \\
\hline ASB9 & -4.60995 & $1.08 \mathrm{E}-17$ & $3.26 \mathrm{E}-14$ & -8.56492 & Down & ankyrin repeat and SOCS box containing 9 \\
\hline LRFN2 & -4.54487 & $1.77 \mathrm{E}-05$ & 0.000726 & -4.29175 & Down & leucine rich repeat and fibronectin type III domain containing 2 \\
\hline NRG3 & -4.53264 & $3.24 \mathrm{E}-05$ & 0.001126 & -4.15624 & Down & neuregulin 3 \\
\hline HSD17B13 & -4.51785 & $1.90 \mathrm{E}-09$ & $5.93 \mathrm{E}-07$ & -6.00595 & Down & hydroxysteroid 17-beta dehydrogenase 13 \\
\hline DLK1 & -4.43907 & $2.20 \mathrm{E}-12$ & $1.90 \mathrm{E}-09$ & -7.02104 & Down & delta like non-canonical Notch ligand 1 \\
\hline LOC100286922 & -4.09518 & 0.00035 & 0.00622 & -3.57543 & Down & DnaJ heat shock protein family (Hsp40) member B3 pseudogene \\
\hline LRRTM3 & -4.05763 & $3.63 \mathrm{E}-06$ & 0.00023 & -4.63163 & Down & leucine rich repeat transmembrane neuronal 3 \\
\hline GABRA2 & -3.9965 & $1.21 \mathrm{E}-06$ & 0.000101 & -4.85468 & Down & gamma-aminobutyric acid type A receptor subunit alpha2 \\
\hline GTSF1 & -3.96587 & $8.59 \mathrm{E}-06$ & 0.00044 & -4.44996 & Down & gametocyte specific factor 1 \\
\hline NTNG2 & -3.89902 & $1.78 \mathrm{E}-07$ & $2.30 \mathrm{E}-05$ & -5.22131 & Down & netrin G2 \\
\hline GLRA1 & -3.83003 & 4.47E-05 & 0.001413 & -4.08161 & Down & glycine receptor alpha 1 \\
\hline DGKG & -3.7646 & $8.17 \mathrm{E}-13$ & $9.53 \mathrm{E}-10$ & -7.15833 & Down & diacylglycerol kinase gamma \\
\hline ISX & -3.75152 & 0.001191 & 0.014761 & -3.24097 & Down & intestine specific homeobox \\
\hline OR10J3 & -3.70449 & $1.79 \mathrm{E}-06$ & 0.000139 & -4.77542 & Down & olfactory receptor family 10 subfamily $\mathrm{J}$ member 3 \\
\hline SLC6A17 & -3.70444 & $1.83 \mathrm{E}-05$ & 0.00074 & -4.28474 & Down & solute carrier family 6 member 17 \\
\hline $\mathrm{DACH} 2$ & -3.67639 & $4.10 \mathrm{E}-08$ & $6.95 \mathrm{E}-06$ & -5.48656 & Down & dachshund family transcription factor 2 \\
\hline VPREB1 & -3.6609 & 0.001658 & 0.018315 & -3.14545 & Down & V-set pre-B cell surrogate light chain 1 \\
\hline RXRG & -3.64353 & $3.01 \mathrm{E}-06$ & 0.000204 & -4.67042 & Down & retinoid $\mathrm{X}$ receptor gamma \\
\hline IFNA16 & -3.63676 & 0.00089 & 0.012039 & -3.32325 & Down & interferon alpha 16 \\
\hline
\end{tabular}




\begin{tabular}{|c|c|c|c|c|c|c|}
\hline G6PC2 & -3.62269 & $3.42 \mathrm{E}-06$ & 0.00022 & -4.64385 & Down & glucose-6-phosphatase catalytic subunit 2 \\
\hline OR4F5 & -3.59416 & 0.001252 & 0.015226 & -3.22678 & Down & olfactory receptor family 4 subfamily $\mathrm{F}$ member 5 \\
\hline SLC18A2 & -3.57954 & $7.56 \mathrm{E}-09$ & $1.80 \mathrm{E}-06$ & -5.77806 & Down & solute carrier family 18 member $\mathrm{A} 2$ \\
\hline BIRC8 & -3.56786 & $5.34 \mathrm{E}-05$ & 0.001609 & -4.04035 & Down & baculoviral IAP repeat containing 8 \\
\hline KLHL1 & -3.55633 & $6.13 \mathrm{E}-05$ & 0.001753 & -4.00789 & Down & kelch like family member 1 \\
\hline SLC26A9 & -3.53742 & 0.000256 & 0.005002 & -3.65613 & Down & solute carrier family 26 member 9 \\
\hline OR6C74 & -3.52371 & 0.000373 & 0.006457 & -3.55827 & Down & olfactory receptor family 6 subfamily $\mathrm{C}$ member 74 \\
\hline DKK4 & -3.51465 & $3.70 \mathrm{E}-05$ & 0.001229 & -4.12522 & Down & dickkopf WNT signaling pathway inhibitor 4 \\
\hline UNC5A & -3.5005 & $3.25 \mathrm{E}-06$ & 0.000214 & -4.65467 & Down & unc-5 netrin receptor A \\
\hline OR5L1 & -3.49176 & 0.000203 & 0.004248 & -3.71483 & Down & olfactory receptor family 5 subfamily L member 1 \\
\hline LOC154761 & -3.48046 & $1.69 \mathrm{E}-05$ & 0.000707 & -4.30203 & Down & family with sequence similarity 115 , member $\mathrm{C}$ pseudogene \\
\hline OR4D2 & -3.47937 & 0.001687 & 0.018539 & -3.14047 & Down & olfactory receptor family 4 subfamily D member 2 \\
\hline KCNG3 & -3.45067 & $5.90 \mathrm{E}-07$ & $5.87 \mathrm{E}-05$ & -4.99431 & Down & potassium voltage-gated channel modifier subfamily $\mathrm{G}$ member 3 \\
\hline ARHGEF35 & -3.42973 & 0.00378 & 0.032645 & -2.89592 & Down & Rho guanine nucleotide exchange factor 35 \\
\hline SLC27A6 & -3.42698 & 0.00025 & 0.004903 & -3.66238 & Down & solute carrier family 27 member 6 \\
\hline OR2T33 & -3.40998 & 0.000418 & 0.007022 & -3.52868 & Down & olfactory receptor family 2 subfamily $\mathrm{T}$ member 33 \\
\hline KIF4B & -3.39216 & 0.000503 & 0.00795 & -3.47931 & Down & kinesin family member $4 \mathrm{~B}$ \\
\hline CLDN25 & -3.35937 & 0.000658 & 0.009732 & -3.40632 & Down & claudin 25 \\
\hline OR2T6 & -3.33501 & 0.000203 & 0.004248 & -3.71558 & Down & olfactory receptor family 2 subfamily T member 6 \\
\hline EBLN1 & -3.32606 & 0.000711 & 0.010271 & -3.38516 & Down & endogenous Bornavirus like nucleoprotein 1 \\
\hline TKTL2 & -3.32283 & 0.000899 & 0.012131 & -3.32029 & Down & transketolase like 2 \\
\hline ST8SIA5 & -3.29995 & $9.50 \mathrm{E}-05$ & 0.002441 & -3.90304 & Down & ST8 alpha-N-acetyl-neuraminide alpha-2,8-sialyltransferase 5 \\
\hline ADAM30 & -3.29013 & 0.003501 & 0.030982 & -2.91998 & Down & ADAM metallopeptidase domain 30 \\
\hline CDHR1 & -3.24111 & 0.000721 & 0.010362 & -3.38165 & Down & cadherin related family member 1 \\
\hline GJA10 & -3.22733 & 0.000173 & 0.003765 & -3.75491 & Down & gap junction protein alpha 10 \\
\hline CYP3A43 & -3.20066 & $3.99 \mathrm{E}-05$ & 0.001294 & -4.10804 & Down & cytochrome P450 family 3 subfamily A member 43 \\
\hline BMP5 & -3.18774 & 4.18E-06 & 0.000255 & -4.60225 & Down & bone morphogenetic protein 5 \\
\hline PRUNE2 & -3.17519 & $1.38 \mathrm{E}-09$ & 4.71E-07 & -6.05767 & Down & prune homolog 2 with $\mathrm{BCH}$ domain \\
\hline LINC00602 & -3.17107 & 0.000318 & 0.005801 & -3.60012 & Down & long intergenic non-protein coding RNA 602 \\
\hline RASD1 & -3.16012 & $1.06 \mathrm{E}-09$ & $3.74 \mathrm{E}-07$ & -6.10078 & Down & ras related dexamethasone induced 1 \\
\hline TAAR9 & -3.13989 & 0.003702 & 0.032231 & -2.90248 & Down & trace amine associated receptor 9 \\
\hline OR8H2 & -3.12734 & 0.000427 & 0.007125 & -3.5231 & Down & olfactory receptor family 8 subfamily $\mathrm{H}$ member 2 \\
\hline INSRR & -3.11972 & 0.005572 & 0.042533 & -2.77196 & Down & insulin receptor related receptor \\
\hline POSTN & -3.11052 & $1.26 \mathrm{E}-07$ & $1.75 \mathrm{E}-05$ & -5.28454 & Down & periostin \\
\hline OR4N2 & -3.09015 & 0.00604 & 0.044854 & -2.74562 & Down & olfactory receptor family 4 subfamily $\mathrm{N}$ member 2 \\
\hline CASQ2 & -3.08655 & 0.001058 & 0.013583 & -3.27466 & Down & calsequestrin 2 \\
\hline LOC441204 & -3.08411 & 7.24E-05 & 0.001987 & -3.96836 & Down & uncharacterized LOC441204 \\
\hline OR2A25 & -3.08173 & 0.000264 & 0.005116 & -3.64842 & Down & olfactory receptor family 2 subfamily A member 25 \\
\hline OR5E1P & -3.0489 & 0.001755 & 0.019094 & -3.12882 & Down & olfactory receptor family 5 subfamily E member 1 pseudogene \\
\hline LY6G6E & -3.04857 & 0.001493 & 0.017122 & -3.17595 & Down & lymphocyte antigen 6 family member G6E \\
\hline SSTR5-AS1 & -3.0425 & $8.27 \mathrm{E}-07$ & 7.44E-05 & -4.92887 & Down & SSTR5 antisense RNA 1 \\
\hline CYP24A1 & -3.03607 & 0.002253 & 0.022897 & -3.0547 & Down & cytochrome P450 family 24 subfamily A member 1 \\
\hline TAS2R7 & -3.02863 & 0.000145 & 0.003362 & -3.79889 & Down & taste 2 receptor member 7 \\
\hline
\end{tabular}




\begin{tabular}{|c|c|c|c|c|c|c|}
\hline SLC8A1-AS1 & -3.02422 & 0.000815 & 0.011262 & -3.34768 & Down & SLC8A1 antisense RNA 1 \\
\hline ZNF385D & -3.02118 & $7.51 \mathrm{E}-07$ & $6.88 \mathrm{E}-05$ & -4.94777 & Down & zinc finger protein $385 \mathrm{D}$ \\
\hline LINC00460 & -3.01407 & 0.001244 & 0.015147 & -3.22856 & Down & long intergenic non-protein coding RNA 460 \\
\hline KIF20A & -3.01006 & 0.000681 & 0.009971 & -3.39723 & Down & kinesin family member $20 \mathrm{~A}$ \\
\hline HLA-DQA1 & -3.00395 & $1.85 \mathrm{E}-08$ & 3.64E-06 & -5.6257 & Down & major histocompatibility complex, class II, DQ alpha 1 \\
\hline ASB5 & -3.00067 & 0.000216 & 0.004436 & -3.69951 & Down & ankyrin repeat and SOCS box containing 5 \\
\hline OR1E2 & -2.99957 & 0.001083 & 0.013816 & -3.26804 & Down & olfactory receptor family 1 subfamily E member 2 \\
\hline TNFAIP8 & -2.99257 & $8.45 \mathrm{E}-15$ & $1.70 \mathrm{E}-11$ & -7.7607 & Down & TNF alpha induced protein 8 \\
\hline OR2B3 & -2.98546 & 0.000293 & 0.005479 & -3.62108 & Down & olfactory receptor family 2 subfamily B member 3 \\
\hline SLC45A3 & -2.97833 & 4.34E-05 & 0.001375 & -4.08865 & Down & solute carrier family 45 member 3 \\
\hline IFNA10 & -2.97627 & 0.000425 & 0.007112 & -3.52402 & Down & interferon alpha 10 \\
\hline VWA5B1 & -2.95932 & 0.001384 & 0.016227 & -3.19796 & Down & von Willebrand factor A domain containing 5B1 \\
\hline USP26 & -2.95706 & 0.002713 & 0.026028 & -2.99855 & Down & ubiquitin specific peptidase 26 \\
\hline TM6SF2 & -2.95528 & $2.99 \mathrm{E}-08$ & 5.40E-06 & -5.54201 & Down & transmembrane 6 superfamily member 2 \\
\hline PPM1E & -2.94698 & $8.01 \mathrm{E}-06$ & 0.000417 & -4.46499 & Down & protein phosphatase, $\mathrm{Mg} 2+/ \mathrm{Mn} 2+$ dependent $1 \mathrm{E}$ \\
\hline FOXM1 & -2.94119 & 0.003185 & 0.029075 & -2.94926 & Down & forkhead box M1 \\
\hline TPX2 & -2.93595 & 0.000949 & 0.012618 & -3.30526 & Down & TPX2 microtubule nucleation factor \\
\hline LRRC10 & -2.93393 & 0.002164 & 0.022223 & -3.06669 & Down & leucine rich repeat containing 10 \\
\hline GREM2 & -2.92963 & 0.002908 & 0.027299 & -2.97732 & Down & gremlin 2, DAN family BMP antagonist \\
\hline OR6N1 & -2.92321 & 0.00263 & 0.025499 & -3.00796 & Down & olfactory receptor family 6 subfamily $\mathrm{N}$ member 1 \\
\hline EIF3IP1 & -2.92189 & 0.003394 & 0.030322 & -2.92956 & Down & eukaryotic translation initiation factor 3 subunit I pseudogene 1 \\
\hline CAPN8 & -2.91404 & 0.000476 & 0.007661 & -3.49417 & Down & calpain 8 \\
\hline GOLGA8CP & -2.90644 & 0.006607 & 0.047649 & -2.71601 & Down & golgin A8 family member $\mathrm{C}$, pseudogene \\
\hline TFF3 & -2.89791 & $8.85 \mathrm{E}-06$ & 0.000445 & -4.44363 & Down & trefoil factor 3 \\
\hline OR4K5 & -2.89759 & 0.000785 & 0.011002 & -3.35799 & Down & olfactory receptor family 4 subfamily $\mathrm{K}$ member 5 \\
\hline HOPX & -2.89043 & $5.18 \mathrm{E}-06$ & 0.000306 & -4.55731 & Down & HOP homeobox \\
\hline MTRNR2L5 & -2.88837 & 0.000627 & 0.009365 & -3.41948 & Down & MT-RNR2 like 5 \\
\hline COMP & -2.88387 & $9.00 \mathrm{E}-07$ & 7.98E-05 & -4.9123 & Down & cartilage oligomeric matrix protein \\
\hline OR4A5 & -2.88266 & 0.000521 & 0.008166 & -3.46976 & Down & olfactory receptor family 4 subfamily A member 5 \\
\hline SULT1C2P1 & -2.87268 & 0.000168 & 0.003688 & -3.76253 & Down & sulfotransferase family $1 \mathrm{C}$ member 2 pseudogene 1 \\
\hline OR5AN1 & -2.86497 & 0.005374 & 0.041436 & -2.78374 & Down & olfactory receptor family 5 subfamily AN member 1 \\
\hline KRTAP1-3 & -2.86473 & 0.002933 & 0.027411 & -2.97471 & Down & keratin associated protein $1-3$ \\
\hline OR5AS1 & -2.8631 & 0.00075 & 0.010703 & -3.37055 & Down & olfactory receptor family 5 subfamily AS member 1 \\
\hline GABRR2 & -2.85852 & 0.001493 & 0.017122 & -3.17608 & Down & gamma-aminobutyric acid type A receptor subunit rho2 \\
\hline OR13G1 & -2.85436 & 0.005275 & 0.040973 & -2.78976 & Down & olfactory receptor family 13 subfamily G member 1 \\
\hline OR2M5 & -2.8505 & 0.001514 & 0.017284 & -3.17193 & Down & olfactory receptor family 2 subfamily M member 5 \\
\hline HTR3A & -2.82474 & 0.000642 & 0.009519 & -3.41324 & Down & 5-hydroxytryptamine receptor $3 \mathrm{~A}$ \\
\hline KRTAP13-3 & -2.82267 & 0.002954 & 0.027543 & -2.97253 & Down & keratin associated protein $13-3$ \\
\hline OR13C5 & -2.82057 & $7.98 \mathrm{E}-05$ & 0.00213 & -3.9449 & Down & olfactory receptor family 13 subfamily $\mathrm{C}$ member 5 \\
\hline OR4C3 & -2.80788 & 0.005491 & 0.042035 & -2.77675 & Down & olfactory receptor family 4 subfamily $\mathrm{C}$ member 3 \\
\hline PPIEL & -2.78532 & 4.64E-05 & 0.001444 & -4.07319 & Down & peptidylprolylisomerase E like pseudogene \\
\hline ASB 11 & -2.78468 & 0.000245 & 0.004837 & -3.66753 & Down & ankyrin repeat and SOCS box containing 11 \\
\hline CHST8 & -2.78461 & $1.89 \mathrm{E}-05$ & 0.00076 & -4.27789 & Down & carbohydrate sulfotransferase 8 \\
\hline
\end{tabular}




\begin{tabular}{|c|c|c|c|c|c|c|}
\hline GOLGA6L1 & -2.7816 & 0.000171 & 0.003726 & -3.75848 & Down & golgin A6 family like 1 \\
\hline MAS1 & -2.77551 & 0.00044 & 0.007269 & -3.51512 & Down & MAS1 proto-oncogene, G protein-coupled receptor \\
\hline OR52L1 & -2.76744 & $8.16 \mathrm{E}-05$ & 0.002168 & -3.93961 & Down & olfactory receptor family 52 subfamily L member 1 \\
\hline PBK & -2.76743 & 0.000196 & 0.004138 & -3.72403 & Down & PDZ binding kinase \\
\hline ANXA2P3 & -2.76623 & 0.001772 & 0.019268 & -3.12596 & Down & annexin A2 pseudogene 3 \\
\hline KRTAP4-2 & -2.7586 & 0.001037 & 0.013422 & -3.28017 & Down & keratin associated protein $4-2$ \\
\hline OR8K1 & -2.75811 & 0.002112 & 0.021778 & -3.07408 & Down & olfactory receptor family 8 subfamily K member 1 \\
\hline TCN1 & -2.75785 & 0.002731 & 0.026128 & -2.99649 & Down & transcobalamin 1 \\
\hline KIRREL3 & -2.75601 & 0.000505 & 0.007982 & -3.47799 & Down & kirre like nephrin family adhesion molecule 3 \\
\hline OR6B2 & -2.7546 & 0.003595 & 0.031565 & -2.91164 & Down & olfactory receptor family 6 subfamily B member 2 \\
\hline KRTAP19-1 & -2.738 & 0.000419 & 0.007044 & -3.52758 & Down & keratin associated protein $19-1$ \\
\hline KRTAP3-1 & -2.73476 & 0.006721 & 0.048118 & -2.71035 & Down & keratin associated protein $3-1$ \\
\hline SLCO5A1 & -2.7339 & 0.000151 & 0.003436 & -3.78966 & Down & solute carrier organic anion transporter family member $5 \mathrm{~A} 1$ \\
\hline IFNA1 & -2.71621 & 0.003812 & 0.032859 & -2.89328 & Down & interferon alpha 1 \\
\hline KRTAP3-2 & -2.71406 & 0.003974 & 0.033866 & -2.8802 & Down & keratin associated protein $3-2$ \\
\hline VENTXP7 & -2.70781 & 0.000793 & 0.011058 & -3.35508 & Down & VENT homeoboxpseudogene 7 \\
\hline LOC341056 & -2.70401 & 0.004623 & 0.037645 & -2.83218 & Down & SUMO1 activating enzyme subunit 1 pseudogene \\
\hline KRTAP9-9 & -2.69101 & 0.005252 & 0.040848 & -2.79118 & Down & keratin associated protein $9-9$ \\
\hline OR56A4 & -2.68936 & 0.002123 & 0.021887 & -3.07243 & Down & olfactory receptor family 56 subfamily A member 4 \\
\hline FAM111B & -2.68489 & 0.000288 & 0.005416 & -3.62612 & Down & family with sequence similarity 111 member B \\
\hline PSMA6 & -2.68174 & $3.99 \mathrm{E}-18$ & $1.80 \mathrm{E}-14$ & -8.67908 & Down & proteasome 20 S subunit alpha 6 \\
\hline DLGAP5 & -2.68048 & 0.001477 & 0.017037 & -3.17907 & Down & DLG associated protein 5 \\
\hline PFKFB2 & -2.67874 & $2.19 \mathrm{E}-10$ & $9.91 \mathrm{E}-08$ & -6.34724 & Down & 6-phosphofructo-2-kinase/fructose-2,6-biphosphatase 2 \\
\hline OR5B17 & -2.67817 & 0.00413 & 0.034912 & -2.86807 & Down & olfactory receptor family 5 subfamily B member 17 \\
\hline LOC100287036 & -2.66753 & 0.003578 & 0.031512 & -2.91317 & Down & uncharacterized LOC100287036 \\
\hline PCDH7 & -2.66116 & $6.16 \mathrm{E}-07$ & $6.09 \mathrm{E}-05$ & -4.98602 & Down & protocadherin 7 \\
\hline MND1 & -2.65071 & $2.22 \mathrm{E}-08$ & 4.27E-06 & -5.59402 & Down & meiotic nuclear divisions 1 \\
\hline RCAN2 & -2.60302 & 0.001595 & 0.01787 & -3.15677 & Down & regulator of calcineurin 2 \\
\hline TMEM108 & -2.59295 & $5.48 \mathrm{E}-05$ & 0.001641 & -4.03417 & Down & transmembrane protein 108 \\
\hline OR51A2 & -2.58736 & 0.004723 & 0.038181 & -2.82532 & Down & olfactory receptor family 51 subfamily A member 2 \\
\hline P2RX5 & -2.58657 & 0.000125 & 0.003005 & -3.8356 & Down & purinergic receptor $\mathrm{P} 2 \mathrm{X} 5$ \\
\hline SLC22A9 & -2.58464 & 0.00124 & 0.01511 & -3.22949 & Down & solute carrier family 22 member 9 \\
\hline OR5T1 & -2.57736 & 0.003632 & 0.031742 & -2.90848 & Down & olfactory receptor family 5 subfamily T member 1 \\
\hline OR1A1 & -2.57723 & 0.002728 & 0.026111 & -2.99685 & Down & olfactory receptor family 1 subfamily A member 1 \\
\hline OR13C8 & -2.57325 & 0.001945 & 0.020542 & -3.09849 & Down & olfactory receptor family 13 subfamily $\mathrm{C}$ member 8 \\
\hline OR13C2 & -2.57298 & 0.005077 & 0.040061 & -2.80213 & Down & olfactory receptor family 13 subfamily $\mathrm{C}$ member 2 \\
\hline GAP43 & -2.57224 & 0.001777 & 0.019296 & -3.12518 & Down & growth associated protein 43 \\
\hline MFAP5 & -2.56407 & 0.000759 & 0.010785 & -3.36736 & Down & microfibril associated protein 5 \\
\hline SGPP2 & -2.55582 & $2.11 \mathrm{E}-05$ & 0.00082 & -4.25256 & Down & sphingosine-1-phosphate phosphatase 2 \\
\hline ADAMTSL1 & -2.55426 & $1.36 \mathrm{E}-07$ & $1.87 \mathrm{E}-05$ & -5.27081 & Down & ADAMTS like 1 \\
\hline OR2L1P & -2.55171 & 0.000488 & 0.007806 & -3.48701 & Down & olfactory receptor family 2 subfamily $L$ member 1 pseudogene \\
\hline TPD52L3 & -2.55159 & 0.001889 & 0.020166 & -3.10709 & Down & TPD52 like 3 \\
\hline PABPC1L2A & -2.55147 & 0.006252 & 0.045885 & -2.73428 & Down & poly(A) binding protein cytoplasmic 1 like $2 \mathrm{~A}$ \\
\hline
\end{tabular}




\begin{tabular}{|c|c|c|c|c|c|c|}
\hline OR51B4 & -2.54936 & 0.001501 & 0.017188 & -3.17446 & Down & olfactory receptor family 51 subfamily B member 4 \\
\hline LCE1F & -2.54374 & 0.002888 & 0.027195 & -2.97945 & Down & late cornified envelope $1 \mathrm{~F}$ \\
\hline KCNQ2 & -2.52303 & 0.001454 & 0.016864 & -3.18366 & Down & potassium voltage-gated channel subfamily Q member 2 \\
\hline SFRP4 & -2.52066 & $1.03 \mathrm{E}-08$ & 2.36E-06 & -5.72526 & Down & secreted frizzled related protein 4 \\
\hline KCNF1 & -2.51814 & 0.000113 & 0.002775 & -3.86075 & Down & potassium voltage-gated channel modifier subfamily $\mathrm{F}$ member 1 \\
\hline OR2AG2 & -2.51736 & 0.004873 & 0.038957 & -2.8153 & Down & olfactory receptor family 2 subfamily AG member 2 \\
\hline CD1E & -2.51051 & 0.002538 & 0.024876 & -3.01877 & Down & CD1e molecule \\
\hline OR2M7 & -2.50383 & 0.004156 & 0.03502 & -2.86606 & Down & olfactory receptor family 2 subfamily M member 7 \\
\hline OR51L1 & -2.49986 & 0.001702 & 0.018656 & -3.13791 & Down & olfactory receptor family 51 subfamily L member 1 \\
\hline LINC00477 & -2.49804 & 0.004433 & 0.036513 & -2.8456 & Down & long intergenic non-protein coding RNA 477 \\
\hline OR5H1 & -2.49529 & 0.0037 & 0.032227 & -2.90267 & Down & olfactory receptor family 5 subfamily $\mathrm{H}$ member 1 \\
\hline FAM83E & -2.49154 & 0.000801 & 0.01113 & -3.35243 & Down & family with sequence similarity 83 member $\mathrm{E}$ \\
\hline CRLF1 & -2.48748 & $1.68 \mathrm{E}-12$ & $1.60 \mathrm{E}-09$ & -7.05875 & Down & cytokine receptor like factor 1 \\
\hline STAG3 & -2.48528 & 0.002489 & 0.024577 & -3.0247 & Down & stromal antigen 3 \\
\hline KRTAP21-2 & -2.47732 & 0.001534 & 0.017433 & -3.16815 & Down & keratin associated protein $21-2$ \\
\hline OR8G1 & -2.4672 & 0.005221 & 0.04074 & -2.79305 & Down & olfactory receptor family 8 subfamily G member 1 \\
\hline OR6K6 & -2.46634 & 0.006059 & 0.044944 & -2.74455 & Down & olfactory receptor family 6 subfamily K member 6 \\
\hline KRTAP19-2 & -2.4657 & 0.003103 & 0.028539 & -2.95735 & Down & keratin associated protein $19-2$ \\
\hline OR10Z1 & -2.45396 & 0.003252 & 0.029509 & -2.94285 & Down & olfactory receptor family 10 subfamily $\mathrm{Z}$ member 1 \\
\hline KRTAP10-1 & -2.45298 & 0.006735 & 0.048175 & -2.70969 & Down & keratin associated protein $10-1$ \\
\hline DNAH11 & -2.45203 & 0.000344 & 0.006141 & -3.57944 & Down & dynein axonemal heavy chain 11 \\
\hline NPTX2 & -2.44884 & $1.08 \mathrm{E}-10$ & $5.76 \mathrm{E}-08$ & -6.455 & Down & neuronal pentraxin 2 \\
\hline $\mathrm{KCNH} 1$ & -2.44466 & 0.001977 & 0.020792 & -3.0937 & Down & potassium voltage-gated channel subfamily $\mathrm{H}$ member 1 \\
\hline OR4K1 & -2.43709 & 0.004239 & 0.035455 & -2.85982 & Down & olfactory receptor family 4 subfamily K member 1 \\
\hline OR5T2 & -2.43076 & 0.002914 & 0.027332 & -2.97665 & Down & olfactory receptor family 5 subfamily $\mathrm{T}$ member 2 \\
\hline PSMD6-AS2 & -2.42892 & 0.000265 & 0.005132 & -3.64722 & Down & PSMD6 antisense RNA 2 \\
\hline EDARADD & -2.4128 & $9.72 \mathrm{E}-06$ & 0.000474 & -4.42333 & Down & EDAR associated death domain \\
\hline SDR16C5 & -2.41156 & 0.00454 & 0.037128 & -2.838 & Down & short chain dehydrogenase/reductase family $16 \mathrm{C}$ member 5 \\
\hline LOC100130673 & -2.41083 & 0.004883 & 0.03897 & -2.81463 & Down & phosphoribosyl pyrophosphate synthetase 2 pseudogene \\
\hline PI16 & -2.40562 & 0.000421 & 0.007072 & -3.52631 & Down & peptidase inhibitor 16 \\
\hline JPH2 & -2.40312 & 0.00471 & 0.038127 & -2.82621 & Down & junctophilin 2 \\
\hline INSC & -2.40292 & 4.17E-06 & 0.000255 & -4.60267 & Down & INSC spindle orientation adaptor protein \\
\hline FN1 & -2.4003 & $9.15 \mathrm{E}-07$ & 8.07E-05 & -4.90913 & Down & fibronectin 1 \\
\hline ACTBL2 & -2.39082 & 0.003746 & 0.03246 & -2.89875 & Down & actin beta like 2 \\
\hline KIF4A & -2.37867 & 0.001252 & 0.015226 & -3.22668 & Down & kinesin family member $4 \mathrm{~A}$ \\
\hline VSIG10L & -2.37789 & 0.001623 & 0.018046 & -3.15176 & Down & V-set and immunoglobulin domain containing 10 like \\
\hline GPD1 & -2.37721 & 0.002655 & 0.025667 & -3.00509 & Down & glycerol-3-phosphate dehydrogenase 1 \\
\hline C1QL1 & -2.37667 & 0.000214 & 0.004411 & -3.7015 & Down & complement $\mathrm{C} 1 \mathrm{q}$ like 1 \\
\hline NPFF & -2.36906 & $8.90 \mathrm{E}-05$ & 0.002312 & -3.91888 & Down & neuropeptide FF-amide peptide precursor \\
\hline OR4N3P & -2.35827 & 0.005904 & 0.044102 & -2.75305 & Down & olfactory receptor family 4 subfamily $\mathrm{N}$ member 3 pseudogene \\
\hline OR2A 12 & -2.34861 & 0.002721 & 0.026055 & -2.99766 & Down & olfactory receptor family 2 subfamily A member 12 \\
\hline CAPNS2 & -2.34428 & 0.000221 & 0.004497 & -3.69321 & Down & calpain small subunit 2 \\
\hline OR5AK4P & -2.34022 & 0.006512 & 0.04726 & -2.72083 & Down & olfactory receptor family 5 subfamily AK member 4 pseudogene \\
\hline
\end{tabular}




\begin{tabular}{|c|c|c|c|c|c|c|}
\hline BEND6 & -2.33639 & 0.000272 & 0.005194 & -3.64043 & Down & BEN domain containing 6 \\
\hline YIPF4 & -2.33303 & $6.30 \mathrm{E}-05$ & 0.00178 & -4.0014 & Down & Yip1 domain family member 4 \\
\hline OR1L8 & -2.33257 & 0.005375 & 0.041436 & -2.78365 & Down & olfactory receptor family 1 subfamily $\mathrm{L}$ member 8 \\
\hline FAM95B1 & -2.31927 & 0.003903 & 0.033444 & -2.88593 & Down & family with sequence similarity 95 member B 1 \\
\hline RDH16 & -2.3132 & 0.00098 & 0.012875 & -3.29622 & Down & retinol dehydrogenase 16 \\
\hline HBD & -2.30048 & 0.006912 & 0.049 & -2.70104 & Down & hemoglobin subunit delta \\
\hline OR1J2 & -2.29925 & 0.005289 & 0.041019 & -2.7889 & Down & olfactory receptor family 1 subfamily $\mathrm{J}$ member 2 \\
\hline TAS2R60 & -2.29771 & 0.000463 & 0.007527 & -3.50125 & Down & taste 2 receptor member 60 \\
\hline VSIG4 & -2.29506 & $5.66 \mathrm{E}-07$ & $5.69 \mathrm{E}-05$ & -5.00245 & Down & V-set and immunoglobulin domain containing 4 \\
\hline IGF2BP3 & -2.29121 & 0.000493 & 0.007844 & -3.48429 & Down & insulin like growth factor 2 mRNA binding protein 3 \\
\hline CHRNA10 & -2.28988 & 0.003958 & 0.033807 & -2.88147 & Down & cholinergic receptor nicotinic alpha 10 subunit \\
\hline OR5AP2 & -2.25924 & 0.006852 & 0.048745 & -2.70396 & Down & olfactory receptor family 5 subfamily AP member 2 \\
\hline MEP1B & -2.25724 & 0.004207 & 0.035254 & -2.86219 & Down & meprin A subunit beta \\
\hline UGT1A9 & -2.25439 & 0.00578 & 0.043574 & -2.76 & Down & UDP glucuronosyltransferase family 1 member A9 \\
\hline OR52K1 & -2.24884 & 0.004392 & 0.03629 & -2.84857 & Down & olfactory receptor family 52 subfamily K member 1 \\
\hline CYP26B1 & -2.24879 & 0.000361 & 0.006326 & -3.56691 & Down & cytochrome P450 family 26 subfamily B member 1 \\
\hline FAT3 & -2.24517 & 0.000527 & 0.008238 & -3.46655 & Down & FAT atypical cadherin 3 \\
\hline IL10 & -2.24228 & 0.003217 & 0.029301 & -2.94624 & Down & interleukin 10 \\
\hline TNFRSF11A & -2.24044 & 7.07E-10 & $2.66 \mathrm{E}-07$ & -6.16461 & Down & TNF receptor superfamily member $11 \mathrm{a}$ \\
\hline GCGR & -2.23561 & 0.000942 & 0.012562 & -3.30743 & Down & glucagon receptor \\
\hline RERGL & -2.21524 & $6.67 \mathrm{E}-06$ & 0.000361 & -4.50409 & Down & RERG like \\
\hline ZMAT4 & -2.21188 & 0.004388 & 0.03629 & -2.84882 & Down & zinc finger matrin-type 4 \\
\hline CCDC54 & -2.20591 & 0.004509 & 0.036964 & -2.84014 & Down & coiled-coil domain containing 54 \\
\hline OR9A2 & -2.19677 & 0.006953 & 0.049212 & -2.69909 & Down & olfactory receptor family 9 subfamily A member 2 \\
\hline SPAG6 & -2.19033 & 0.006245 & 0.045876 & -2.73463 & Down & sperm associated antigen 6 \\
\hline LOC401127 & -2.18482 & 0.000134 & 0.003165 & -3.81831 & Down & WD repeat domain 5 pseudogene \\
\hline ENTPD3 & -2.18044 & $2.71 \mathrm{E}-12$ & 2.23E-09 & -6.99221 & Down & ectonucleoside triphosphate diphosphohydrolase 3 \\
\hline LCN2 & -2.16225 & $4.27 \mathrm{E}-05$ & 0.001359 & -4.09226 & Down & lipocalin 2 \\
\hline TOP2A & -2.14257 & 0.001988 & 0.020883 & -3.09206 & Down & DNA topoisomerase II alpha \\
\hline ACTL7A & -2.13887 & 0.002923 & 0.027371 & -2.97574 & Down & actin like $7 \mathrm{~A}$ \\
\hline OXGR1 & -2.13657 & 0.003157 & 0.028911 & -2.95204 & Down & oxoglutarate receptor 1 \\
\hline MESP2 & -2.13597 & 0.004817 & 0.038713 & -2.81903 & Down & mesoderm posterior bHLH transcription factor 2 \\
\hline $\mathrm{CDH} 22$ & -2.13575 & $3.22 \mathrm{E}-05$ & 0.001126 & -4.15707 & Down & cadherin 22 \\
\hline OR10A5 & -2.13555 & 0.00036 & 0.006308 & -3.56815 & Down & olfactory receptor family 10 subfamily A member 5 \\
\hline $\mathrm{SPC} 24$ & -2.13072 & 0.002388 & 0.023883 & -3.03725 & Down & $\begin{array}{l}\text { SPC24 component of NDC80 kinetochore complex } \\
\text { putative deoxyuridine 5'-triphosphate nucleotidohydrolase-like protein }\end{array}$ \\
\hline LOC100506422 & -2.12894 & 0.001293 & 0.015506 & -3.21745 & Down & FLJ16323 \\
\hline NSUN5P2 & -2.12488 & 0.004023 & 0.034205 & -2.87632 & Down & NSUN5 pseudogene 2 \\
\hline KLHDC8A & -2.12063 & 0.001931 & 0.020472 & -3.10071 & Down & kelch domain containing $8 \mathrm{~A}$ \\
\hline ANKRD34C & -2.11947 & 0.005215 & 0.040726 & -2.79342 & Down & ankyrin repeat domain $34 \mathrm{C}$ \\
\hline OR4C46 & -2.11678 & 0.004308 & 0.035862 & -2.85472 & Down & olfactory receptor family 4 subfamily $\mathrm{C}$ member 46 \\
\hline LINC00671 & -2.11267 & 0.000874 & 0.01186 & -3.32835 & Down & long intergenic non-protein coding RNA 671 \\
\hline UCHL1 & -2.10092 & 0.000329 & 0.005946 & -3.59133 & Down & ubiquitin C-terminal hydrolase L1 \\
\hline
\end{tabular}




\begin{tabular}{|c|c|c|c|c|c|c|}
\hline HLA-C & -2.09812 & 0.001034 & 0.01341 & -3.28109 & Down & major histocompatibility complex, class I, C \\
\hline CLEC4D & -2.09688 & 0.006021 & 0.044768 & -2.74665 & Down & C-type lectin domain family 4 member D \\
\hline FGL1 & -2.09534 & $2.36 \mathrm{E}-05$ & 0.00089 & -4.22771 & Down & fibrinogen like 1 \\
\hline LRRC10B & -2.09389 & 0.001064 & 0.013642 & -3.27304 & Down & leucine rich repeat containing $10 \mathrm{~B}$ \\
\hline CDKN3 & -2.09092 & 0.0001 & 0.002543 & -3.88942 & Down & cyclin dependent kinase inhibitor 3 \\
\hline TMEM200C & -2.08833 & 0.000653 & 0.009666 & -3.40863 & Down & transmembrane protein $200 \mathrm{C}$ \\
\hline KANK4 & -2.07825 & 0.000722 & 0.010375 & -3.38106 & Down & $\mathrm{KN}$ motif and ankyrin repeat domains 4 \\
\hline ACTC1 & -2.07805 & 0.001404 & 0.016404 & -3.1939 & Down & actin alpha cardiac muscle 1 \\
\hline COL6A4P2 & -2.06787 & 0.003406 & 0.030366 & -2.92853 & Down & collagen type VI alpha 4 pseudogene 2 \\
\hline VASP & -2.06614 & $9.06 \mathrm{E}-11$ & $5.12 \mathrm{E}-08$ & -6.48188 & Down & vasodilator stimulated phosphoprotein \\
\hline LCN10 & -2.05205 & 0.000462 & 0.00752 & -3.50197 & Down & lipocalin 10 \\
\hline MEG3 & -2.04725 & $1.56 \mathrm{E}-08$ & $3.21 \mathrm{E}-06$ & -5.65483 & Down & maternally expressed 3 \\
\hline CIT & -2.04665 & 0.000351 & 0.00623 & -3.57439 & Down & citron rho-interacting serine/threonine kinase \\
\hline CTNNA3 & -2.03117 & 0.004056 & 0.034415 & -2.87379 & Down & catenin alpha 3 \\
\hline OR52W1 & -2.02704 & 0.004903 & 0.039089 & -2.81336 & Down & olfactory receptor family 52 subfamily $\mathrm{W}$ member 1 \\
\hline IL5RA & -2.02549 & 0.006579 & 0.047591 & -2.71742 & Down & interleukin 5 receptor subunit alpha \\
\hline RPL31 & -2.02494 & 0.001538 & 0.017454 & -3.16745 & Down & ribosomal protein L31 \\
\hline CTSE & -2.00792 & 0.005802 & 0.043589 & -2.75877 & Down & cathepsin E \\
\hline SOSTDC1 & -2.00044 & 0.005797 & 0.043583 & -2.75905 & Down & sclerostin domain containing 1 \\
\hline TTC8 & -1.99853 & $2.42 \mathrm{E}-07$ & $2.95 \mathrm{E}-05$ & -5.16352 & Down & tetratricopeptide repeat domain 8 \\
\hline RADIL & -1.98793 & 0.001675 & 0.018469 & -3.14246 & Down & Rap associating with DIL domain \\
\hline TAS2R8 & -1.98705 & 0.004385 & 0.03629 & -2.84903 & Down & taste 2 receptor member 8 \\
\hline OIP5 & -1.97891 & 0.000709 & 0.010265 & -3.38597 & Down & Opa interacting protein 5 \\
\hline OLFM4 & -1.97222 & 0.00062 & 0.009266 & -3.42261 & Down & olfactomedin 4 \\
\hline NDUFA8 & -1.95217 & $1.65 \mathrm{E}-12$ & $1.60 \mathrm{E}-09$ & -7.06142 & Down & NADH:ubiquinoneoxidoreductase subunit A8 \\
\hline TSPAN1 & -1.94046 & $1.70 \mathrm{E}-05$ & 0.000707 & -4.30155 & Down & tetraspanin 1 \\
\hline SDHAP2 & -1.93873 & $2.15 \mathrm{E}-07$ & $2.68 \mathrm{E}-05$ & -5.18585 & Down & succinate dehydrogenase complex flavoprotein subunit A pseudogene 2 \\
\hline MYCN & -1.92871 & 0.006923 & 0.049039 & -2.70052 & Down & MYCN proto-oncogene, bHLH transcription factor \\
\hline GPR141 & -1.91909 & 0.000936 & 0.012505 & -3.30911 & Down & G protein-coupled receptor 141 \\
\hline NTN1 & -1.91802 & $6.50 \mathrm{E}-07$ & $6.32 \mathrm{E}-05$ & -4.9757 & Down & netrin 1 \\
\hline MAGEE2 & -1.90962 & 0.000537 & 0.00834 & -3.46166 & Down & MAGE family member E2 \\
\hline EEF1A2 & -1.90299 & 0.000516 & 0.008113 & -3.47224 & Down & eukaryotic translation elongation factor 1 alpha 2 \\
\hline MAP3K8 & -1.90261 & 0.002553 & 0.024928 & -3.01704 & Down & mitogen-activated protein kinase kinasekinase 8 \\
\hline OR52E6 & -1.89409 & 0.007 & 0.049484 & -2.69686 & Down & olfactory receptor family 52 subfamily E member 6 \\
\hline P2RX6 & -1.8888 & 0.002619 & 0.025432 & -3.00924 & Down & purinergic receptor $\mathrm{P} 2 \mathrm{X} 6$ \\
\hline CTNNA2 & -1.88542 & 0.001368 & 0.016106 & -3.20124 & Down & catenin alpha 2 \\
\hline SNORD17 & -1.87942 & 0.000449 & 0.007397 & -3.50975 & Down & small nucleolar RNA, C/D box 17 \\
\hline DIRC3 & -1.87831 & 0.00023 & 0.004625 & -3.68404 & Down & disrupted in renal carcinoma 3 \\
\hline KIF6 & -1.87185 & $7.20 \mathrm{E}-06$ & 0.000384 & -4.4878 & Down & kinesin family member 6 \\
\hline TTN & -1.86646 & $2.37 \mathrm{E}-05$ & 0.00089 & -4.22669 & Down & titin \\
\hline SAMD3 & -1.85982 & 0.003005 & 0.027939 & -2.96719 & Down & sterile alpha motif domain containing 3 \\
\hline OR6K3 & -1.85822 & 0.00637 & 0.046452 & -2.72811 & Down & olfactory receptor family 6 subfamily K member 3 \\
\hline QRICH2 & -1.85193 & 7.62E-05 & 0.002061 & -3.95612 & Down & glutamine rich 2 \\
\hline
\end{tabular}




\begin{tabular}{|c|c|c|c|c|c|c|}
\hline RRM2 & -1.85099 & 0.002235 & 0.022764 & -3.05702 & Down & ribonucleotidereductase regulatory subunit M2 \\
\hline $\mathrm{BCO} 2$ & -1.84966 & $5.49 \mathrm{E}-05$ & 0.001643 & -4.03358 & Down & beta-carotene oxygenase 2 \\
\hline MUSTN1 & -1.84629 & 0.000187 & 0.003999 & -3.73656 & Down & musculoskeletal, embryonic nuclear protein 1 \\
\hline OR11H2 & -1.84559 & 0.001589 & 0.017817 & -3.1579 & Down & olfactory receptor family 11 subfamily $\mathrm{H}$ member 2 \\
\hline ZNF695 & -1.84353 & 0.000466 & 0.007558 & -3.49967 & Down & zinc finger protein 695 \\
\hline SULT1C2 & -1.84327 & 0.000838 & 0.011496 & -3.33987 & Down & sulfotransferase family $1 \mathrm{C}$ member 2 \\
\hline GTF2H2C & -1.84144 & $2.42 \mathrm{E}-08$ & $4.62 \mathrm{E}-06$ & -5.57866 & Down & GTF2H2 family member C \\
\hline TK1 & -1.83218 & 0.000127 & 0.003035 & -3.83165 & Down & thymidine kinase 1 \\
\hline GINS2 & -1.83103 & $6.19 \mathrm{E}-07$ & $6.09 \mathrm{E}-05$ & -4.98512 & Down & GINS complex subunit 2 \\
\hline $\mathrm{CCR} 2$ & -1.82698 & 0.004504 & 0.036953 & -2.84055 & Down & C-C motif chemokine receptor 2 \\
\hline SHCBP1 & -1.82541 & 0.005054 & 0.039942 & -2.80359 & Down & SHC binding and spindle associated 1 \\
\hline RAB11B-AS1 & -1.8231 & $1.61 \mathrm{E}-05$ & 0.000683 & -4.31271 & Down & RAB11B antisense RNA 1 \\
\hline PRAM1 & -1.81806 & 0.005685 & 0.043083 & -2.76544 & Down & PML-RARA regulated adaptor molecule 1 \\
\hline NCKAP5 & -1.81025 & $9.58 \mathrm{E}-07$ & $8.38 \mathrm{E}-05$ & -4.90001 & Down & NCK associated protein 5 \\
\hline P2RY12 & -1.80448 & $1.20 \mathrm{E}-05$ & 0.000557 & -4.37801 & Down & purinergic receptor $\mathrm{P} 2 \mathrm{Y} 12$ \\
\hline CNN1 & -1.80432 & 0.000511 & 0.008054 & -3.47488 & Down & calponin 1 \\
\hline HRC & -1.80167 & $5.89 \mathrm{E}-05$ & 0.001709 & -4.01703 & Down & histidine rich calcium binding protein \\
\hline CYP4Z1 & -1.78642 & 0.005884 & 0.044023 & -2.75418 & Down & cytochrome $\mathrm{P} 450$ family 4 subfamily $\mathrm{Z}$ member 1 \\
\hline IP6K3 & -1.78353 & 0.00152 & 0.017335 & -3.17089 & Down & inositol hexakisphosphate kinase 3 \\
\hline PTGS2 & -1.7827 & 0.003252 & 0.029509 & -2.94289 & Down & prostaglandin-endoperoxide synthase 2 \\
\hline DEF8 & -1.77864 & 0.000794 & 0.011065 & -3.35471 & Down & differentially expressed in FDCP 8 homolog \\
\hline FOXD2 & -1.77487 & 0.000539 & 0.008367 & -3.46036 & Down & forkhead box D2 \\
\hline APOC1 & -1.77454 & $4.60 \mathrm{E}-05$ & 0.001437 & -4.07517 & Down & apolipoprotein $\mathrm{C} 1$ \\
\hline LYZ & -1.77313 & $5.00 \mathrm{E}-05$ & 0.001534 & -4.0555 & Down & lysozyme \\
\hline ITGBL1 & -1.76632 & $1.37 \mathrm{E}-07$ & $1.87 \mathrm{E}-05$ & -5.26957 & Down & integrin subunit beta like 1 \\
\hline GLP1R & -1.7604 & $9.18 \mathrm{E}-08$ & $1.36 \mathrm{E}-05$ & -5.34227 & Down & glucagon like peptide 1 receptor \\
\hline CYP3A5 & -1.75739 & 0.000151 & 0.003436 & -3.79001 & Down & cytochrome P450 family 3 subfamily A member 5 \\
\hline SH3BP2 & -1.75378 & 0.00039 & 0.006665 & -3.54652 & Down & SH3 domain binding protein 2 \\
\hline SNORA47 & -1.75268 & $8.24 \mathrm{E}-07$ & 7.44E-05 & -4.9295 & Down & small nucleolar RNA, H/ACA box 47 \\
\hline NDRG4 & -1.74784 & 0.002093 & 0.02164 & -3.07666 & Down & NDRG family member 4 \\
\hline KLRK1 & -1.74544 & 0.000776 & 0.010938 & -3.36131 & Down & killer cell lectin like receptor $\mathrm{K} 1$ \\
\hline CNGA4 & -1.73089 & 0.00257 & 0.025014 & -3.01493 & Down & cyclic nucleotide gated channel subunit alpha 4 \\
\hline APOC2 & -1.71885 & 0.000977 & 0.012856 & -3.29702 & Down & apolipoprotein $\mathrm{C} 2$ \\
\hline SCD5 & -1.71546 & $1.24 \mathrm{E}-07$ & $1.74 \mathrm{E}-05$ & -5.28776 & Down & stearoyl-CoA desaturase 5 \\
\hline KRTAP5-1 & -1.71212 & 0.001104 & 0.014013 & -3.26265 & Down & keratin associated protein 5-1 \\
\hline FAM223A & -1.71176 & 0.006595 & 0.047609 & -2.71663 & Down & family with sequence similarity 223 member A \\
\hline ANKRD23 & -1.70813 & $1.69 \mathrm{E}-06$ & 0.000135 & -4.78678 & Down & ankyrin repeat domain 23 \\
\hline HADH & -1.70627 & $3.96 \mathrm{E}-09$ & $1.04 \mathrm{E}-06$ & -5.88592 & Down & hydroxyacyl-CoA dehydrogenase \\
\hline SERPINA3 & -1.70483 & 0.00017 & 0.003704 & -3.76058 & Down & serpin family A member 3 \\
\hline OR52D1 & -1.7042 & 0.004591 & 0.037466 & -2.83438 & Down & olfactory receptor family 52 subfamily D member 1 \\
\hline TMEM178A & -1.70223 & 0.002146 & 0.022047 & -3.06927 & Down & transmembrane protein $178 \mathrm{~A}$ \\
\hline BMS1P4 & -1.69662 & 4.36E-07 & 4.67E-05 & -5.05261 & Down & BMS1 pseudogene 4 \\
\hline SMAD9 & -1.68648 & 0.006737 & 0.048175 & -2.70957 & Down & SMAD family member 9 \\
\hline
\end{tabular}




\begin{tabular}{|c|c|c|c|c|c|c|}
\hline PIGP & -1.68357 & 4.36E-08 & 7.24E-06 & -5.47564 & Down & phosphatidylinositol glycan anchor biosynthesis class $\mathrm{P}$ \\
\hline GALK2 & -1.68337 & $2.87 \mathrm{E}-13$ & 4.33E-10 & -7.30016 & Down & galactokinase 2 \\
\hline SNORA70E & -1.68291 & 0.001609 & 0.017966 & -3.1543 & Down & small nucleolar RNA, H/ACA box 70E \\
\hline NEFM & -1.6821 & 4.63E-05 & 0.001444 & -4.07361 & Down & neurofilament medium \\
\hline ZNF622 & -1.67707 & $3.95 \mathrm{E}-08$ & $6.81 \mathrm{E}-06$ & -5.49285 & Down & zinc finger protein 622 \\
\hline EFNA4 & -1.67629 & 0.001144 & 0.014391 & -3.25251 & Down & ephrin A4 \\
\hline LRP5L & -1.67397 & $1.35 \mathrm{E}-05$ & 0.000604 & -4.35245 & Down & LDL receptor related protein 5 like \\
\hline MED10 & -1.67292 & $3.27 \mathrm{E}-06$ & 0.000215 & -4.65306 & Down & mediator complex subunit 10 \\
\hline PIR & -1.67257 & $1.57 \mathrm{E}-07$ & $2.11 \mathrm{E}-05$ & -5.24394 & Down & pirin \\
\hline HSD17B3 & -1.67244 & 0.00193 & 0.020472 & -3.10075 & Down & hydroxysteroid 17-beta dehydrogenase 3 \\
\hline MRO & -1.66683 & $2.46 \mathrm{E}-05$ & 0.000915 & -4.21819 & Down & maestro \\
\hline PTGFR & -1.66615 & 4.11E-08 & $6.95 \mathrm{E}-06$ & -5.48615 & Down & prostaglandin F receptor \\
\hline GUSBP11 & -1.66179 & $9.52 \mathrm{E}-08$ & $1.40 \mathrm{E}-05$ & -5.33562 & Down & GUSB pseudogene 11 \\
\hline CDK15 & -1.66068 & 0.000948 & 0.012618 & -3.30537 & Down & cyclin dependent kinase 15 \\
\hline WDR3 & -1.65943 & $1.43 \mathrm{E}-08$ & $3.05 \mathrm{E}-06$ & -5.66959 & Down & WD repeat domain 3 \\
\hline SCRG1 & -1.65505 & 0.001442 & 0.016755 & -3.1861 & Down & stimulator of chondrogenesis 1 \\
\hline NR6A1 & -1.65044 & 0.00046 & 0.007518 & -3.50276 & Down & nuclear receptor subfamily 6 group A member 1 \\
\hline FAM72D & -1.63864 & 0.00183 & 0.019741 & -3.11653 & Down & family with sequence similarity 72 member D \\
\hline ZNF391 & -1.63472 & $8.82 \mathrm{E}-06$ & 0.000445 & -4.44436 & Down & zinc finger protein 391 \\
\hline $\mathrm{CFB}$ & -1.63155 & 0.000144 & 0.003338 & -3.80159 & Down & complement factor B \\
\hline LGI2 & -1.62508 & $2.48 \mathrm{E}-06$ & 0.000175 & -4.70977 & Down & leucine rich repeat LGI family member 2 \\
\hline FCHO1 & -1.62484 & 0.005264 & 0.04091 & -2.79039 & Down & FCH and mu domain containing endocytic adaptor 1 \\
\hline LRRC7 & -1.62384 & 0.002558 & 0.024957 & -3.01644 & Down & leucine rich repeat containing 7 \\
\hline NEK6 & -1.62009 & 0.00659 & 0.047609 & -2.71687 & Down & NIMA related kinase 6 \\
\hline LOC648987 & -1.61592 & 0.003007 & 0.02794 & -2.96703 & Down & uncharacterized LOC648987 \\
\hline MMP28 & -1.60978 & 0.000384 & 0.006598 & -3.55064 & Down & matrix metallopeptidase 28 \\
\hline LHFPL3-AS2 & -1.60714 & 0.000745 & 0.010639 & -3.37256 & Down & LHFPL3 antisense RNA 2 \\
\hline AKR1C2 & -1.60408 & $2.37 \mathrm{E}-05$ & 0.00089 & -4.22683 & Down & aldo-ketoreductase family 1 member $\mathrm{C} 2$ \\
\hline BUB1B & -1.60351 & 0.005799 & 0.043583 & -2.75895 & Down & BUB1 mitotic checkpoint serine/threonine kinase B \\
\hline LOC100507547 & -1.60229 & 0.000828 & 0.011404 & -3.34317 & Down & uncharacterized LOC100507547 \\
\hline $\mathrm{CDH} 23$ & -1.59792 & 0.001165 & 0.01459 & -3.24742 & Down & cadherin related 23 \\
\hline ANXA10 & -1.59619 & $7.10 \mathrm{E}-06$ & 0.000381 & -4.49071 & Down & annexin A10 \\
\hline ADAMTS2 & -1.59391 & 7.57E-07 & $6.88 \mathrm{E}-05$ & -4.94615 & Down & ADAM metallopeptidase with thrombospondin type 1 motif 2 \\
\hline PAPOLB & -1.58767 & 0.005074 & 0.040061 & -2.80231 & Down & poly(A) polymerase beta \\
\hline CDKN1C & -1.58201 & $2.08 \mathrm{E}-06$ & 0.000154 & -4.74542 & Down & cyclin dependent kinase inhibitor $1 \mathrm{C}$ \\
\hline ATP2C1 & -1.58082 & 0.001222 & 0.015003 & -3.23363 & Down & ATPase secretory pathway $\mathrm{Ca} 2+$ transporting 1 \\
\hline SPAG17 & -1.57901 & 0.003276 & 0.029678 & -2.94057 & Down & sperm associated antigen 17 \\
\hline P2RY1 & -1.57648 & 0.000798 & 0.011091 & -3.35364 & Down & purinergic receptor $\mathrm{P} 2 \mathrm{Y} 1$ \\
\hline IGSF11 & -1.57462 & $1.96 \mathrm{E}-05$ & 0.000779 & -4.26992 & Down & immunoglobulin superfamily member 11 \\
\hline COMMD7 & -1.57449 & 0.000354 & 0.006238 & -3.57221 & Down & COMM domain containing 7 \\
\hline LOC440173 & -1.5733 & 0.000203 & 0.004248 & -3.71519 & Down & uncharacterized LOC440173 \\
\hline UBXN10 & -1.56955 & 0.003965 & 0.033807 & -2.8809 & Down & UBX domain protein 10 \\
\hline TSHZ3 & -1.56942 & $3.81 \mathrm{E}-05$ & 0.001252 & -4.11863 & Down & teashirt zinc finger homeobox 3 \\
\hline
\end{tabular}




\begin{tabular}{|c|c|c|c|c|c|c|}
\hline LRRC39 & -1.56781 & 0.00276 & 0.02628 & -2.99327 & Down & leucine rich repeat containing 39 \\
\hline PDLIM3 & -1.56765 & $3.35 \mathrm{E}-05$ & 0.001154 & -4.14833 & Down & PDZ and LIM domain 3 \\
\hline IFI27L2 & -1.56751 & 0.004728 & 0.038202 & -2.825 & Down & interferon alpha inducible protein 27 like 2 \\
\hline EFCAB12 & -1.56177 & 0.005243 & 0.040847 & -2.79172 & Down & EF-hand calcium binding domain 12 \\
\hline SCGB2A1 & -1.56061 & 0.005011 & 0.039689 & -2.80634 & Down & secretoglobin family $2 \mathrm{~A}$ member 1 \\
\hline CRYGS & -1.56043 & 0.003935 & 0.033661 & -2.88331 & Down & crystallin gamma $S$ \\
\hline ARHGAP20 & -1.55688 & 0.001308 & 0.015618 & -3.21424 & Down & Rho GTPase activating protein 20 \\
\hline FRMPD1 & -1.54919 & 0.001419 & 0.016541 & -3.19075 & Down & FERM and PDZ domain containing 1 \\
\hline KIF20B & -1.54488 & 0.001915 & 0.020374 & -3.10318 & Down & kinesin family member $20 \mathrm{~B}$ \\
\hline SELL & -1.54158 & 0.003719 & 0.032311 & -2.90103 & Down & selectin $\mathrm{L}$ \\
\hline NEDD8 & -1.54099 & 4.08E-09 & $1.04 \mathrm{E}-06$ & -5.88096 & Down & NEDD8 ubiquitin like modifier \\
\hline RASSF1 & -1.54021 & 0.000352 & 0.006238 & -3.57352 & Down & Ras association domain family member 1 \\
\hline ESR1 & -1.53465 & 0.003504 & 0.030999 & -2.91966 & Down & estrogen receptor 1 \\
\hline ERVK13-1 & -1.52459 & 0.000155 & 0.003502 & -3.78254 & Down & endogenous retrovirus group $\mathrm{K} 13$ member 1 \\
\hline HEBP2 & -1.51608 & $1.06 \mathrm{E}-06$ & $9.13 \mathrm{E}-05$ & -4.88012 & Down & heme binding protein 2 \\
\hline ARHGAP22 & -1.51421 & 0.002497 & 0.024632 & -3.02369 & Down & Rho GTPase activating protein 22 \\
\hline TYW1B & -1.51088 & $2.73 \mathrm{E}-06$ & 0.000187 & -4.69036 & Down & tRNA-yW synthesizing protein 1 homolog B \\
\hline AGAP2 & -1.51064 & 0.003808 & 0.03285 & -2.89366 & Down & ArfGAP with GTPase domain, ankyrin repeat and PH domain 2 \\
\hline CYP4F12 & -1.5094 & 0.004865 & 0.038909 & -2.81584 & Down & cytochrome P450 family 4 subfamily F member 12 \\
\hline RASD2 & -1.50824 & $1.28 \mathrm{E}-06$ & 0.000107 & -4.84244 & Down & RASD family member 2 \\
\hline SLC26A7 & -1.50389 & 0.002177 & 0.022312 & -3.06497 & Down & solute carrier family 26 member 7 \\
\hline LY6G5B & -1.49949 & 0.002268 & 0.023028 & -3.05265 & Down & lymphocyte antigen 6 family member G5B \\
\hline TFCP2L1 & -1.49843 & $5.31 \mathrm{E}-06$ & 0.000312 & -4.55219 & Down & transcription factor CP2 like 1 \\
\hline CSF2RA & -1.49594 & 0.002137 & 0.02198 & -3.07048 & Down & colony stimulating factor 2 receptor subunit alpha \\
\hline TDH & -1.49341 & 0.001129 & 0.014269 & -3.25632 & Down & L-threonine dehydrogenase (pseudogene) \\
\hline RELT & -1.49125 & 0.001848 & 0.019864 & -3.11363 & Down & RELT TNF receptor \\
\hline MAP1A & -1.48562 & 0.001649 & 0.018241 & -3.14714 & Down & microtubule associated protein $1 \mathrm{~A}$ \\
\hline LOXL1 & -1.48506 & 0.000251 & 0.004917 & -3.66139 & Down & lysyl oxidase like 1 \\
\hline KIF18A & -1.48239 & 0.001571 & 0.017708 & -3.16123 & Down & kinesin family member $18 \mathrm{~A}$ \\
\hline B3GNT3 & -1.47982 & 0.002083 & 0.021574 & -3.07809 & Down & UDP-GlcNAc:betaGal beta-1,3-N-acetylglucosaminyltransferase 3 \\
\hline LOC646214 & -1.47392 & 0.001568 & 0.017688 & -3.16181 & Down & p21 (RAC1) activated kinase 2 pseudogene \\
\hline PRICKLE4 & -1.47244 & 0.003718 & 0.032311 & -2.90114 & Down & prickle planar cell polarity protein 4 \\
\hline MYO1F & -1.47133 & 0.000544 & 0.008416 & -3.45796 & Down & myosin IF \\
\hline JMJD6 & -1.47043 & 4.70E-07 & 4.99E-05 & -5.03799 & Down & jumonji domain containing 6 , arginine demethylase and lysine hydroxylase \\
\hline TXNDC9 & -1.46925 & $6.09 \mathrm{E}-13$ & $7.86 \mathrm{E}-10$ & -7.19855 & Down & thioredoxin domain containing 9 \\
\hline STXBP5-AS1 & -1.4673 & 0.002667 & 0.025755 & -3.00372 & Down & STXBP5 antisense RNA 1 \\
\hline LUC7L & -1.46492 & $1.72 \mathrm{E}-06$ & 0.000136 & -4.78434 & Down & LUC7 like \\
\hline ARG2 & -1.46353 & 0.002923 & 0.027371 & -2.97571 & Down & arginase 2 \\
\hline POU5F1 & -1.45988 & 0.006916 & 0.049011 & -2.70084 & Down & POU class 5 homeobox 1 \\
\hline ARHGAP9 & -1.45129 & 0.002566 & 0.025001 & -3.01541 & Down & Rho GTPase activating protein 9 \\
\hline LINC00239 & -1.45125 & 0.001024 & 0.013326 & -3.28388 & Down & long intergenic non-protein coding RNA 239 \\
\hline MS4A7 & -1.44992 & $2.59 \mathrm{E}-05$ & 0.000948 & -4.20697 & Down & membrane spanning 4-domains A7 \\
\hline ROBO1 & -1.44661 & 0.000429 & 0.007144 & -3.52164 & Down & roundabout guidance receptor 1 \\
\hline
\end{tabular}




\begin{tabular}{|c|c|c|c|c|c|c|}
\hline TRIM66 & -1.44341 & $5.54 \mathrm{E}-06$ & 0.000322 & -4.5431 & Down & tripartite motif containing 66 \\
\hline ALOX5 & -1.43679 & $1.24 \mathrm{E}-07$ & $1.74 \mathrm{E}-05$ & -5.28802 & Down & arachidonate 5-lipoxygenase \\
\hline GPX2 & -1.43654 & 0.000227 & 0.004581 & -3.68729 & Down & glutathione peroxidase 2 \\
\hline EXOSC8 & -1.43535 & $3.46 \mathrm{E}-10$ & $1.40 \mathrm{E}-07$ & -6.27648 & Down & exosome component 8 \\
\hline NUSAP1 & -1.43456 & 0.001488 & 0.017083 & -3.17698 & Down & nucleolar and spindle associated protein 1 \\
\hline ANLN & -1.43239 & 0.004239 & 0.035455 & -2.8598 & Down & anillin actin binding protein \\
\hline CDK1 & -1.43222 & 0.001258 & 0.015231 & -3.22537 & Down & cyclin dependent kinase 1 \\
\hline SELPLG & -1.43155 & 0.000579 & 0.008821 & -3.44138 & Down & selectin $\mathrm{P}$ ligand \\
\hline GREB1 & -1.42927 & $3.36 \mathrm{E}-07$ & $3.75 \mathrm{E}-05$ & -5.10196 & Down & growth regulating estrogen receptor binding 1 \\
\hline MYH11 & -1.42608 & 0.004478 & 0.036813 & -2.84233 & Down & myosin heavy chain 11 \\
\hline $\mathrm{ABCB} 1$ & -1.42508 & 0.001795 & 0.019432 & -3.12223 & Down & ATP binding cassette subfamily B member 1 \\
\hline CHCHD1 & -1.41714 & 0.001135 & 0.014326 & -3.25479 & Down & coiled-coil-helix-coiled-coil-helix domain containing 1 \\
\hline PDE1C & -1.41678 & 0.001008 & 0.013153 & -3.28817 & Down & phosphodiesterase $1 \mathrm{C}$ \\
\hline DLG2 & -1.41507 & $6.13 \mathrm{E}-05$ & 0.001753 & -4.00758 & Down & discs large MAGUK scaffold protein 2 \\
\hline SNORA57 & -1.41264 & 0.000168 & 0.00368 & -3.76338 & Down & small nucleolar RNA, H/ACA box 57 \\
\hline COQ5 & -1.41257 & $1.02 \mathrm{E}-06$ & $8.87 \mathrm{E}-05$ & -4.88694 & Down & coenzyme Q5, methyltransferase \\
\hline CYP2J2 & -1.40784 & $7.09 \mathrm{E}-05$ & 0.001948 & -3.97338 & Down & cytochrome P450 family 2 subfamily $\mathrm{J}$ member 2 \\
\hline TEKT2 & -1.40714 & 0.001087 & 0.013854 & -3.26686 & Down & tektin 2 \\
\hline CPA4 & -1.39844 & 0.002227 & 0.022694 & -3.05821 & Down & carboxypeptidase A4 \\
\hline OR4F3 & -1.39842 & 0.006622 & 0.04769 & -2.71528 & Down & olfactory receptor family 4 subfamily F member 3 \\
\hline ADAMTS10 & -1.39793 & 0.00084 & 0.011516 & -3.33917 & Down & ADAM metallopeptidase with thrombospondin type 1 motif 10 \\
\hline VAV3 & -1.39763 & $3.65 \mathrm{E}-06$ & 0.000231 & -4.63055 & Down & vav guanine nucleotide exchange factor 3 \\
\hline HSD17B7P2 & -1.39759 & $1.68 \mathrm{E}-05$ & 0.000705 & -4.30357 & Down & hydroxysteroid 17-beta dehydrogenase 7 pseudogene 2 \\
\hline TYMS & -1.39182 & 8.67E-05 & 0.00227 & -3.92507 & Down & thymidylatesynthetase \\
\hline SCN1B & -1.39167 & $3.70 \mathrm{E}-06$ & 0.000233 & -4.62739 & Down & sodium voltage-gated channel beta subunit 1 \\
\hline LAT & -1.38953 & 0.001091 & 0.013873 & -3.26588 & Down & linker for activation of $\mathrm{T}$ cells \\
\hline SNORA71B & -1.3858 & 0.001448 & 0.016813 & -3.18491 & Down & small nucleolar RNA, H/ACA box 71B \\
\hline SMIM5 & -1.38397 & 0.002396 & 0.023909 & -3.03617 & Down & small integral membrane protein 5 \\
\hline MATN3 & -1.38264 & 0.00087 & 0.011855 & -3.32948 & Down & matrilin 3 \\
\hline RNASE2 & -1.37954 & 0.004946 & 0.039334 & -2.81051 & Down & ribonuclease A family member 2 \\
\hline SWT1 & -1.36623 & $1.40 \mathrm{E}-05$ & 0.000618 & -4.3442 & Down & SWT1 RNA endoribonuclease homolog \\
\hline LAMB3 & -1.36487 & 0.002986 & 0.027804 & -2.96915 & Down & laminin subunit beta 3 \\
\hline LINC00244 & -1.36128 & 0.005216 & 0.040726 & -2.79338 & Down & long intergenic non-protein coding RNA 244 \\
\hline PRODH & -1.36073 & 0.001733 & 0.018929 & -3.1326 & Down & proline dehydrogenase 1 \\
\hline SRD5A1 & -1.35922 & 4.03E-06 & 0.000249 & -4.60986 & Down & steroid 5 alpha-reductase 1 \\
\hline SRPX2 & -1.35844 & $5.74 \mathrm{E}-07$ & $5.74 \mathrm{E}-05$ & -4.99961 & Down & sushi repeat containing protein $\mathrm{X}$-linked 2 \\
\hline APOBEC2 & -1.35451 & $1.34 \mathrm{E}-06$ & 0.000111 & -4.8333 & Down & apolipoprotein B mRNA editing enzyme catalytic subunit 2 \\
\hline PKDREJ & -1.35249 & 0.002568 & 0.025007 & -3.01517 & Down & polycystin family receptor for egg jelly \\
\hline SGIP1 & -1.35053 & 0.000715 & 0.010307 & -3.38374 & Down & SH3GL interacting endocytic adaptor 1 \\
\hline NAPSB & -1.34741 & 0.001225 & 0.015005 & -3.23311 & Down & napsin B aspartic peptidase, pseudogene \\
\hline MBL1P & -1.34188 & 0.004945 & 0.039334 & -2.81059 & Down & mannose binding lectin 1 , pseudogene \\
\hline SLC7A7 & -1.33735 & $1.58 \mathrm{E}-05$ & 0.000674 & -4.31659 & Down & solute carrier family 7 member 7 \\
\hline GLG1 & -1.33647 & 4.71E-07 & 4.99E-05 & -5.03762 & Down & golgi glycoprotein 1 \\
\hline
\end{tabular}


bioRxiv preprint doi: https://doi.org/10.1101/2021.06.08.447531; this version posted June 9, 2021. The copyright holder for this preprint (which was not certified by peer review) is the author/funder. All rights reserved. No reuse allowed without permission.

\begin{tabular}{ccccccc}
\hline SNORA10 & -1.33039 & 0.001471 & 0.017006 & -3.18032 & Down & small nucleolar RNA, H/ACA box 10 \\
TPM2 & -1.32665 & $6.85 \mathrm{E}-08$ & $1.04 \mathrm{E}-05$ & -5.39512 & Down & tropomyosin 2 \\
MEG8 & -1.32203 & $1.68 \mathrm{E}-07$ & $2.23 \mathrm{E}-05$ & -5.23175 & Down & maternally expressed 8, small nucleolar RNA host gene \\
ASB16 & -1.32095 & $5.04 \mathrm{E}-05$ & 0.001536 & -4.05368 & Down & ankyrin repeat and SOCS box containing 16 \\
RAD51AP1 & -1.31844 & 0.001646 & 0.018238 & -3.14755 & Down & RAD51 associated protein 1 \\
TBC1D3 & -1.31758 & 0.000265 & 0.005132 & -3.6469 & Down & TBC1 domain family member 3 \\
SIX2 & -1.31048 & 0.000344 & 0.006141 & -3.57942 & Down & SIX homeobox 2 \\
TBC1D3F & -1.30768 & 0.000476 & 0.007661 & -3.49393 & Down & TBC1 domain family member 3F \\
SAMHD1 & -1.30624 & $3.02 \mathrm{E}-08$ & $5.40 \mathrm{E}-06$ & -5.54048 & Down & SAM and HD domain containing deoxynucleoside triphosphate \\
FAM227A & -1.3019 & 0.001032 & 0.01339 & -3.28173 & Down & family with sequence similarity 227 member A \\
LOC100506123 & -1.30135 & 0.001802 & 0.019495 & -3.12109 & Down & uncharacterized LOC100506123 \\
SERTAD4-AS1 & -1.30081 & 0.003311 & 0.029845 & -2.93729 & Down & SERTAD4 antisense RNA 1 \\
\hline
\end{tabular}

Table 3 The enriched GO terms of the up and down regulated differentially expressed genes

\begin{tabular}{|c|c|c|c|c|c|c|}
\hline GO ID & CATEGORY & GO Name & $\begin{array}{c}\text { Adjusted } \mathbf{p} \\
\text { value }\end{array}$ & $\begin{array}{c}\text { negative } \\
\text { log10 } \\
\text { of adjusted } \\
\text { p value }\end{array}$ & $\begin{array}{c}\text { Gene } \\
\text { Count }\end{array}$ & Gene \\
\hline \multicolumn{7}{|c|}{ Up regulated genes } \\
\hline GO:0007275 & $\mathrm{BP}$ & $\begin{array}{c}\text { multicellular organism } \\
\text { development }\end{array}$ & $1.03027 \mathrm{E}-05$ & 4.987047489 & 192 & $\begin{array}{c}\text { IGF2,KRT6A,LCE3D,SPRR } \\
\text { 3,FLG,SPRR2D,SPRR1B,S } \\
\text { LITRK6,FGF21,TBX22,CA } \\
\text { LCR,SPRR1A,USH2A,OTX } \\
\text { 2,DCC,KCP,NOG,STAR,K } \\
\text { RT16,IL1RN,SHISA2,AQP } \\
\text { 5,SYNDIG1,TFAP2C,ERRF } \\
\text { I1,PLP1,ALOX12,KRT13,S } \\
\text { PRR2E,TENM1,PEMT,LY6 } \\
\text { H,FAP,EYA4,LCE3E,EGR1 } \\
\text {,CSGALNACT1,MAL,MM } \\
\text { P16,PTGER4,COL6A3,OAS } \\
\text { 2,ETV4,MAOB,GPC6,SOC } \\
\text { S5,BCL9,POU6F2,BTG2,P } \\
\text { RR15,VEGFC,FAM20C,MP } \\
\text { Z,TMEM176A,KLK13,RPS } \\
\text { 6,ID3,ALOXE3,DDIT4,IRF } \\
\text { 2BP2,KLF15,EGR3,RNF16 } \\
\text { 5,LTBP4,CREB3L1,EMX1, } \\
\text { KLF3,ZFP36,QDPR,ETV5, } \\
\text { KL,GADD45B,NXN,TLE3, } \\
\text { HEYL,HRAS,GLI,SFTPD, } \\
\text { MYC,IGSF8,DMD,FKBP8, } \\
\text { DBP,MTCH1,KLF10,PODX } \\
\text { L,BVES,MNT,LSR,CEL,FO } \\
\text { SL2,WASF1,PAPSS2,NR1 } \\
\text { D1,DUSP4,SNX19,FOXN3, } \\
\text { IL6ST,IL6R,PCDHB6,KLF6 } \\
\text {,ZFP36L1,PBX1,SH3RF1,C } \\
\text { NTN3,NHEJ1,BOC,STAT1, } \\
\text { DUSP1,CLSTN2,DIP2B,M } \\
\text { YADM,PCDHB11,APOD,N } \\
\text { R0B2,NHS,SYVN1,TCF7L } \\
\text { 2,DLL4,NNMT,SMAD1,TP } \\
\text { 53,PCDH18,SUN2,SOS1,P } \\
\text { RKACA,EGFR,ETS1,PIK3 } \\
\text { CA,TSHZ1,GCNT2,PKN1, } \\
\text { TNFRSF1A.ELOVL1,NCS }\end{array}$ \\
\hline
\end{tabular}


bioRxiv preprint doi: https://doi.org/10.1101/2021.06.08.447531; this version posted June 9, 2021. The copyright holder for this preprint (which was not certified by peer review) is the author/funder. All rights reserved. No reuse allowed without permission.

GO:0006807

$\mathrm{BP}$ nitrogen compound metabolic process
TN,MFAP2,YBX1,PLCE1, NDST1,KCNJ8,GAMT,DG CR2,TPI1,JMJD8,NES,WD TC1,MAML1,PCDHB4,NFI B,MAPK3,SLC23A2,FOXK 1,CAMSAP3,ACVR2B,PLO D3,ZFHX3,SMURF1,PRMT 6,PRKCSH,ETV6,GSK3A, WDR74,BCOR,NPAS2,USP 1,RBM47,RNF43,TCOF1,N CL,METTL14,KCTD11,HS P90AA1,BTG1,GAB1,S1PR 1,THRB,EDNRB,SYBU,CD NF,MEX3C,SIAH2,NFKBI A,GJA1,CD34,DEAF1,INS R,NR1D2,GADD45G,ZNRF 3,MBOAT7,BSG,BTF3 CRNN,PGA5,CGA,FGA,IG F2,FGB,APOA5,SPRR3,FL G,SPRR1B,FGF21,FGG,TB X22,CALCR,PGC,SPRR1A, ABCB11,OTX2,MUC21,N OG,HSFX2,ZSCAN10,TFA P2C,ERRFI1,RUNX1T1,AL OX12,SPRR2E,PDK4,TEN M1,HAO1,PEMT,FAP,EYA 4,ZNF554,EGR1,CSGALN ACT1,GCG,MMP16,ADA MTS8,COL6A3,MAPK4,O AS2,ETV4,MAOB,GPC6,S OCS5,GMNC,BCL9,PDK3, POU6F2,BTG2,A4GNT,CS T6,VEGFC,FAM20C,USP2 7X,STK32B,KLK13,RPS6,I D3,PGAP2,ALOXE3,LSM1 1,BCAP31,DDIT4,DPP4,TY SND1,IRF2BP2,KLF15,EG R3,RNF165,PHLDA1,LTBP 4,IKZF4,CREB3L1,A1CF,E MX1,NAT10,ACSL6,KLF3, ZFP36,QDPR,OAS1,ETV5, GADD45B,MAN1A1,NXN, TLE3,RPL8,HEYL,PER3,H RAS,GLI3,SFTPD,MYC,RP RD2,DMD,ZNF416,FKBP8, RPS28,DBP,MUC6,MTCH1 ,CHST10,KLF9,EIF4B,KLF 10,GLTP,MNT,CEL,NUP20 5,FOSL2,ZNF362,PAPSS2, NR1D1,DUSP4,SMCR8,FE CH,FOXN3,IL6ST,IL6R,ZN F581,KLF6,CPA1,ABCA1, ZFP36L1,PBX1,SH3RF1,U RM1,ERN1,RPL18,RNF24, PRRC1,NHEJ1,PDK2,STA T1,HSPA2,DUSP1,DIP2B,F MOD,MYADM,APOD,GLS ,FBXO32,SRM,DIRAS3,NR 0B2,SYVN1,ARL6IP1,TCF 7L2,TMUB1,MRPL37,DLL 4,HELZ2,NNMT,SMAD1,T P53,ELK1,PTBP1,PRKACA ,BACH2,CTSF,EGFR,ETS1 ,PIK3CA,ZNRF1,CMPK2,G UK1,TSHZ1,ZNF326,MED 13L,GCNT2,SAE1,PKN1,T NFRSF1A,ELOVL1,TUT1, NCSTN,YBX1,PPP1R3B,P LCE1,NDST1,ATF6B,GAM T,TPI1,JMJD8,SECISBP2L, 
bioRxiv preprint doi: https://doi.org/10.1101/2021.06.08.447531; this version posted June 9, 2021. The copyright holder for this preprint (which was not certified by peer review) is the author/funder. All rights reserved. No reuse allowed without permission.

membrane-enclosed lumen
PRPF8,EIF3B,WDTC1,MA ML1,CRNKL1,NFIB,MAP K3,RPL18A,CNDP2,SERT AD2,RCE1,FOXK1,ZNF64 6,ACVR2B,PLOD3,ZFHX3, SMURF1,AOX1,RPS15,PR MT6,TRIM24,PRKCSH,ET V6,GSK3A,WDR74,LARP6 ,BCOR,URB1,ZNF341,SGT A,STUB1,NPAS2,MAOA,U SP1,RBM47,RNF43,SHISA 5,TCOF1,NCL,FKBP5,RB M22,METTL14,PIGM,ATF 7IP,POLR1D,UBAP2,UBE2 E2,SPPL3,KCTD11,HSP90 AA1,BTG1,S1PR1,THRB,R PL39,UTP14A,EDNRB,CR TC3,AK1,MED25,ERP29,R BM23,RNASEK,LPCAT3,C ASC3,MTMR3,TNKS,SF3A 1,ADPRHL1,MEX3C,SIAH 2,ACD,NFKBIA,GJA1,RNP S1,ATP13A2,TXNDC5,MR PL49,SLC35C2,CD34,SQS TM1,DEAF1,INSR,RPL19, NR1D2,AGBL5,SP2,SLC2 A4RG,MRPS18B,NEDD9,G ADD45G,ZNRF3,MAST3,S NX12,BAZ2A,MBOAT7,GI D8,DCPS,LIG3,SP4,KLF11, CIZ1,LNX1,RALB,BTF3,Z NF836

PGA5,CGA,FGA,IGF2,FGB ,APOA5,FGG,MUC21,STA R,ZSCAN10,TFAP2C,RUN X1T1,SLC7A14,PDK4,TEN M1,HAO1,ZNF554,EGR1,G CG,MMP16,COL6A3,MAP K4,OAS2,ETV4,GPC6,BCL 9,PDK3,VEGFC,FAM20C, RPS6,LSM11,TYSND1,IRF 2BP2,KLF15,PHLDA1,IKZ F4,A1CF,EMX1,NAT10,KL F3,OAS1,ETV5,GRIK5,GP R63,TLE3,HEYL,HRAS,GL I3,MYC,RPRD2,IRS1,RPS2 8,MUC6,KLF9,PODXL,MN T,NUP205,FOSL2,NR1D1, DUSP4,SMCR8,FECH,KLF 6,PBX1,RPL18,ABCG2,NH EJ1,PDK2,SELENBP1,STA T1,HSPA2,FMOD,GLS,FB XO32,NR0B2,NHS,SYVN1 ,TCF7L2,TMUB1,MRPL37, HELZ2,SMAD1,TP53,ELK 1,SUN2,PTBP1,PRKACA,B ACH2,TOR2A,CTSF,EGFR ,ETS1,CMPK2,C17ORF49, ZNF326,SAE1,PKN1,TUT1 ,YBX1,ME2,JMJD8,PRPF8, WDTC1,MAML1,CRNKL1, NFIB,MAPK3,CNDP2,SER TAD2,FOXK1,CAMSAP3,P LOD3,FAM193B,ZFHX3,S MURF1,RPS15,PRMT6,TRI M24,PRKCSH,ETV6,WDR 74,BCOR,URB1,STUB1,NP AS2,USP1,SHISA5,TCOF1, NCL,FKBP5, RBM22,METT L14,MZT2B,ATF7IP,POLR 
bioRxiv preprint doi: https://doi.org/10.1101/2021.06.08.447531; this version posted June 9, 2021. The copyright holder for this preprint (which was not certified by peer review) is the author/funder. All rights reserved. No reuse allowed without permission.

GO:0031981

1D,FIGN,HSP90AA1,BTG1 ,S1PR1,THRB,UTP14A,CR TC3,MED25,ERP29,CASC3 ,TNKS,SF3A1,CHID1,SIA H2, ACD,NFKBIA,ARHGA P17,GJA1,RNPS1,ATP13A 2,TXNDC5,MRPL49,SLC3 5C2,SQSTM1,DEAF1,INSR ,RPL19,NR1D2,SP2,SLC2A 4RG,MRPS18B,NEDD9,BA Z2A,CCDC86,GID8,DCPS, LIG3,SP4,KLF11,CIZ1 ZSCAN10,TFAP2C,RUNX 1T1,SLC7A14,TENM1,ZNF 554,EGR1,MAPK4,OAS2,E TV4,BCL9,PDK3,RPS6,LS M11,IRF2BP2,KLF15,PHL DA1,IKZF4,A1CF,EMX1,N AT10,KLF3,OAS1,ETV5,G RIK5,GPR63,TLE3,HEYL, HRAS,GLI3,MYC,RPRD2,I RS1,RPS28,KLF9,PODXL, MNT,NUP205,FOSL2,NR1 D1,DUSP4,SMCR8,KLF6,P BX1,RPL18,ABCG2,NHEJ1 ,PDK2,SELENBP1,STAT1, HSPA2,FBXO32,NR0B2,N HS,SYVN1,TCF7L2,TMUB 1,HELZ2,SMAD1,TP53,EL K1,SUN2,PTBP1,PRKACA, BACH2,ETS1,CMPK2,C17 ORF49,ZNF326,SAE1,PKN 1,TUT1,YBX1,PRPF8,WDT C1,MAML1,CRNKL1,NFIB ,MAPK3,CNDP2,SERTAD2 ,FOXK1,CAMSAP3,FAM1 93B,ZFHX3,SMURF1,RPS1 5,PRMT6,TRIM24,ETV6,W DR74,BCOR,URB1,STUB1 ,NPAS2,USP1,TCOF1,NCL, FKBP5,RBM22,METTL14, MZT2B,ATF7IP,POLR1D,F IGN,HSP90AA1,BTG1,S1P R1,THRB,UTP14A,CRTC3, MED25,CASC3,TNKS,SF3 A1,SIAH2,ACD,NFKBIA,A RHGAP17,GJA1,RNPS1,SL C35C2,SQSTM1,DEAF1, IN SR,RPL19,NR1D2,SP2,SLC 2A4RG,MRPS18B,NEDD9, BAZ2A,CCDC86,GID8,DC PS,LIG3,SP4,KLF11,CIZ1

T6A,FGB,LCE3D,SLC6A15 ,APOA5,SPRR3,FLG,SLIT RK6,FGF21,FGG,TBX22,C ALCR,SPRR1A,ABCB11,U SH2A,OTX2,HBM,DCC,PO TED, KCP,RGPD3,NOG,ST AR,KRT16,HSFX2,IL1RN, ZSCAN10,SHISA2,TACR1, AQP5,SYNDIG1,TFAP2C, ERRFI1,TMEM174,CNTN AP4,PLP1,RUNX1T1,ALO X12,KRT13,SLC7A14,SPR R2E,PDK4,TENM1,PRLHR ,SLC22A11,PEMT,LY6H,T MEM236,FAP,EYA4,BTBD 11,FBP2,LCE3E,ZNF554,E GR1,CSGALNACT1,MT2A 
bioRxiv preprint doi: https://doi.org/10.1101/2021.06.08.447531; this version posted June 9, 2021. The copyright holder for this preprint (which was not certified by peer review) is the author/funder. All rights reserved. No reuse allowed without permission.

,MAL,SLC38A4,GCG,ASIC 1,ADAMTS8,PTGER4,TM EM201,COL6A3,MAPK4,O AS2,AQP7,SLC25A48,ETV 4,MAOB, GPC6,KCNJ2,MT 1E,SOCS5,GMNC,BCL9,P DK3,ABCC9,POU6F2,BTG 2,CST6,PRR15,VEGFC,FA M20C,C16ORF89,TMEM17 6A,KLK13,RPS6,ID3,PGAP 2,ALOXE3,LSM11,BCAP3 1,DDIT4,DPP4,TYSND1,K LF15,RNF165,AQP8,SLC22 A17,PHLDA1,FAM86B2,L TBP4,IKZF4,CREB3L1, A1 CF,EMX1,NAT10,NETO2, ACSL6,KLF3,ZFP36,QDPR ,OAS1,ETV5,GRIK5,KL,Z NF385C,GADD45B,SLC29 A3,CGREF1,TLE3,RPL8,H EYL,PER3,HRAS,GLI3,W DR89,KIAA0408,SFTPD,M YC,TTI1,IFIT3,IGSF8,RPR D2,DMD,AQP12B,FKBP8,I RS1,KIAA1958,RPS28,TM EM140,MUC6,MTCH1,AB HD15,EIF4B,KLF10,PODX L,BVES,GLTP,MNT,CEL, NUP205,FOSL2,SLC1 A5,W ASF1,PAPSS2,TMCO4,NR 1D1,DUSP4,SNX19,SMCR 8,FECH,FOXN3,IL6ST,IL6 R,PCDHB6,ZNF581,KLF6, CPA1,ABCA1,ZFP36L1,PB X1,DYSF,SH3RF1,PLEKH G6,URM1,ERN1,RPL18,C NTN3,CYGB,RNF24,ABC G2,PRRC1,NHEJ1,PDK2,B OC,SELENBP1,STAT1,HS PA2,DUSP1,DIP2B,FMOD, MYADM,ARPC1A,KCTD1 2,APOD,GLS,FBXO32,SR M,DIRAS3,NR0B2,SYVN1, ARL6IP1,TCF7L2,TMUB1, DHRS11,DLL4,HELZ2,SM AD1,TP53,PCDH18,ELK1, SUN2,TMEM150A,PTBP1, SOS1,PRKACA,BACH2,T OR2A,EGFR,ETS1,PIK3CA ,ZNRF1,C17ORF49,GUK1, ZNF326,GCNT2,SAE1,GTP BP8,PKN1,TNFRSF1 A,EL OVL1,TUT1,NCSTN,MFA P2,YBX1,PPP1R3B,PLCE1, NDST1,KCNJ8,ATF6B,GA MT,DGCR2,TPI1,JMJD8,N ES,CDC42EP3,SECISBP2L, PRPF8,DNAJC4,EIF3B,EP HX1,WDTC1,MAML1,CR NKL1,MAPK3,RPL18A,FA M83B,SERTAD2,FOXK1,Z NF646,CAMSAP3,ACVR2 B,ATXN7L1,LRRC8B,PLO D3,FAM193B,ZFHX3,SMU RF1,AOX1,RPS15,PRMT6, TRIM24,PRKCSH,ETV6,G SK3A,WDR74,KCNC4,LA RP6,BCOR,PSD4,RAB4A,Z NF341,SGTA,STUB1,SLC3 5E1,NPAS2,MAOA,USP1, 
bioRxiv preprint doi: https://doi.org/10.1101/2021.06.08.447531; this version posted June 9, 2021. The copyright holder for this preprint (which was not certified by peer review) is the author/funder. All rights reserved. No reuse allowed without permission.

GO:0140110

MF

transcription regulator

$0.019982707 \quad 1.699345683$ activity
RBM47,RNF43,KIAA0930,

SHISA5,TCOF1,NCL,FKBP 5,RBM22,SLC48A1,TRAPP C3,METTL14,MZT2B,ATF 7IP,RWDD2B,POLR1D,UB IAD1,SFXN2,FIGN,UBAP2 ,UBE2E2,MX1,SPPL3,KCT D11,HSP90AA1,BTG1,GA B1,PXMP2,S1PR1,THRB,U TP14A,EDNRB,CRTC3,SY BU,MED25,ERP29,RBM23, CDNF,RNASEK,CASC $3, \mathrm{M}$ TMR3,TNKS,SF3A1,CHID 1,AGPAT3,MEX3C,SIAH2, ACD,NFKBIA,CDC42EP4, ARHGAP17,GJA1,RNPS1, ATP13A2,ZSWIM3,TXND C5,PPFIBP2,MRPL49,SLC3 5C2,CD34,SQSTM1,DEAF 1,CPNE8,INSR,RPL19,NR1 D2,AGBL5,SP2,YIPF3,MR PS18B,NEDD9,GADD45G, ZNRF3,MAST3,SNX12,TM ED5,BAZ2A,CCDC86,MB OAT7,GID8,DCPS,LIG3,B SG,SP4,KLF11,CIZ1,LNX1, RALB,BTF3,NET1 TBX22,OTX2,HSFX2,ZSC AN10,TFAP2C,RUNX1T1, ZNF554,EGR1,ETV4,BCL9 ,POU6F2,BTG2,IRF2BP2,K LF15,EGR3,IKZF4,CREB3 L1,EMX1,KLF3,ETV5,TLE 3,HEYL,GLI3,MYC,ZNF41 6,DBP,KLF9,KLF10,MNT, FOSL2,ZNF362,NR1D1,FO XN3,ZNF581,KLF6,PBX1, STAT1,NR0B2,TCF7L2,HE LZ2,SMAD1,TP53,ELK1,B ACH2,ETS1,TSHZ1,MED1 3L,PKN1,ATF6B,MAML1, NFIB,SERTAD2,FOXK1,Z NF646,ZFHX3,TRIM24,ET V6,BCOR,ZNF341,NPAS2, ATF7IP,BTG1,THRB,SIAH 2,DEAF1,NR1D2,SP2,SLC2 A4RG,SP4,KLF11,ZNF836

Down regulated genes

DMBT1,OR10J3,OR4F5,O R6C74,OR5L1,OR4D2,OR2 T33,OR2T6,GJA10,OR8H2, OR4N2,CASQ2,OR2A25,T AS2R7, OR1E2,OR2B3, OR6 N1,OR4K5,OR4A5,OR5AN 1,OR5AS1,OR13G1,OR2M 5,OR13C5,OR4C3,OR52L1, OR8K1,OR6B2,OR56A4,O R5B17,OR51A2,OR5T1,OR 1A1,OR13C8,OR13C2,OR5 1B4,OR2AG2,OR2M7,OR5 1L1,OR5H1,OR8G1, OR6K6 ,OR10Z1,OR4K1,OR5T2,O R2A12,OR1L8,OR1J2,TAS 2R60,CHRNA10,OR5AP2, OR52K1,OR9A2,OR10A5, OR4C46,OR52W1,TAS2R8, OR52E6,TTN,OR6K3,OR11 H2,OR52D1,PKDREJ organismal process
IAPP,HAPLN4,ADCYAP1, DMBT1,RGS16,PREX1,NR 
bioRxiv preprint doi: https://doi.org/10.1101/2021.06.08.447531; this version posted June 9, 2021. The copyright holder for this preprint (which was not certified by peer review) is the author/funder. All rights reserved. No reuse allowed without permission.

G3,LRRTM3,GABRA2,GT SF1,NTNG2,GLRA1,DGK G,ISX,OR10J3,SLC6A17,D ACH2,IFNA16,OR4F5,SLC 18A2,KLHL1,OR6C74,DK K4,UNC5A,OR5L1,OR4D2, OR2T33,OR2T6,CDHR1,GJ A10,BMP5,OR8H2,INSRR, POSTN,OR4N2,CASQ2,OR 2A25,CYP24A1,TAS2R7,O R1E2,OR2B3,SLC45A3,IF NA10,LRRC10,GREM2,OR 6N1,CAPN8,TFF3,OR4K5, HOPX,COMP,OR4A5,OR5 AN1,KRTAP1-

3,OR5AS1,GABRR2,OR13 G1,OR2M5,HTR3A,KRTA P13-

3,OR13C5,OR4C3,CHST8, MAS1,OR52L1,KRTAP42,OR8K1,KIRREL3,OR6B2 ,KRTAP19-1,KRTAP31,KRTAP3-2,KRTAP9 9,OR56A4,PSMA6,OR5B17 ,TMEM108,OR51A2,P2RX 5,OR5T1, OR1A1,OR13C8, OR13C2,GAP43,MFAP5,A DAMTSL1,OR51B4,LCE1F ,KCNQ2,SFRP4,OR2AG2, OR2M7,OR51L1,OR5H1,C RLF1,KRTAP21-

2,OR8G1,OR6K6,KRTAP1 9-2,OR10Z1,KRTAP101,DNAH11,NPTX2,OR4K1, OR5T2,EDARADD,PI16,JP H2,INSC,FN1, ACTBL2,C1 QL1,NPFF,OR2A12,BEND 6,OR1L8,HBD, OR1J2,TAS 2R60,VSIG4,IGF2BP3, CHR NA10,OR5AP2,OR52K1,C YP26B1,FAT3,IL10,TNFRS F11A,GCGR,OR9A2,LCN2, TOP2A,MESP2,CDH22,OR 10A5,OR4C46,UCHL1,FGL 1,ACTC1,VASP,CIT,CTNN A3,OR52W1,IL5RA,SOST DC1,TTC8,RADIL,TAS2R8 ,NTN1,OR52E6,P2RX6,CT NNA2,TTN,OR6K3,MUST N1,OR11H2,CCR2,P2RY12 ,CNN1,HRC,PTGS2,DEF8, APOC1,LYZ,GLP1R,NDR G4,CNGA4,APOC2,KRTA P5-

1,HADH,SERPINA3,OR52 D1,TMEM178A,EFNA4,PI R,HSD17B3,PTGFR,SCRG 1,NR6A1,LGI2,AKR1C2,C DH23,ADAMTS2,P2RY1,I GSF11,TSHZ3,PDLIM3,CR YGS,KIF20B,ESR1,ARHG AP22,AGAP2,CYP4F12,SL C26A7,TFCP2L1,RELT,M AP1A,LOXL1,KIF18A,PRI CKLE4,JMJD6,ARG2,POU 5F1,ROBO1,ALOX5,ANLN ,CDK1,SELPLG,GREB1,M YH11,ABCB1,CYP2J2,VA V3,TYMS,SCN1B,MATN3, LAMB3,SRD5A1,SRPX2,S 
bioRxiv preprint doi: https://doi.org/10.1101/2021.06.08.447531; this version posted June 9, 2021. The copyright holder for this preprint (which was not certified by peer review) is the author/funder. All rights reserved. No reuse allowed without permission.

GO:0071944

$\mathrm{CC}$

cell periphery

$1.40 \mathrm{E}-07$

6.853891822

186

GIP1,GLG1,TPM2,SIX2,SA MHD1

HAPLN4,CSNK1G1,IGLL5

,PLCH2,SLCO1A2,DMBT1 ,RGS16,PREX1,LRFN2,NR G3,LRRTM3,GABRA2,NT NG2,GLRA1,DGKG,OR10J 3,SLC6A17,OR4F5,SLC18 A2,SLC26A9,OR6C74,UNC 5A,OR5L1,OR4D2,KCNG3, SLC27A6,OR2T33,CLDN2 5,OR2T6,ADAM30,CDHR1 ,GJA10,RASD1,TAAR9,OR 8H2,INSRR,POSTN,OR4N2 ,OR2A25,LY6G6E,TAS2R7 ,KIF20A,OR1E2,OR2B3,SL C45A3,OR6N1,OR4K5,CO MP,OR4A5,OR5AN1,OR5 AS1,GABRR2,OR13G1,OR 2M5,HTR3A,OR13C5,OR4 C3,MAS1,OR52L1,OR8K1, KIRREL3,OR6B2,SLCO5A 1,OR56A4,OR5B17,PCDH7 ,OR51A2,P2RX5,SLC22A9, OR5T1,OR1A1,OR13C8,O R13C2,GAP43,MFAP5,AD AMTSL1,OR51B4,KCNQ2, KCNF1,OR2AG2,CD1E,OR 2M7,OR51L1,OR5H1,CRL F1,OR8G1,OR6K6,OR10Z1 ,KCNH1,OR4K1,OR5T2,S DR16C5,JPH2,INSC,FN1,O R2A12,CAPNS2,YIPF4,OR 1L8,OR1J2,TAS2R60,CHR NA10,OR5AP2,MEP1B,OR 52K1,FAT3,TNFRSF11A,G CGR,OR9A2,ENTPD3,OX GR1,CDH22,OR10A5,OR4 C46,UCHL1,HLA-

C,CLEC4D,FGL1,VASP,O R52W1,IL5RA,TTC8,TAS2 R8,OLFM4,TSPAN1,GPR1 41,NTN1, OR52E6,P2RX6,C TNNA2,TTN,OR6K3,OR11 H2,CCR2,PRAM1,P2RY12, PTGS2,ITGBL1,GLP1R,ND RG4,KLRK1,CNGA4,SERP INA3,OR52D1,EFNA4,PTG FR,CFB,FCHO1,LRRC7,M MP28,CDH23,ADAMTS2, ATP2C1,P2RY1,IGSF11,TS HZ3,FRMPD1,SELL,ESR1, CYP4F12,RASD2,SLC26A 7,LY6G5B,CSF2RA,RELT, LOXL1,KIF18A,B3GNT3, MYO1F,JMJD6,ROBO1,A NLN,SELPLG,ABCB1,DL G2,ADAMTS10,VAV3,SC N1B,LAT,MATN3,LAMB3, SRPX2,SGIP1,SLC7A7,GL G1,SAMHD1 CSNK1G1,IGLL5,PLCH2,S LCO1A2,RGS16,PREX1,L RFN2,NRG3,LRRTM3,GA BRA2,NTNG2,GLRA1,DG KG,OR10J3,SLC6A17,OR4 F5,SLC18A2,SLC26A9,OR 6C74,UNC5A,OR5L1,OR4 D2,KCNG3,SLC27A6,OR2 T33,CLDN25,OR2T6,ADA 
bioRxiv preprint doi: https://doi.org/10.1101/2021.06.08.447531; this version posted June 9, 2021. The copyright holder for this preprint (which was not certified by peer review) is the author/funder. All rights reserved. No reuse allowed without permission.

transmembranesignalin $\mathrm{g}$ receptor activity
M30,CDHR1,GJA10,RASD

1,TAAR9,OR8H2,INSRR,O R4N2,OR2A25,LY6G6E,T AS2R7,KIF20A,OR1E2,OR 2B3,SLC45A3, OR6N1, OR4 K5,OR4A5,OR5AN1,OR5A S1,GABRR2,OR13G1,OR2 M5,HTR3A,OR13C5,OR4C 3,MAS1,OR52L1,OR8K1,K IRREL3,OR6B2,SLCO5A1, OR56A4,OR5B17,PCDH7, OR51A2,P2RX5,SLC22A9, OR5T1,OR1A1,OR13C8,O R13C2,GAP43,ADAMTSL1 ,OR51B4,KCNQ2,KCNF1, OR2AG2,CD1E,OR2M7,O R51L1,OR5H1,CRLF1,OR8 G1,OR6K6,OR10Z1,KCNH 1,OR4K1,OR5T2,SDR16C5 ,JPH2,INSC,FN1,OR2A12, CAPNS2,YIPF4,OR1L8,OR 1J2,TAS2R60,CHRNA10,O R5AP2,MEP1B,OR52K1,F AT3,TNFRSF11A,GCGR,O R9A2,ENTPD3,OXGR1,CD H22, OR10A5,OR4C46,UC HL1,HLA-

C,CLEC4D,VASP,OR52W1 ,IL5RA,TTC8,TAS2R8, OLF M4,TSPAN1,GPR141,OR52 E6,P2RX6,CTNNA2,TTN,O R6K3,OR11H2,CCR2,PRA M1,P2RY12,PTGS2,ITGBL 1,GLP1R,NDRG4,KLRK1, CNGA4,OR52D1,EFNA4,P TGFR,CFB,FCHO1,LRRC7 ,CDH23,ATP2C1,P2RY1,IG SF11,TSHZ3,FRMPD1,SEL L,ESR1,CYP4F12,RASD2,S LC26A7,LY6G5B,CSF2RA, RELT,KIF18A,B3GNT3,M YO1F,JMJD6,ROBO1,SEL PLG,ABCB1,DLG2,VAV3, SCN1B,LAT,SRPX2,SGIP1 ,SLC7A7,GLG1,SAMHD1 GABRA2,GLRA1,OR10J3, OR4F5,OR6C74,UNC5A,O R5L1,OR4D2,OR2T33,OR2 T6,TAAR9, OR8H2,INSRR, OR4N2,OR2A25,TAS2R7, OR1E2,OR2B3, OR6N1,OR 4K5, OR4A5,OR5AN1, OR5 AS1,GABRR2,OR13G1,OR 2M5,HTR3A,OR13C5,OR4 C3,MAS1,OR52L1, OR8K1, OR6B2,OR56A4,OR5B17,O R51A2,P2RX5,OR5T1,OR1 A1,OR13C8,OR13C2,OR51 B4,OR2AG2,OR2M7,OR51 L1,OR5H1,CRLF1, OR8G1, OR6K6,OR10Z1,OR4K1,O R5T2,OR2A12,OR1L8,OR1 J2,TAS2R60,CHRNA10,OR 5AP2,OR52K1,TNFRSF11 A,GCGR,OR9A2,OXGR1,O R10A5,OR4C46,OR52W1,I L5RA,SOSTDC1,TAS2R8, GPR141,OR52E6,P2RX6,O R6K3,OR11H2,CCR2,P2RY 12,GLP1R,OR52D1,EFNA4 
bioRxiv preprint doi: https://doi.org/10.1101/2021.06.08.447531; this version posted June 9, 2021. The copyright holder for this preprint (which was not certified by peer review) is the author/funder. All rights reserved. No reuse allowed without permission.

GO:0060089
MF molecular transducer activity
2.72E-18 $\quad 17.56616903$
,PTGFR,P2RY1,CSF2RA,R OBO1

DMBT1,GABRA2,GLRA1, OR10J3,RXRG,OR4F5,OR6 C74,UNC5A,OR5L1,OR4D 2,OR2T33,OR2T6,TAAR9, OR8H2,INSRR,OR4N2,OR 2A25,TAS2R7, OR1E2, OR2 B3,OR6N1,OR4K5,OR4A5, OR5AN1,OR5AS1,GABRR 2,OR13G1,OR2M5,HTR3A, OR13C5,OR4C3,MAS1,OR 52L1,OR8K1,OR6B2,OR56 A4,OR5B17,OR51A2,P2RX 5,OR5T1,OR1A1,OR13C8, OR13C2,OR51B4,OR2AG2, OR2M7,OR51L1,OR5H1,C RLF1, OR8G1,OR6K6,OR10 Z1,OR4K1,OR5T2,OR2A12 ,OR1L8,OR1J2,TAS2R60,C HRNA10,OR5AP2,OR52K1 ,TNFRSF11A,GCGR,OR9A 2,OXGR1,OR10A5,OR4C4 6,OR52W1,IL5RA,SOSTD C1,TAS2R8,GPR141,OR52 E6,P2RX6,OR6K3,OR11H2 ,CCR2,P2RY12,GLP1R,KL RK1,OR52D1,EFNA4,PTG FR,P2RY1,ESR1,CSF2RA,J MJD6,ROBO1

Table 4 The enriched pathway terms of the up and down regulated differentially expressed genes

\begin{tabular}{|c|c|c|c|c|c|}
\hline Pathway ID & Pathway Name & Adjusted $p$ value & $\begin{array}{l}\text { Negative } \\
\text { log10 of } \\
\text { adjusted } p \\
\text { value }\end{array}$ & $\begin{array}{l}\text { Gene } \\
\text { Count }\end{array}$ & Gene \\
\hline \multicolumn{6}{|c|}{ Up regulated genes } \\
\hline $\begin{array}{l}\text { REAC:R-HSA- } \\
5663202\end{array}$ & $\begin{array}{l}\text { Diseases of signal } \\
\text { transduction by } \\
\text { growth factor } \\
\text { receptors and second } \\
\text { messengers }\end{array}$ & 0.002918856 & 2.534787284 & 25 & $\begin{array}{l}\text { FGA, FGB,FGG,HEYL,HRAS, MYC,IRS1,KIA } \\
\text { A1549,STAT1,SYVN1,TCF7L2,DLL4,SOS1 } \\
\text {,EGFR,PIK3CA,NCSTN,MAML1,MAPK3,T } \\
\text { RIM24,ETV6,GSK3A, RNF43,HSP90AA1, } \\
\text { GAB1,TNKS }\end{array}$ \\
\hline $\begin{array}{l}\text { REAC:R-HSA- } \\
6809371\end{array}$ & $\begin{array}{l}\text { Formation of the } \\
\text { cornified envelope }\end{array}$ & 0.009712336 & 2.012676308 & 12 & $\begin{array}{l}\text { KRT6A,LCE3D, SPRR3, FLG,SPRR2D,SPRR } \\
\text { 1B,SPRR1A,KRT16, KRT13,SPRR2E,LCE3E } \\
\text {,KLK13 }\end{array}$ \\
\hline $\begin{array}{l}\text { REAC:R-HSA- } \\
156827\end{array}$ & $\begin{array}{l}\text { L13a-mediated } \\
\text { translational silencing } \\
\text { of Ceruloplasmin } \\
\text { expression }\end{array}$ & 0.027095018 & 1.567110554 & 10 & $\begin{array}{l}\text { RPS6, RPL8, RPS28,EIF4B,RPL18, EIF3B,RP } \\
\text { L18A,RPS15,RPL39, RPL19 }\end{array}$ \\
\hline $\begin{array}{l}\text { REAC:R-HSA- } \\
1643685\end{array}$ & Disease & 0.027095018 & 1.567110554 & 60 & $\begin{array}{l}\text { CGA,FGA,FGB,FGG,CALCR,ABCB11,MUC } \\
\text { 21,GCG,ADAMTS8,PTGER4,GPC6,ABCC9 } \\
\text {,RPS6,SLC29A3,RPL8,HEYL,HRAS,SFTPD, } \\
\text { MYC,IRS1,RPS28,MUC6,NUP205,WASF1 } \\
\text {,PAPSS2,KIAA1549,IL6R,ABCA1,RPL18,S } \\
\text { TAT1,FMOD, ARPC1A,SYVN1,TCF7L2,DLL } \\
\text { 4,ELK1,SOS1,PRKACA, EGFR,PIK3CA,NCS } \\
\text { TN,MAML1,M APK3,RPL18A, RPS15,TRI } \\
\text { M24,PRKCSH,ETV6,GSK3A,MAOA,RNF4 } \\
\text { 3,HSP90AA1,GAB1,S1PR1,RPL39,TNKS, } \\
\text { NFKBIA,RPL19,SLC39A4,BSG }\end{array}$ \\
\hline $\begin{array}{l}\text { REAC:R-HSA- } \\
9006934\end{array}$ & $\begin{array}{l}\text { Signaling by Receptor } \\
\text { Tyrosine Kinases }\end{array}$ & 0.03209698 & 1.493535827 & 25 & $\begin{array}{l}\text { IGF2, EGR1,COL6A3, VEGFC,ID3, EGR3, HR } \\
\text { AS,IRS1, WASF1,DUSP4,STAT1,ELK1,PTB } \\
\text { P1,SOS1,PRKACA, EGFR,PIK3CA, NCSTN, } \\
\text { MAPK3,RAB4A,STUB1, HSP90AA1,GAB1, }\end{array}$ \\
\hline
\end{tabular}


bioRxiv preprint doi: https://doi.org/10.1101/2021.06.08.447531; this version posted June 9, 2021. The copyright holder for this preprint (which was not certified by peer review) is the author/funder. All rights reserved. No reuse allowed without permission.

\begin{tabular}{|c|c|c|c|}
\hline $\begin{array}{l}\text { REAC:R-HSA- } \\
1266738\end{array}$ & $\begin{array}{l}\text { Developmental } \\
\text { Biology }\end{array}$ & 0.032172975 & $1.492508778 \quad 45$ \\
\hline
\end{tabular}

INSR, RALB

KRT6A, LCE3D, SPRR3, FLG,SPRR2D,SPRR 1B,SPRR1A,DCC,KRT16,ZSCAN10,KRT13 ,SPRR2E,LCE3E,COL6A3,MPZ,KLK13,RPS 6, RPL8, HRAS, MYC, RPS28,IL6R, PBX1, RPL 18, ARPC1A, HELZ2,SOS1, PRKACA, EGFR, PIK3CA,MED13L,NCSTN,MAML1,MAPK 3,RPL18A, ACVR2B,RPS15, HSP90AA1,GA B1,RPL39,MED25,CASC3,SIAH2,RNPS1, RPL19

\begin{tabular}{|c|c|c|c|c|}
\hline & & \multicolumn{3}{|c|}{ Down regulated genes } \\
\hline $\begin{array}{l}\text { REAC:R-HSA- } \\
381753\end{array}$ & $\begin{array}{l}\text { Olfactory Signaling } \\
\text { Pathway }\end{array}$ & $4.32 \mathrm{E}-23$ & 22.36427935 & 54 \\
\hline
\end{tabular}

OR10J3,OR4F5,OR6C74,OR5L1,OR4D2,
OR2T33,OR2T6, OR8H2,OR4N2,OR2A25, OR1E2,OR2B3, OR6N1,OR4K5, OR4A5,O R5AN1,OR5AS1,OR13G1,OR2M5,OR13 C5,OR4C3,OR52L1,OR8K1,OR6B2,OR56 A4,OR5B17,OR51A2,OR5T1,OR1A1,OR1 3C8,OR13C2,OR51B4,OR2AG2,OR2M7, OR51L1,OR5H1,OR8G1,OR6K6,OR10Z1, OR4K1,OR5T2,OR2A12,OR1L8,OR1J2, O R5AP2,OR52K1,OR9A2,OR10A5,OR4C4 6,OR52W1,OR52E6,OR6K3,OR11H2,OR 52D1

\begin{tabular}{|c|c|c|c|}
\hline $\begin{array}{l}\text { REAC:R-HSA- } \\
9709957\end{array}$ & Sensory Perception & $4.85 \mathrm{E}-21$ & 20.31389969 \\
\hline
\end{tabular}

REAC:R-HSA418555
$6.29 \mathrm{E}-20$ events
REAC:R-HSA388396
GPCR downstream signalling
$9.32 \mathrm{E}-15$

(1)

(2)

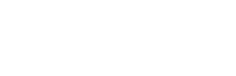


bioRxiv preprint doi: https://doi.org/10.1101/2021.06.08.447531; this version posted June 9, 2021. The copyright holder for this preprint (which was not certified by peer review) is the author/funder. All rights reserved. No reuse allowed without permission.

$\begin{array}{llll}\text { REAC:R-HSA- Signal Transduction } & 7.38146 E-05 & 4.131857963 & 105\end{array}$ 162582

Table 5 Topology table for up and down regulated genes.

\begin{tabular}{|c|c|c|c|c|c|}
\hline Regulation & Node & Degree & Betweenness & Stress & Closeness \\
\hline Up & MYC & 769 & 0.24506 & $1.04 \mathrm{E}+08$ & 0.402932 \\
\hline Up & EGFR & 469 & 0.138032 & 61812344 & 0.381322 \\
\hline Up & LNX1 & 301 & 0.098028 & 35639540 & 0.344753 \\
\hline Up & YBX1 & 242 & 0.052423 & 15440248 & 0.370488 \\
\hline $\mathrm{Up}$ & HSP90AA1 & 198 & 0.042012 & 18645766 & 0.349323 \\
\hline Up & RNPS1 & 148 & 0.029398 & 16186898 & 0.324119 \\
\hline Up & SGTA & 139 & 0.039126 & 11319544 & 0.315439 \\
\hline Up & TNFRSF1A & 116 & 0.016842 & 8191032 & 0.328598 \\
\hline Up & SQSTM1 & 112 & 0.025913 & 6213766 & 0.344335 \\
\hline Up & MAST3 & 105 & 0.022 & 12287012 & 0.305669 \\
\hline Up & POU6F2 & 99 & 0.028224 & 4939174 & 0.317338 \\
\hline Up & STUB1 & 95 & 0.01869 & 5557470 & 0.333856 \\
\hline Up & FKBP5 & 94 & 0.015263 & 3991284 & 0.329764 \\
\hline Up & PRMT6 & 82 & 0.023047 & 4016020 & 0.301486 \\
\hline Up & MAPK3 & 78 & 0.01798 & 4710364 & 0.312259 \\
\hline Up & SMAD1 & 77 & 0.014129 & 5216492 & 0.309237 \\
\hline Up & TFAP2C & 77 & 0.020062 & 3309460 & 0.333573 \\
\hline Up & NCL & 73 & 0.015947 & 5344646 & 0.374917 \\
\hline Up & ETS1 & 69 & 0.014065 & 3895426 & 0.310987 \\
\hline Up & MEX3C & 68 & 0.003769 & 2594352 & 0.310439 \\
\hline $\mathrm{Up}$ & ACD & 66 & 0.014094 & 3525238 & 0.307138 \\
\hline Up & NFKBIA & 66 & 0.008138 & 4939524 & 0.310854 \\
\hline Up & GAB1 & 61 & 0.005759 & 2357788 & 0.296365 \\
\hline Up & ZNF581 & 58 & 0.008074 & 2392056 & 0.303509 \\
\hline Up & PRKACA & 58 & 0.012141 & 2683394 & 0.312833 \\
\hline Up & KRT13 & 56 & 0.009539 & 2356276 & 0.31577 \\
\hline Up & SF3A1 & 54 & 0.005297 & 3631052 & 0.304231 \\
\hline Up & STAT1 & 54 & 0.010129 & 1749810 & 0.330531 \\
\hline
\end{tabular}

OR4N2,OR2A25,TAS2R7,OR1E2,OR2B3, OR6N1,OR4K5, OR4A5,OR5AN1,OR5AS1 OR13G1,OR2M5,OR13C5,OR4C3,OR52 L1,OR8K1,OR6B2,OR56A4,OR5B17,OR5 1A2,OR5T1,OR1A1,OR13C8,OR13C2,OR 51B4,OR2AG2,OR2M7,OR51L1,OR5H1, OR8G1,OR6K6,OR10Z1,OR4K1,OR5T2,N PFF,OR2A12,OR1L8,RDH16,OR1J2,TAS2 R60,OR5AP2,OR52K1,OR9A2,OXGR1,O R10A5, OR4C46,OR52W1,TAS2 R8,OR52 E6,OR6K3,BCO2,OR11H2,CCR2,P2RY12, GLP1R,APOC2,OR52D1,PTGFR,P2RY1,P DE1C, VAV3

IAPP,ADCYAP1, RGS16,PREX1,NRG3,DLK 1,DGKG,OR10J3,RXRG,OR4F5,OR6C74, DKK4,OR5L1,OR4D2,ARHGEF35,OR2T33 ,OR2T6,TAAR9,OR8H2,OR4N2,OR2A25, TAS2R7,OR1E2, OR2B3,GREM2,OR6N1,T FF3,OR4K5, OR4A5,OR5AN1,OR5AS1,OR 13G1,OR2M5,OR13C5,OR4C3,OR52L1, OR8K1,OR6B2,OR56A4,PSM A6, DLGAP5 ,OR5B17,OR51A2,OR5T1,OR1A1,OR13C 8,OR13C2,OR51B4,OR2AG2,OR2M7,OR 51L1,OR5H1,OR8G1, OR6K6,OR10Z1, OR 4K1, OR5T2,SDR16C5,FN1,NPFF,OR2A12 ,OR1L8,RDH16,OR112,TAS2R60,OR5AP2 ,OR52K1,CYP26B1,OR9A2,OXGR1,OR10 A5,SPC24,OR4C46, CIT,OR52W1,IL5RA, T AS2R8,OR52E6,OR6K3,BCO2,OR11H2,C CR2,P2RY12,APOC1,GLP1R,APOC2,OR5 2D1,SMAD9, PTGFR,BUB1B,P2RY1, ARH GAP20, NEDD8, ESR1,ARHGAP22,CSF2RA ,KIF18A,ARHGAP9,CDK1,GREB1,MYH11, PDE1C,DLG2,VAV3,LAMB3 


\begin{tabular}{|c|c|c|c|c|c|}
\hline Up & ATF7IP & 54 & 0.011319 & 2610676 & 0.297746 \\
\hline Up & FOXK1 & 52 & 0.010322 & 2431366 & 0.309968 \\
\hline Up & KRT16 & 52 & 0.009137 & 2768286 & 0.302646 \\
\hline Up & RPS6 & 50 & 0.005709 & 1809230 & 0.323503 \\
\hline Up & IFIT3 & 48 & 0.004333 & 1419676 & 0.307396 \\
\hline Up & UBE2E2 & 48 & 0.009384 & 2778786 & 0.289714 \\
\hline Up & PKN1 & 47 & 0.007325 & 2119206 & 0.29714 \\
\hline Up & ARL6IP1 & 46 & 0.011853 & 5167578 & 0.284047 \\
\hline Up & UTP14A & 45 & 0.00788 & 1716012 & 0.322239 \\
\hline Up & PRPF8 & 44 & 0.006824 & 1731078 & 0.329977 \\
\hline Up & GADD45G & 44 & 0.007648 & 1727574 & 0.29879 \\
\hline Up & ATP13A2 & 43 & 0.011364 & 3235048 & 0.28605 \\
\hline Up & HRAS & 42 & 0.006113 & 1934688 & 0.306916 \\
\hline Up & DCC & 42 & 0.005613 & 2081812 & 0.292265 \\
\hline Up & SUN2 & 42 & 0.004561 & 2137880 & 0.299806 \\
\hline Up & DYSF & 41 & 0.007116 & 2286238 & 0.293962 \\
\hline Up & NCSTN & 40 & 0.007729 & 5776106 & 0.274308 \\
\hline Up & RPL8 & 37 & 0.004561 & 1421422 & 0.324922 \\
\hline Up & BACH2 & 37 & 0.008838 & 2796552 & 0.273369 \\
\hline Up & PIK3CA & 37 & 0.005768 & 1280756 & 0.304576 \\
\hline Up & РTBP1 & 36 & 0.003339 & 1190818 & 0.333507 \\
\hline Up & FKBP8 & 35 & 0.00586 & 1371274 & 0.3223 \\
\hline Up & NES & 35 & 0.007013 & 1126640 & 0.295338 \\
\hline Up & KRT6A & 34 & 0.005784 & 1381296 & 0.320281 \\
\hline Up & NUP205 & 33 & 0.005495 & 1090580 & 0.323442 \\
\hline Up & FOXP1 & 33 & 0.006278 & 1144548 & 0.31992 \\
\hline Up & INSR & 33 & 0.003132 & 1562024 & 0.279757 \\
\hline Up & BCAP31 & 32 & 0.00482 & 1838970 & 0.292131 \\
\hline Up & BTF3 & 31 & 0.00454 & 1476600 & 0.290636 \\
\hline Up & RPL18A & 31 & 0.002498 & 754566 & 0.318306 \\
\hline Up & KIAA0408 & 30 & 0.00425 & 1221042 & 0.302575 \\
\hline Up & USP1 & 30 & 0.004591 & 2441058 & 0.280879 \\
\hline Up & EIF3B & 29 & 0.003846 & 916674 & 0.315848 \\
\hline Up & HSPA2 & 28 & 0.002862 & 684442 & 0.313947 \\
\hline Up & RPS28 & 28 & 0.002873 & 1278818 & 0.301718 \\
\hline Up & SOS1 & 28 & 0.002513 & 879664 & 0.284205 \\
\hline Up & ERRFI1 & 26 & 0.002199 & 611152 & 0.311214 \\
\hline Up & LCE3E & 26 & 0.001327 & 524110 & 0.25448 \\
\hline Up & GSK3A & 26 & 0.004252 & 1655588 & 0.292867 \\
\hline Up & NAT10 & 26 & 0.001696 & 666842 & 0.325191 \\
\hline Up & LIG3 & 26 & 0.00228 & 725644 & 0.294691 \\
\hline Up & RPL18 & 25 & $9.73 \mathrm{E}-04$ & 477540 & 0.322646 \\
\hline Up & SLC1A5 & 25 & 0.004674 & 807018 & 0.306677 \\
\hline Up & EIF4B & 25 & 0.00188 & 620280 & 0.295594 \\
\hline Up & NEDD9 & 24 & 0.003127 & 549922 & 0.289271 \\
\hline Up & CASC3 & 23 & 0.002491 & 601190 & 0.302503 \\
\hline Up & FOSL2 & 23 & 0.003682 & 831006 & 0.310911 \\
\hline Up & SMURF1 & 22 & 0.002704 & 664080 & 0.284142 \\
\hline Up & PLOD3 & 22 & 0.003554 & 1082282 & 0.335808 \\
\hline Up & TCOF1 & 22 & 0.00218 & 501286 & 0.314295 \\
\hline Up & ZNF326 & 22 & 0.001349 & 640724 & 0.29001 \\
\hline Up & SP4 & 22 & 0.003993 & 853624 & 0.26749 \\
\hline Up & EGR1 & 21 & 0.002422 & 466912 & 0.302056 \\
\hline Up & MAGEA2 & 21 & 0.004402 & 1011862 & 0.293759 \\
\hline Up & CREB3L1 & 21 & 0.006704 & 4786040 & 0.227129 \\
\hline Up & WASF1 & 20 & 0.003044 & 1067564 & 0.274868 \\
\hline Up & IRS1 & 20 & 0.001568 & 411892 & 0.309837 \\
\hline Up & CRTC3 & 20 & 0.002135 & 967284 & 0.279558 \\
\hline Up & FBP2 & 20 & $9.48 \mathrm{E}-04$ & 423694 & 0.288846 \\
\hline Up & MED25 & 20 & 0.001218 & 294794 & 0.275609 \\
\hline Up & LCE3D & 20 & $4.82 \mathrm{E}-04$ & 304904 & 0.263329 \\
\hline Up & DEAF1 & 19 & 0.002531 & 618844 & 0.3017 \\
\hline Up & PDK3 & 19 & 0.003011 & 604606 & 0.307526 \\
\hline Up & RPL19 & 19 & $6.37 \mathrm{E}-04$ & 392064 & 0.319241 \\
\hline Up & ABCA1 & 19 & 0.004473 & 1062228 & 0.298441 \\
\hline Up & SAE1 & 19 & 0.003167 & 702666 & 0.299157 \\
\hline Up & MAL & 19 & 0.004533 & 1470896 & 0.264227 \\
\hline Up & RAB4A & 19 & 0.003857 & 747204 & 0.292398 \\
\hline Up & RALB & 19 & 0.001738 & 1634506 & 0.255536 \\
\hline Up & TRAPPC3 & 19 & 0.005096 & 1890182 & 0.252046 \\
\hline
\end{tabular}




\begin{tabular}{|c|c|c|c|c|c|}
\hline Up & DPP4 & 19 & 0.00527 & 1619646 & 0.234023 \\
\hline Up & PRKCSH & 18 & 0.002123 & 375070 & 0.316043 \\
\hline Up & RBM22 & 18 & 0.002051 & 950490 & 0.283386 \\
\hline Up & CAMSAP3 & 18 & 0.002085 & 1031300 & 0.274014 \\
\hline Up & AK1 & 18 & 0.002632 & 1174620 & 0.257986 \\
\hline Up & TTI1 & 17 & 0.001947 & 994560 & 0.275505 \\
\hline Up & RUNX1T1 & 17 & 0.002454 & 1455104 & 0.275046 \\
\hline Up & RPS15 & 16 & 0.00225 & 468552 & 0.316395 \\
\hline Up & NR0B2 & 16 & 0.002709 & 597146 & 0.313581 \\
\hline Up & POLR1D & 16 & 0.001752 & 656232 & 0.282369 \\
\hline Up & FAM83B & 16 & $8.49 \mathrm{E}-04$ & 301500 & 0.277314 \\
\hline Up & PBX1 & 16 & 0.001944 & 703560 & 0.258718 \\
\hline Up & TCF7L2 & 15 & 0.001345 & 373312 & 0.28326 \\
\hline Up & $\mathrm{BCOR}$ & 15 & 0.002336 & 806128 & 0.273164 \\
\hline Up & ID3 & 15 & 0.002818 & 819716 & 0.269962 \\
\hline Up & SLC35E1 & 15 & 0.003323 & 1409720 & 0.24654 \\
\hline Up & TPI1 & 14 & 0.002071 & 457522 & 0.314391 \\
\hline Up & SIAH2 & 14 & 0.001994 & 845214 & 0.269677 \\
\hline Up & TNKS & 14 & 0.002475 & 650184 & 0.251959 \\
\hline Up & RBM23 & 14 & $2.87 \mathrm{E}-04$ & 166572 & 0.276758 \\
\hline Up & HEYL & 14 & 0.002211 & 402860 & 0.280864 \\
\hline Up & MRPL37 & 2 & $1.61 \mathrm{E}-04$ & 51382 & 0.28108 \\
\hline Up & GID8 & 2 & $4.01 \mathrm{E}-05$ & 6218 & 0.246921 \\
\hline Up & DIP2B & 2 & 0 & 0 & 0.291299 \\
\hline Up & SH3RF1 & 2 & $2.53 \mathrm{E}-04$ & 99400 & 0.287919 \\
\hline Up & ZFP36L1 & 2 & $9.45 \mathrm{E}-05$ & 13940 & 0.255792 \\
\hline Up & GCG & 2 & $1.27 \mathrm{E}-04$ & 41870 & 0.209131 \\
\hline Up & YIPF3 & 2 & $7.28 \mathrm{E}-05$ & 18416 & 0.211048 \\
\hline Up & FGB & 1 & 0 & 0 & 0.254404 \\
\hline Up & FAM20C & 1 & 0 & 0 & 0.254404 \\
\hline Up & GLI3 & 1 & 0 & 0 & 0.236207 \\
\hline Up & NXN & 1 & 0 & 0 & 0.215614 \\
\hline Up & PHLDA1 & 1 & 0 & 0 & 0.276071 \\
\hline Up & SPRR1A & 1 & 0 & 0 & 0.276071 \\
\hline Up & DNAJC4 & 1 & 0 & 0 & 0.276071 \\
\hline Up & MRPL49 & 1 & 0 & 0 & 0.270347 \\
\hline Up & COL6A3 & 1 & 0 & 0 & 0.22719 \\
\hline Up & MZT2B & 1 & 0 & 0 & 0.287223 \\
\hline Up & ZFHX3 & 1 & 0 & 0 & 0.287223 \\
\hline Up & SNX19 & 1 & 0 & 0 & 0.287223 \\
\hline Up & KLF10 & 1 & 0 & 0 & 0.287223 \\
\hline Up & ST6GALNAC6 & 1 & 0 & 0 & 0.287223 \\
\hline Up & RPRD2 & 1 & 0 & 0 & 0.287223 \\
\hline Up & ETV6 & 1 & 0 & 0 & 0.287223 \\
\hline Up & SYVN1 & 1 & 0 & 0 & 0.273764 \\
\hline Up & SPRR2D & 1 & 0 & 0 & 0.229084 \\
\hline $\mathrm{Up}$ & FGF21 & 1 & 0 & 0 & 0.239809 \\
\hline Up & TMEM174 & 1 & 0 & 0 & 0.239809 \\
\hline Up & CYGB & 1 & 0 & 0 & 0.222435 \\
\hline Up & CRNN & 1 & 0 & 0 & 0.256151 \\
\hline Up & PLCE1 & 1 & 0 & 0 & 0.258901 \\
\hline Up & SFTPD & 1 & 0 & 0 & 0.201125 \\
\hline Up & TRIM24 & 1 & 0 & 0 & 0.273179 \\
\hline $\mathrm{Up}$ & APOD & 1 & 0 & 0 & 0.273179 \\
\hline Up & THRB & 1 & 0 & 0 & 0.21607 \\
\hline Up & IKZF4 & 1 & 0 & 0 & 0.23715 \\
\hline Up & SPRR3 & 1 & 0 & 0 & 0.23715 \\
\hline Up & CNTNAP4 & 1 & 0 & 0 & 0.23412 \\
\hline Up & ZNRF1 & 1 & 0 & 0 & 0.224644 \\
\hline Up & ATXN7L1 & 1 & 0 & 0 & 0.211048 \\
\hline Up & FLG & 1 & 0 & 0 & 0.219296 \\
\hline Up & MT2A & 1 & 0 & 0 & 0.250147 \\
\hline Up & SHISA5 & 1 & 0 & 0 & 0.250147 \\
\hline Up & RWDD2B & 1 & 0 & 0 & 0.230063 \\
\hline Up & OAS1 & 1 & 0 & 0 & 0.231658 \\
\hline Up & TMED5 & 1 & 0 & 0 & 0.231658 \\
\hline Up & NR1D2 & 1 & 0 & 0 & 0.231658 \\
\hline Up & GPATCH4 & 1 & 0 & 0 & 0.228011 \\
\hline Up & KLF11 & 1 & 0 & 0 & 0.217829 \\
\hline Up & ZFP36 & 1 & 0 & 0 & 0.239696 \\
\hline
\end{tabular}




\begin{tabular}{|c|c|c|c|c|c|}
\hline Up & MTMR3 & 1 & 0 & 0 & 0.239696 \\
\hline Up & FOXN3 & 1 & 0 & 0 & 0.239696 \\
\hline Up & PGAP2 & 1 & 0 & 0 & 0.221817 \\
\hline Up & ELK1 & 1 & 0 & 0 & 0.237967 \\
\hline Up & DUSP1 & 1 & 0 & 0 & 0.237967 \\
\hline Up & IL6ST & 1 & 0 & 0 & 0.248433 \\
\hline Up & SNX12 & 1 & 0 & 0 & 0.221222 \\
\hline Up & LSM11 & 1 & 0 & 0 & 0.237183 \\
\hline Up & MED13L & 1 & 0 & 0 & 0.232501 \\
\hline Down & ESR1 & 448 & 0.115717 & 68567806 & 0.375827 \\
\hline Down & FN1 & 445 & 0.130416 & 47618446 & 0.393806 \\
\hline Down & TK1 & 155 & 0.044276 & 10622930 & 0.341187 \\
\hline Down & ANLN & 102 & 0.019831 & 5950428 & 0.327945 \\
\hline Down & SMAD9 & 99 & 0.023512 & 10495428 & 0.31337 \\
\hline Down & NEDD8 & 94 & 0.013216 & 4708022 & 0.323626 \\
\hline Down & TTN & 88 & 0.021791 & 4877390 & 0.354606 \\
\hline Down & CDK1 & 76 & 0.019122 & 4123802 & 0.343387 \\
\hline Down & KRTAP4-2 & 73 & 0.019925 & 3654538 & 0.300106 \\
\hline Down & MED10 & 65 & 0.012717 & 3973710 & 0.302915 \\
\hline Down & EXOSC8 & 61 & 0.015702 & 2371472 & 0.315244 \\
\hline Down & NEK6 & 61 & 0.009473 & 2973110 & 0.31289 \\
\hline Down & OIP5 & 60 & 0.013758 & 3810166 & 0.30688 \\
\hline Down & PSMA6 & 57 & 0.012284 & 2937164 & 0.324778 \\
\hline Down & BUB1B & 54 & 0.010813 & 5323030 & 0.298111 \\
\hline Down & FOXM1 & 43 & 0.007242 & 2131654 & 0.300317 \\
\hline Down & RPL31 & 35 & 0.003717 & 1156016 & 0.323013 \\
\hline Down & EEF1A2 & 33 & 0.002074 & 927396 & 0.307212 \\
\hline Down & JMJD6 & 31 & 0.006976 & 4154054 & 0.261751 \\
\hline Down & VASP & 30 & 0.005691 & 1017020 & 0.316768 \\
\hline Down & МАР3К8 & 30 & 0.001715 & 773154 & 0.310458 \\
\hline Down & UCHL1 & 28 & 0.003224 & 905164 & 0.308808 \\
\hline Down & TOP2A & 28 & 0.0032 & 1042178 & 0.328788 \\
\hline Down & MYH11 & 28 & 0.003406 & 1173838 & 0.305103 \\
\hline Down & RASSF1 & 27 & 0.004112 & 1253252 & 0.299175 \\
\hline Down & KRTAP3-2 & 27 & 0.004532 & 1398432 & 0.265421 \\
\hline Down & TXNDC9 & 26 & 0.004126 & 1143166 & 0.278477 \\
\hline Down & ACTC1 & 24 & 0.004063 & 1053202 & 0.329594 \\
\hline Down & SPC24 & 23 & 0.002762 & 801496 & 0.268982 \\
\hline Down & SH3BP2 & 21 & 0.001863 & 813564 & 0.277887 \\
\hline Down & IGF2BP3 & 20 & 0.001318 & 388432 & 0.332401 \\
\hline Down & KIF20A & 20 & 0.004794 & 850452 & 0.262706 \\
\hline Down & SFRP4 & 20 & 0.001565 & 724830 & 0.277404 \\
\hline Down & KIF20B & 18 & 0.003465 & 529620 & 0.306935 \\
\hline Down & RASD1 & 18 & 0.001969 & 611526 & 0.282869 \\
\hline Down & NEFM & 18 & 0.002405 & 500776 & 0.29515 \\
\hline Down & RADIL & 18 & 0.001925 & 718708 & 0.28187 \\
\hline Down & LCE1F & 18 & $5.31 \mathrm{E}-04$ & 1078996 & 0.215551 \\
\hline Down & LUC7L & 17 & 0.001779 & 331232 & 0.297175 \\
\hline Down & LYZ & 17 & 0.002823 & 462382 & 0.311441 \\
\hline Down & PFKFB2 & 17 & 0.002624 & 984686 & 0.285029 \\
\hline Down & ACTBL2 & 17 & $5.95 \mathrm{E}-04$ & 248094 & 0.310647 \\
\hline Down & FCHO1 & 17 & 0.002083 & 725112 & 0.267588 \\
\hline Down & KIF18A & 17 & 0.002914 & 1632588 & 0.264802 \\
\hline Down & SAMHD1 & 16 & 0.002408 & 964652 & 0.269962 \\
\hline Down & LAT & 15 & 0.002067 & 607316 & 0.301593 \\
\hline Down & PBK & 15 & 0.002668 & 669380 & 0.294912 \\
\hline Down & TPX2 & 15 & $9.04 \mathrm{E}-04$ & 407858 & 0.293506 \\
\hline Down & RRM2 & 15 & 0.002347 & 419566 & 0.272147 \\
\hline Down & LAMB3 & 15 & 0.002279 & 1460718 & 0.265531 \\
\hline Down & ALOX5 & 15 & 0.003126 & 496364 & 0.267099 \\
\hline Down & TPM2 & 15 & 4.76E-04 & 162954 & 0.290092 \\
\hline Down & IP6K3 & 14 & 0.001497 & 346042 & 0.275387 \\
\hline Down & VAV3 & 14 & 0.001429 & 470180 & 0.297573 \\
\hline Down & NDUFA8 & 13 & 0.00167 & 479156 & 0.290455 \\
\hline Down & BIRC8 & 13 & 0.002152 & 927372 & 0.24679 \\
\hline Down & DLG2 & 13 & 0.002105 & 767688 & 0.273896 \\
\hline Down & MYCN & 12 & $1.11 \mathrm{E}-04$ & 41976 & 0.304939 \\
\hline Down & PRAM1 & 12 & 0.001039 & 343780 & 0.260883 \\
\hline Down & PCDH7 & 12 & 0.001704 & 788890 & 0.266375 \\
\hline Down & EDARADD & 11 & 0.001215 & 325252 & 0.268544 \\
\hline
\end{tabular}




\begin{tabular}{|c|c|c|c|c|c|}
\hline Down & GREB1 & 11 & $9.15 \mathrm{E}-04$ & 206196 & 0.268968 \\
\hline Down & ZNF622 & 11 & $8.30 \mathrm{E}-04$ & 730808 & 0.269663 \\
\hline Down & RXRG & 11 & 0.002054 & 800986 & 0.250012 \\
\hline Down & GLP1R & 11 & $3.87 \mathrm{E}-04$ & 306068 & 0.257778 \\
\hline Down & TTC8 & 11 & 0.003532 & 958578 & 0.227362 \\
\hline Down & SERPINA3 & 10 & 0.002011 & 543412 & 0.243151 \\
\hline Down & CDK15 & 10 & 2.37E-04 & 85694 & 0.294623 \\
\hline Down & HLA-DQA1 & 10 & 0.001488 & 682934 & 0.249878 \\
\hline Down & HSD17B3 & 10 & $1.13 \mathrm{E}-04$ & 75794 & 0.26087 \\
\hline Down & TSHZ3 & 10 & 0.001111 & 304690 & 0.256253 \\
\hline Down & MAP1A & 9 & $8.61 \mathrm{E}-04$ & 207068 & 0.312393 \\
\hline Down & CSNK1G1 & 9 & 0.001614 & 637430 & 0.248529 \\
\hline Down & GTF2H2C & 9 & 0.001734 & 341202 & 0.245876 \\
\hline Down & PDLIM3 & 9 & 0.001957 & 559870 & 0.239831 \\
\hline Down & WDR3 & 9 & $6.45 \mathrm{E}-04$ & 234640 & 0.274455 \\
\hline Down & TNFAIP8 & 9 & $9.44 \mathrm{E}-04$ & 850962 & 0.230957 \\
\hline Down & ADAMTS10 & 8 & $9.45 \mathrm{E}-04$ & 260474 & 0.258443 \\
\hline Down & ABCB1 & 8 & $9.74 \mathrm{E}-04$ & 146904 & 0.3 \\
\hline Down & QRICH2 & 8 & 0.001291 & 295070 & 0.261336 \\
\hline Down & INS & 8 & $4.75 \mathrm{E}-04$ & 194074 & 0.248216 \\
\hline Down & COMP & 8 & 0.001207 & 326670 & 0.231995 \\
\hline Down & SHCBP1 & 7 & 4.46E-04 & 233846 & 0.256678 \\
\hline Down & DLGAP5 & 7 & $1.46 \mathrm{E}-04$ & 74806 & 0.290108 \\
\hline Down & ARHGAP9 & 7 & $3.62 \mathrm{E}-04$ & 66924 & 0.28522 \\
\hline Down & KCNH1 & 7 & $3.41 \mathrm{E}-04$ & 213892 & 0.253094 \\
\hline Down & KLHL1 & 6 & $1.15 \mathrm{E}-04$ & 30788 & 0.283638 \\
\hline Down & LCN2 & 6 & 4.47E-04 & 83350 & 0.256575 \\
\hline Down & TYMS & 6 & $4.58 \mathrm{E}-04$ & 134624 & 0.25317 \\
\hline Down & CDKN1C & 6 & $4.20 \mathrm{E}-04$ & 155814 & 0.26589 \\
\hline Down & DMBT1 & 6 & 0.001176 & 361022 & 0.251748 \\
\hline Down & SULT1C2 & 6 & 4.34E-04 & 98520 & 0.244289 \\
\hline Down & IL10 & 6 & $8.05 \mathrm{E}-04$ & 231670 & 0.245675 \\
\hline Down & SAMD3 & 6 & $6.69 \mathrm{E}-04$ & 135970 & 0.268713 \\
\hline Down & NCKAP5 & 6 & 4.03E-05 & 22814 & 0.2639 \\
\hline Down & CNN1 & 6 & $2.65 \mathrm{E}-04$ & 64314 & 0.23624 \\
\hline Down & PREX1 & 6 & $8.35 \mathrm{E}-04$ & 387030 & 0.254975 \\
\hline Down & CTNNA2 & 5 & $5.71 \mathrm{E}-04$ & 182504 & 0.281204 \\
\hline Down & POU5F1 & 5 & 7.40E-04 & 107680 & 0.274839 \\
\hline Down & POSTN & 5 & $5.96 \mathrm{E}-04$ & 207158 & 0.228766 \\
\hline Down & CSF2RA & 5 & $8.10 \mathrm{E}-04$ & 258390 & 0.252907 \\
\hline Down & MATN3 & 5 & $1.69 \mathrm{E}-04$ & 28890 & 0.235848 \\
\hline Down & ASB9 & 5 & $5.76 \mathrm{E}-04$ & 238362 & 0.238055 \\
\hline Down & KRTAP5-1 & 5 & 0.001174 & 179682 & 0.190051 \\
\hline Down & IL5RA & 5 & 0.001176 & 281872 & 0.257441 \\
\hline Down & KANK4 & 5 & 7.94E-04 & 141232 & 0.240633 \\
\hline Down & ASB16 & 5 & $2.41 \mathrm{E}-05$ & 16592 & 0.266028 \\
\hline Down & KIF4A & 5 & 4.60E-05 & 13994 & 0.259374 \\
\hline Down & ROBO1 & 5 & 4.93E-04 & 116624 & 0.246421 \\
\hline Down & TNFRSF11A & 4 & 4.04E-04 & 116804 & 0.251934 \\
\hline Down & KRTAP3-1 & 4 & $2.89 \mathrm{E}-05$ & 20452 & 0.252494 \\
\hline Down & UBXN10 & 4 & $5.63 \mathrm{E}-04$ & 69202 & 0.248047 \\
\hline Down & GLG1 & 4 & 4.17E-04 & 62018 & 0.265572 \\
\hline Down & LOXL1 & 4 & $4.78 \mathrm{E}-04$ & 74588 & 0.250404 \\
\hline Down & COMMD7 & 4 & 4.03E-04 & 180366 & 0.233127 \\
\hline Down & SELPLG & 4 & 8.09E-04 & 244340 & 0.221136 \\
\hline Down & YIPF4 & 4 & 4.79E-05 & 15522 & 0.197986 \\
\hline Down & TMEM108 & 4 & 2.77E-05 & 10972 & 0.243081 \\
\hline Down & KRTAP13-3 & 3 & $3.50 \mathrm{E}-07$ & 422 & 0.210396 \\
\hline Down & LRRC7 & 3 & $7.82 \mathrm{E}-04$ & 166682 & 0.180159 \\
\hline Down & GPX2 & 2 & 0 & 0 & 0.299578 \\
\hline Down & $\mathrm{CDH} 23$ & 1 & 0 & 0 & 0.215614 \\
\hline Down & ISX & 1 & 0 & 0 & 0.240905 \\
\hline Down & NPTX2 & 1 & 0 & 0 & 0.287223 \\
\hline Down & KCNG3 & 1 & 0 & 0 & 0.287223 \\
\hline Down & SMIM5 & 1 & 0 & 0 & 0.239809 \\
\hline Down & TFF3 & 1 & 0 & 0 & 0.239809 \\
\hline Down & FAM111B & 1 & 0 & 0 & 0.222435 \\
\hline Down & CDKN3 & 1 & 0 & 0 & 0.255626 \\
\hline Down & IFI27L2 & 1 & 0 & 0 & 0.250147 \\
\hline Down & NTN1 & 1 & 0 & 0 & 0.226175 \\
\hline
\end{tabular}




\begin{tabular}{lcclll} 
Down & AGAP2 & 1 & 0 & 0 & 0.218611 \\
Down & PIR & 1 & 0 & 0 & 0.238611 \\
Down & RNASE2 & 1 & 0 & 0 & 0.215016 \\
Down & ADCYAP1 & 1 & 0 & 0 & 0.189649 \\
Down & HADH & 1 & 0 & 0 & 0.248433 \\
Down & NDRG4 & 1 & 0 & 0 & 0.221222 \\
\hline
\end{tabular}

Table 6 miRNA - target gene and TF - target gene interaction

\begin{tabular}{|c|c|c|c|c|c|c|c|}
\hline Regulation & Target Genes & Degree & MicroRNA & Regulation & Target Genes & Degree & TF \\
\hline $\mathrm{Up}$ & $\mathrm{MYC}$ & 194 & hsa-mir-4677-3p & Up & MAPK3 & 48 & JUND \\
\hline Up & HSP90AA1 & 188 & hsa-mir-3125 & Up & HSP90AA1 & 35 & HSF2 \\
\hline Up & FKBP5 & 116 & hsa-mir-4779 & Up & SQSTM1 & 34 & SMAD4 \\
\hline Up & RNPS1 & 109 & hsa-mir-548az-3p & Up & STUB1 & 31 & ATF6 \\
\hline Up & SQSTM1 & 108 & hsa-mir-106a-5p & Up & EGFR & 27 & ELF3 \\
\hline Up & EGFR & 83 & hsa-mir-219a-5p & Up & YBX1 & 24 & TFAP2A \\
\hline Up & MAST3 & 76 & hsa-mir-129-2-3p & Up & LNX1 & 21 & MAX \\
\hline Up & YBX1 & 48 & hsa-mir-1537-3p & Up & FKBP5 & 20 & PGR \\
\hline Up & PRMT6 & 43 & hsa-mir-4330 & Up & PRMT6 & 9 & YY1 \\
\hline Up & MAPK3 & 33 & hsa-mir-3158-3p & Up & SGTA & 7 & MXI1 \\
\hline Up & SGTA & 24 & hsa-mir-421 & $\mathrm{Up}$ & POU6F2 & 7 & ALX1 \\
\hline Up & TNFRSF1A & 22 & hsa-mir-548an & Up & RNPS1 & 7 & STAT3 \\
\hline Up & STUB1 & 16 & hsa-mir-942-5p & Up & TNFRSF1A & 6 & EP300 \\
\hline Up & POU6F2 & 15 & hsa-mir-7850-5p & Up & MAST3 & 1 & NFYA \\
\hline Down & ANLN & 127 & hsa-mir-664a-3p & Down & ESR1 & 126 & FOXF2 \\
\hline Down & CDK1 & 109 & hsa-mir-5688 & Down & SMAD9 & 38 & $\mathrm{XAB} 2$ \\
\hline Down & FN1 & 105 & hsa-mir-199b-3p & Down & CDK1 & 36 & KHDRBS1 \\
\hline Down & ESR1 & 98 & hsa-mir-206 & Down & FN1 & 25 & RELA \\
\hline Down & TK1 & 80 & hsa-mir-6512-3p & Down & NEK6 & 16 & SRY \\
\hline Down & OIP5 & 62 & hsa-mir-767-5p & Down & TK1 & 11 & DRAP1 \\
\hline Down & SMAD9 & 58 & hsa-mir-3689a-3p & Down & NEDD8 & 10 & PARP1 \\
\hline Down & MED10 & 41 & hsa-mir-647 & Down & TTN & 10 & FOXD3 \\
\hline Down & NEK6 & 34 & hsa-mir-4485-3p & Down & ANLN & 9 & JUN \\
\hline Down & BUB1B & 32 & hsa-mir-449b-5p & Down & BUB1B & 9 & MYB \\
\hline Down & TTN & 31 & hsa-mir-181c-5p & Down & MED10 & 6 & KDM4B \\
\hline Down & NEDD8 & 26 & hsa-mir-583 & Down & PSMA6 & 6 & EBF1 \\
\hline Down & PSMA6 & 17 & hsa-mir-539-5p & Down & OIP5 & 5 & GATA2 \\
\hline Down & EXOSC8 & 17 & hsa-mir-191-5p & Down & KRTAP4-2 & 1 & TBP \\
\hline
\end{tabular}

\section{Figures}




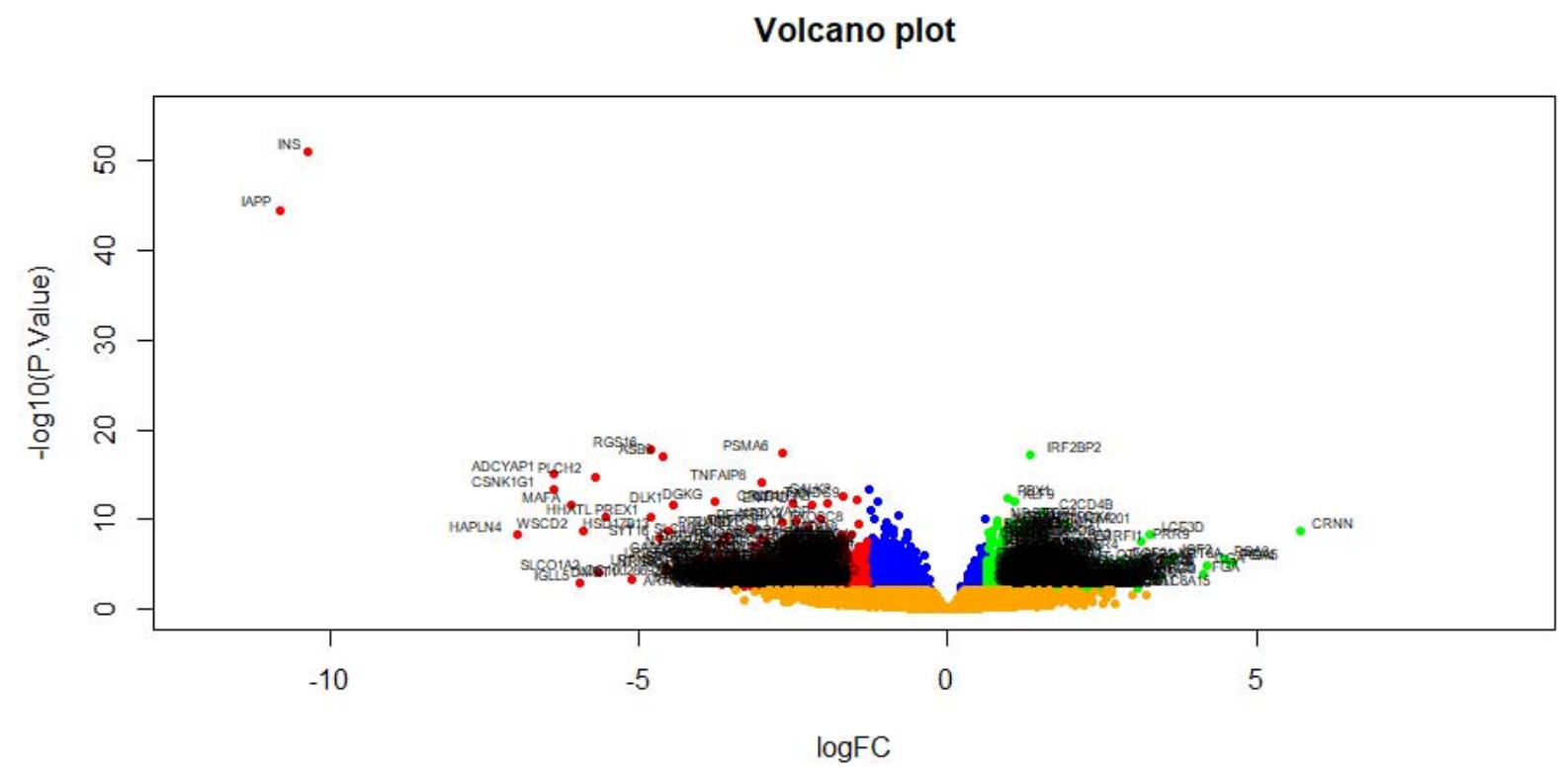

Fig. 1. Volcano plot of differentially expressed genes. Genes with a significant change of more than two-fold were selected. Green dot represented up regulated significant genes and red dot represented down regulated significant genes.
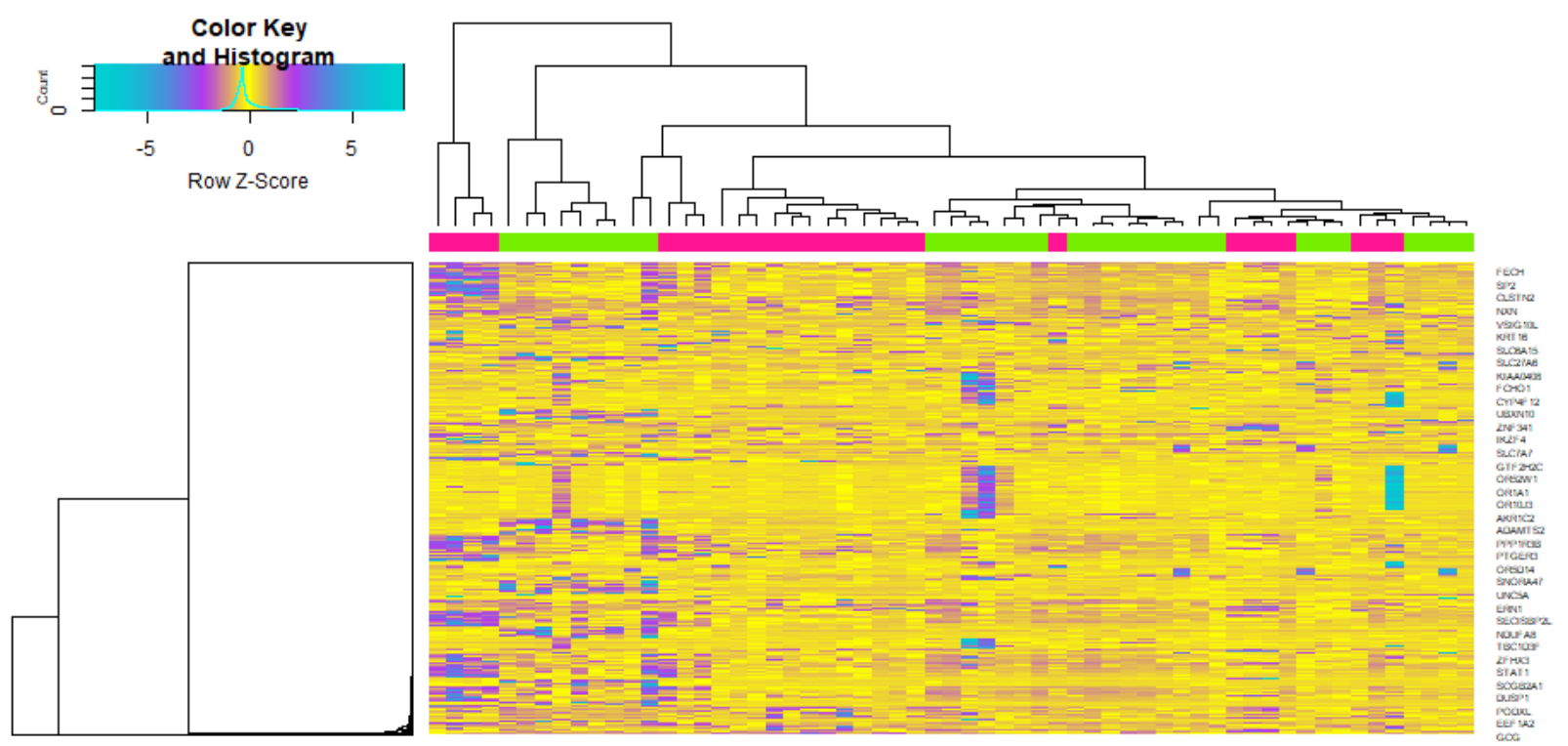

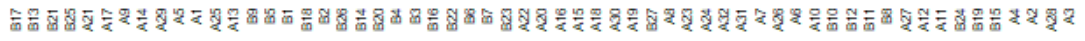

Fig. 2. Heat map of differentially expressed genes. Legend on the top left indicate log fold change of genes. (A1 $\mathrm{A} 32=$ normal control samples; $\mathrm{B} 1-\mathrm{B} 27=\mathrm{T} 1 \mathrm{DM}$ samples) 


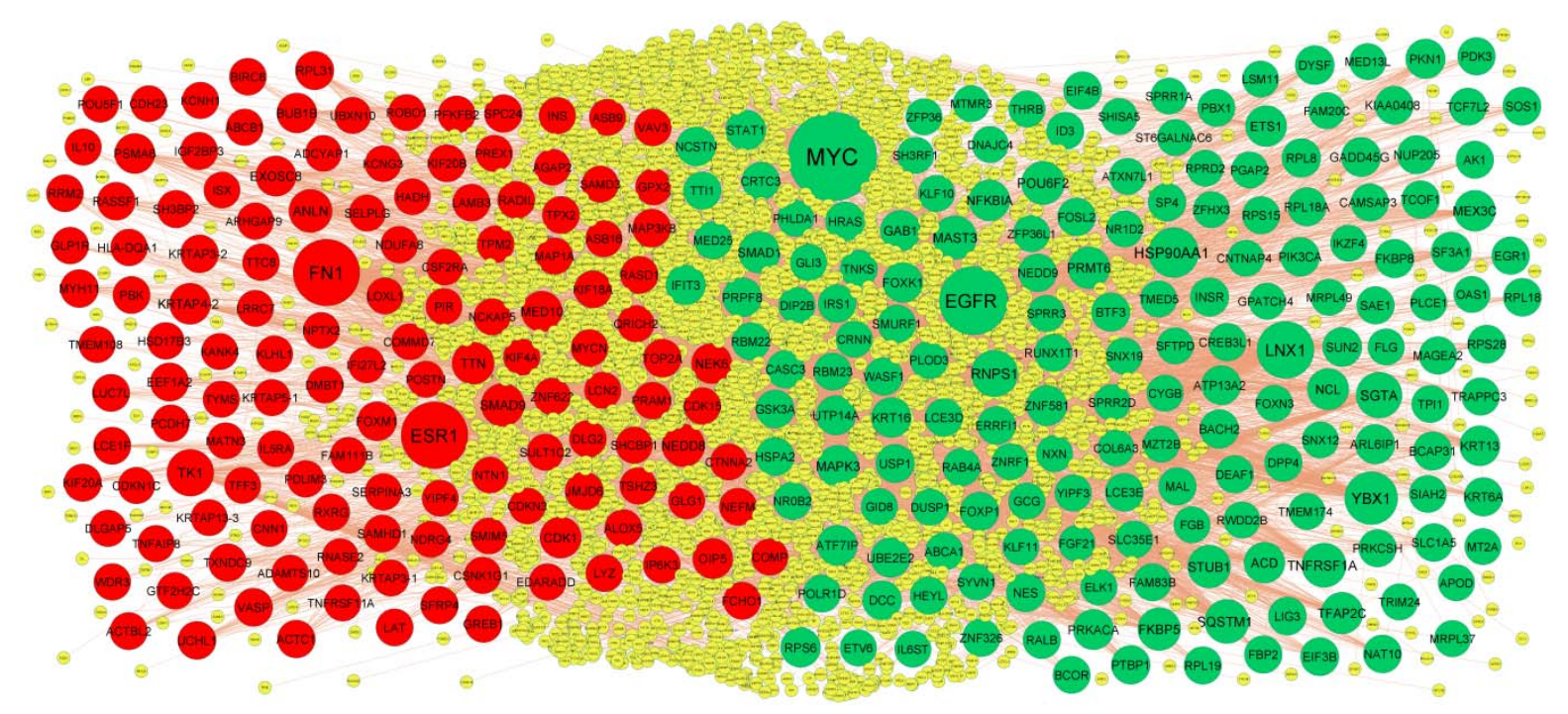

Fig. 3. PPI network of DEGs. The PPI network of DEGs was constructed using Cytoscap. Up regulated genes are marked in green; down regulated genes are marked in red

A

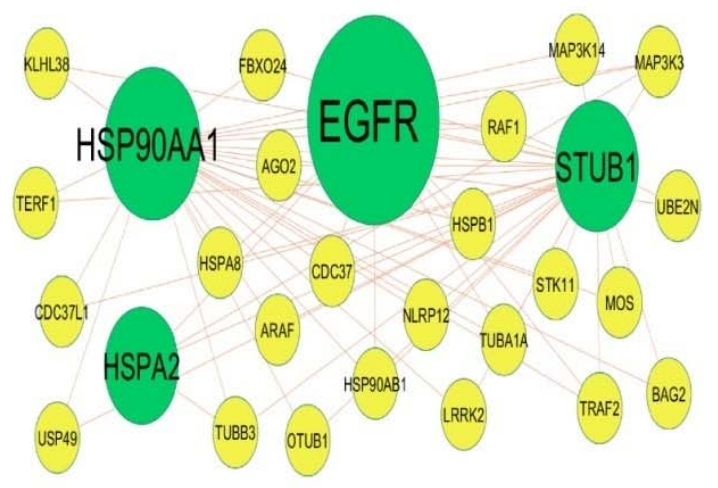

B

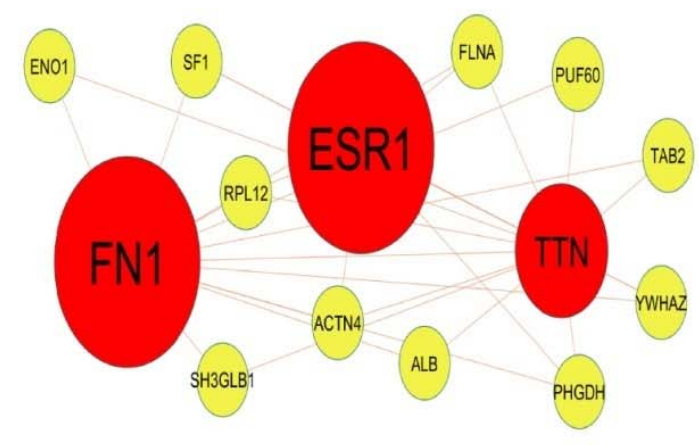

Fig. 4. Modules of isolated form PPI of DEGs. (A) The most significant module was obtained from PPI network with 28 nodes and 63 edges for up regulated genes (B) The most significant module was obtained from PPI network with 14 nodes and 30 edges for down regulated genes. Up regulated genes are marked in green; down regulated genes are marked in red. 
bioRxiv preprint doi: https://doi.org/10.1101/2021.06.08.447531; this version posted June 9, 2021. The copyright holder for this preprint (which was not certified by peer review) is the author/funder. All rights reserved. No reuse allowed without permission.

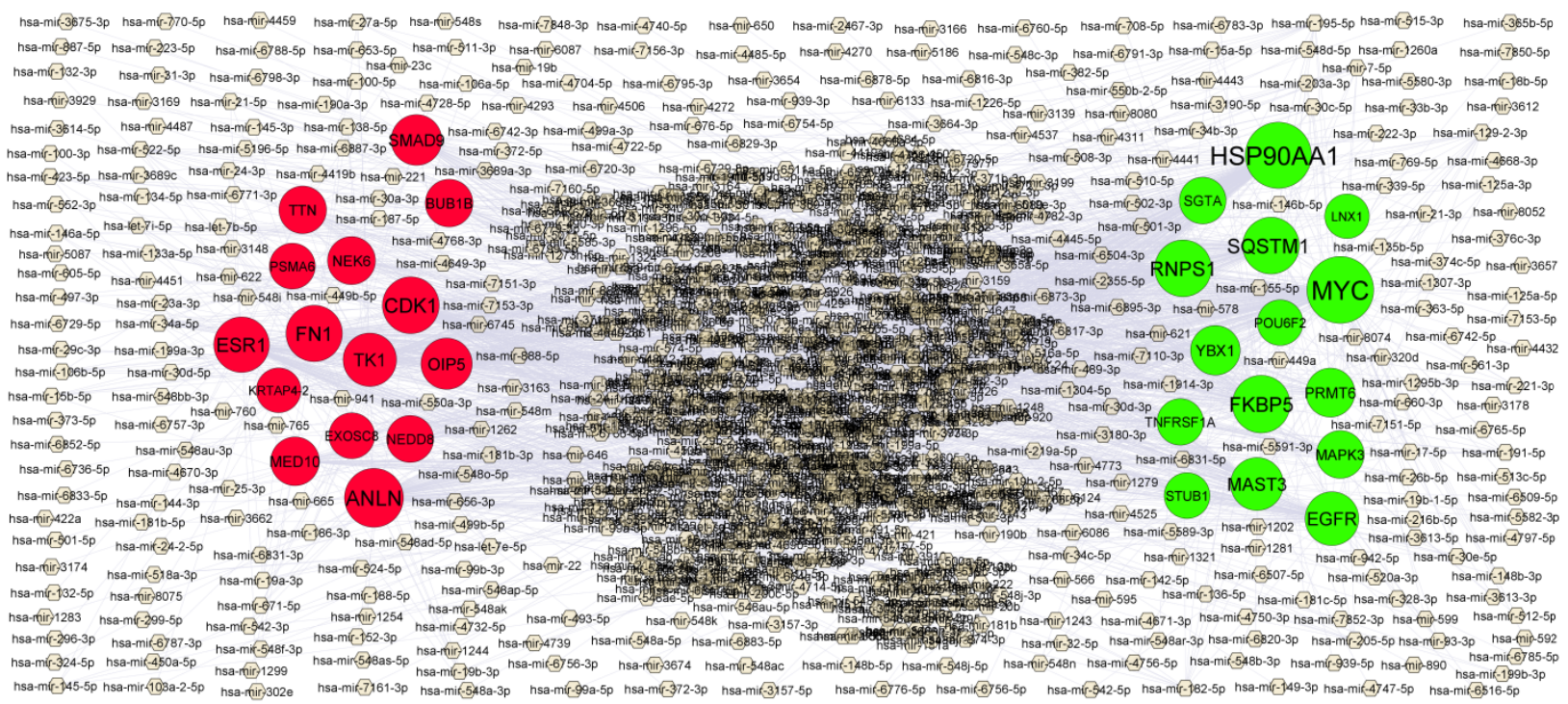

Fig. 5. MiRNA - hub gene regulatory network. The chocolate color diamond nodes represent the key miRNAs; up regulated genes are marked in green; down regulated genes are marked in red.

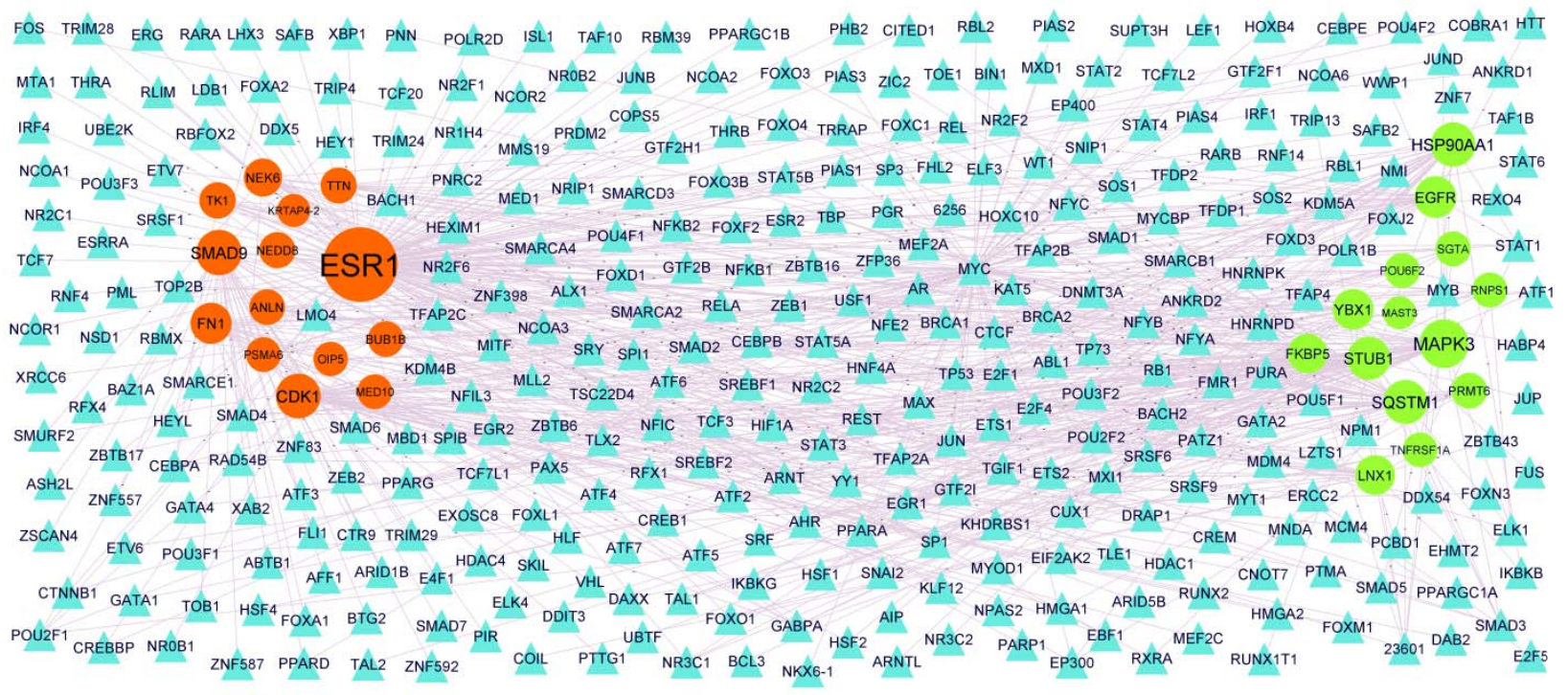

Fig. 6. TF - hub gene regulatory network. The blue color triangle nodes represent the key TFs; up regulated genes are marked in green; down regulated genes are marked in red. 

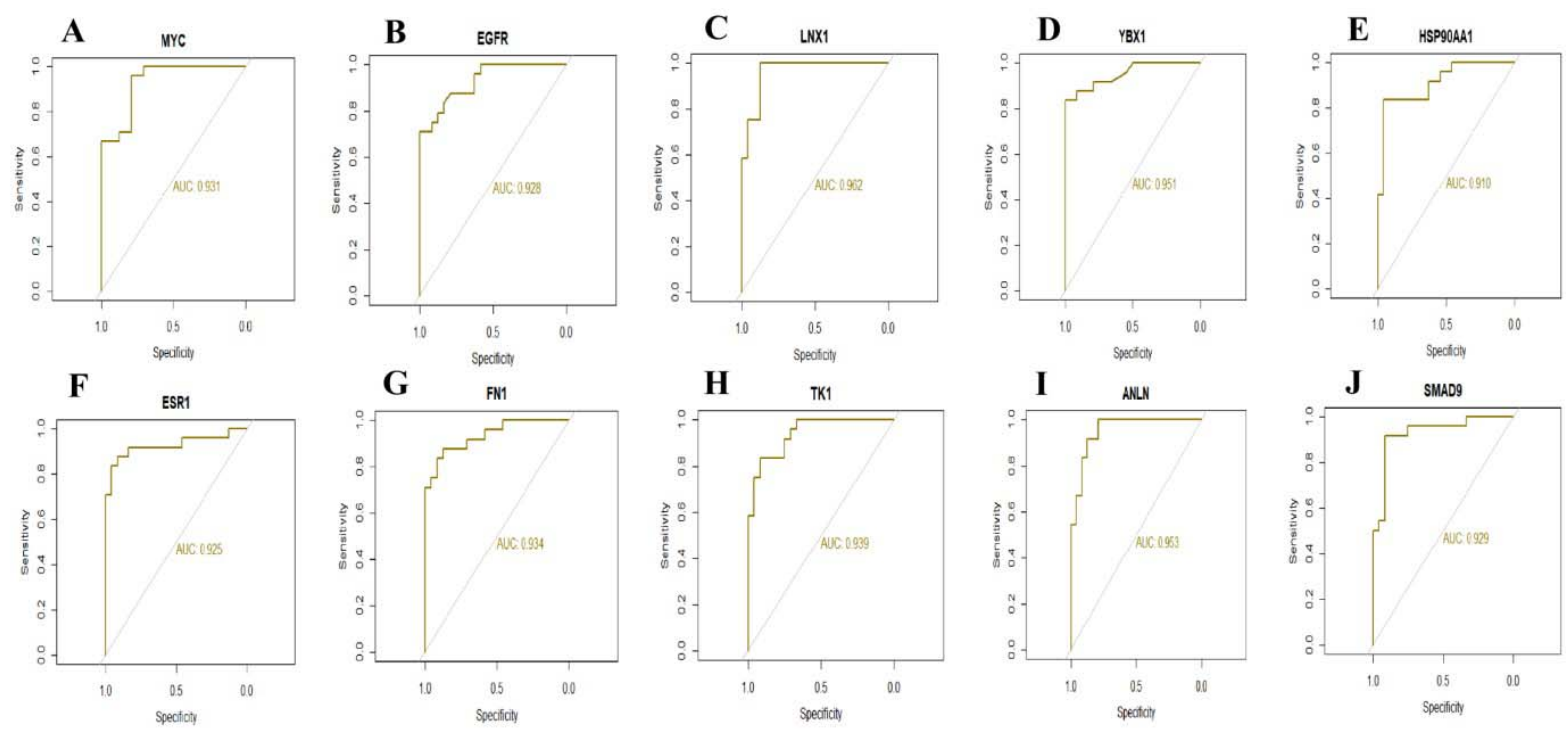

Fig. 7 ROC curve validated the sensitivity, specificity of hub genes as a predictive biomarker for dementia prognosis. A) MYC B) EGFR C) LNX1 D) YBX1 E) HSP90AA1 F) ESR1 G) FN1 H) TK1 I) ANLN J) SMAD9
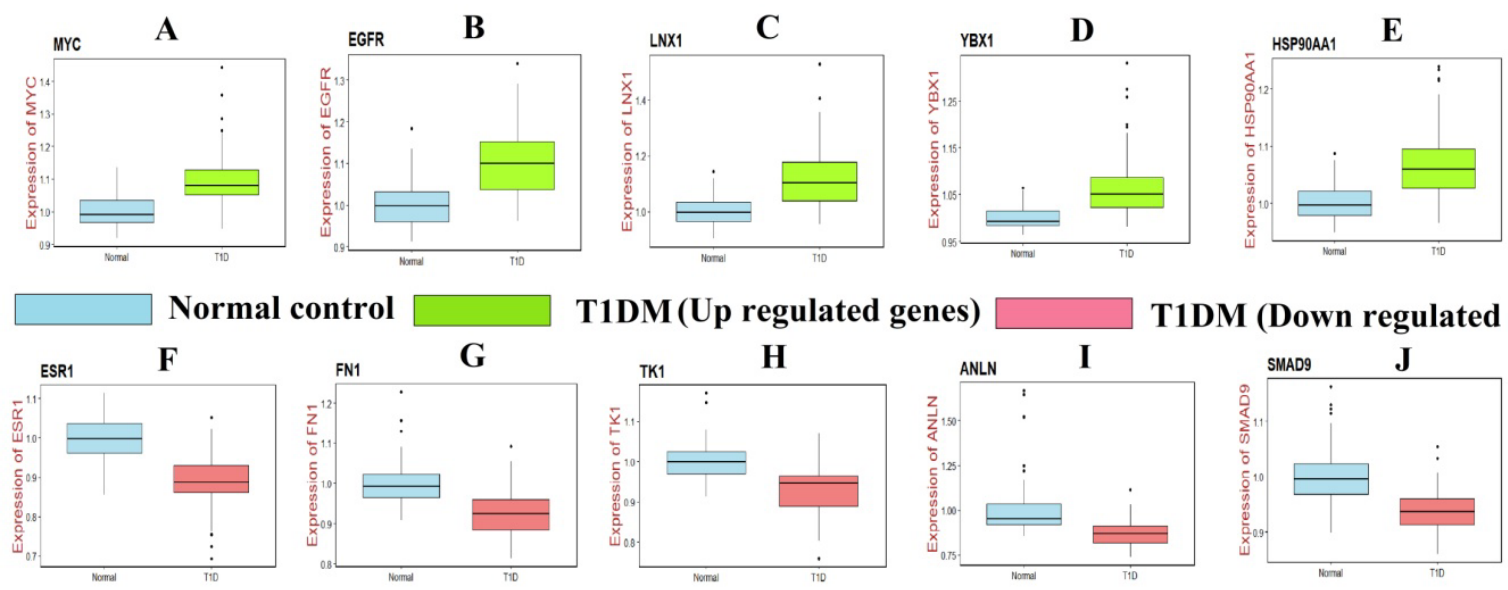

T1DM(Up regulated genes)

T1DM (Down regulated genes )
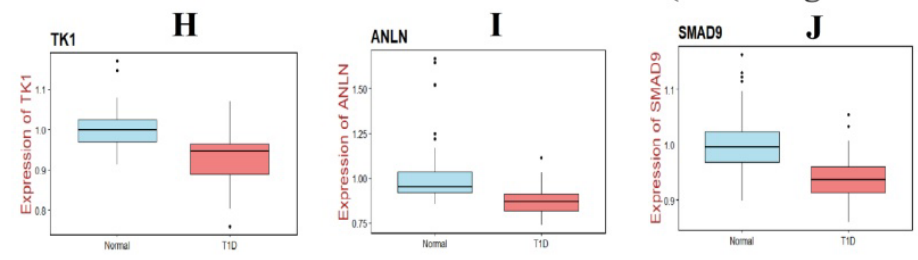

Fig. 8 Validation of hub genes by RT- PCR. A) MYC B) EGFR C) LNX1 D) YBX1 E) HSP90AA1 F) ESR1 G) FN1 H) TK1 I) ANLN J) SMAD9 
bioRxiv preprint doi: https://doi.org/10.1101/2021.06.08.447531; this version posted June 9, 2021. The copyright holder for this preprint (which was not certified by peer review) is the author/funder. All rights reserved. No reuse allowed without permission. 